\title{
Stereodivergent routes in organic synthesis: Marine natural products, lactones, other natural products, heterocycles and unnatural compounds
}

\author{
Carmen Nájera, ${ }^{a *}$ Francisco Foubelo, ${ }^{a, b, c}$ José M. Sansano ${ }^{a, b, c}$ and Miguel Yus ${ }^{a}$
}

Enantio- and diastereodivergent routes to marine-origin natural products with different size of cyclic ethers and lactones have been carried out in order to assign stereochemical features. Kainoid amino acids such as isodomic acids have been synthesized using diastereodivergent routes. The bis(indole) alkaloid dragmacidin $\mathrm{F}$ has been prepared by enantiodivergent strategies as well as furanoterpenes and the tetracyclic agelastatin $A$. Natural products containing fivemembered lactones like quercus lactones, muricatacins, goniofufuranones, methylenolactocins and frenolicin B have been synthesized using stereodivergent routes. Macrolides are very abundant lactones and have been mainly prepared from the corresponding seco-acids by lactonization, such as lasidiodiplodin, zaeralanes, macrosphelides and haloprins, or by ringclosing metathesis, such as aspercyclides, micrcarpelides, macrolides FD-891 and 892, and tetradic-5-en-9-olides. Other natural products including cyclic ethers (such as sesamin, asarinin, acetogenins, centrolobines and nabilones), alcohols (such as sulcatol), esters (such as methyl jasmonates), polycyclic precursors of fredericamycin, amino alcohols (such as ambroxol and sphingosines), isoprostanes, isofurans, polyketides precursors of anachelins, brevicomins, gummiferol, shikimic acid and the related compounds, and the pheromone dispalure have been synthesized stereodiveregently. Heterocyclic systems such as epoxides, theobroxides and bromoxones, oxetan-3-ones, 5- to 8-membered cyclic ethers, azetidones, $\mathrm{Y}$-lactams, oxazolidinones, bis(oxazolines), dihydropyridoisoindolines and octahydroisoquinolines have been prepared following stereodivergent routes. Stereodivergent routes to unnatural compounds such as alkenes, dienes, allenes, cyclopropanes, alcohols, aldols, amines, amino alcohols, $\beta$ amino acids, carboxylic acids, lactones, nitriles and $\alpha$-amino nitriles have been considered as well.

\footnotetext{
a Centro de Innovación en Química Avanzada (ORFEO-CINQA), Universidad de Alicante, Apdo. 99, E-03080 Alicante, Spain, E-mail: cnajera@ua.es

${ }^{b}$ Departamento de Química Orgánica, Facultad de Ciencias, Universidad de Alicante, Apdo. 99, E-03080 Alicante, Spain

c Instituto de Síntesis Orgánica (ISO), Universidad de Alicante, Apdo. 99, E-03080 Alicante, Spain
} 


\section{Introduction}

In a previous review article, enantio- and diastereodivergent routes for natural products, such as carbohydrates, amino acids, alkaloids and terpenes were reported. ${ }^{1}$ These stereodivergent routes are efficient approaches to access different naturally occurring or biologically active enantiomers and diastereomers starting from the same starting material. In this article, stereodivergent synthesis of marine-origin, lactones, other natural products, as well as heterocyclic and unnatural compounds will be considered.

\section{Marine-origin natural products}

Marine organisms are rich sources of biologically active natural products. ${ }^{2}$ They are found as secondary metabolites of marine invertebrates, such as sponges, bryozoans, tunicates and ascidians. Cyclic ethers and lactones constitute important structural units present in a large number of marine natural products. Kanto and Sasaki ${ }^{3}$ performed synthetic studies of the C-1-C-12 fragment of amphirionin-5, a tetrahydrofuran-containing linear polyketide isolated from the dinoflagellate Amphidinium sp. (KCA09053 strain). This compound exhibits potent proliferation-promoting activity on murine bone marrow stromal ST-2 cells and murine osteoblastic MC3T3-E1 cells. The mentioned fragments were prepared by diastereodivergent routes starting from a chiral allylic alcohol, which was submitted to a Katsuki-Sharpless asymmetric epoxidation. By using (+)diisopropyl tartrate (DIPT), as chiral ligand, an epoxy alcohol was obtained, which was mesylated and subjected to Sharpless asymmetric dihydroxylation using ADmix- $\beta$, taking also place a concomitant stereospecific cyclization to form the tetrahydrofuran ring of the $(3 S, 4 S, 5 R)$-fragment in $81 \%$ overall yield (Scheme 1$)$. For the $(3 R, 4 R, 5 R)$-fragment a similar route but using (-)-DIPT for the epoxidation step provided this segment in $47 \%$ overall yield. From these diastereomers, two more fragments of C-4-C-5 and C-9 of amphirionin-5 were prepared. Further synthetic studies by the same group allowed the configurational assignment of the C-1-C-15 fragment. 


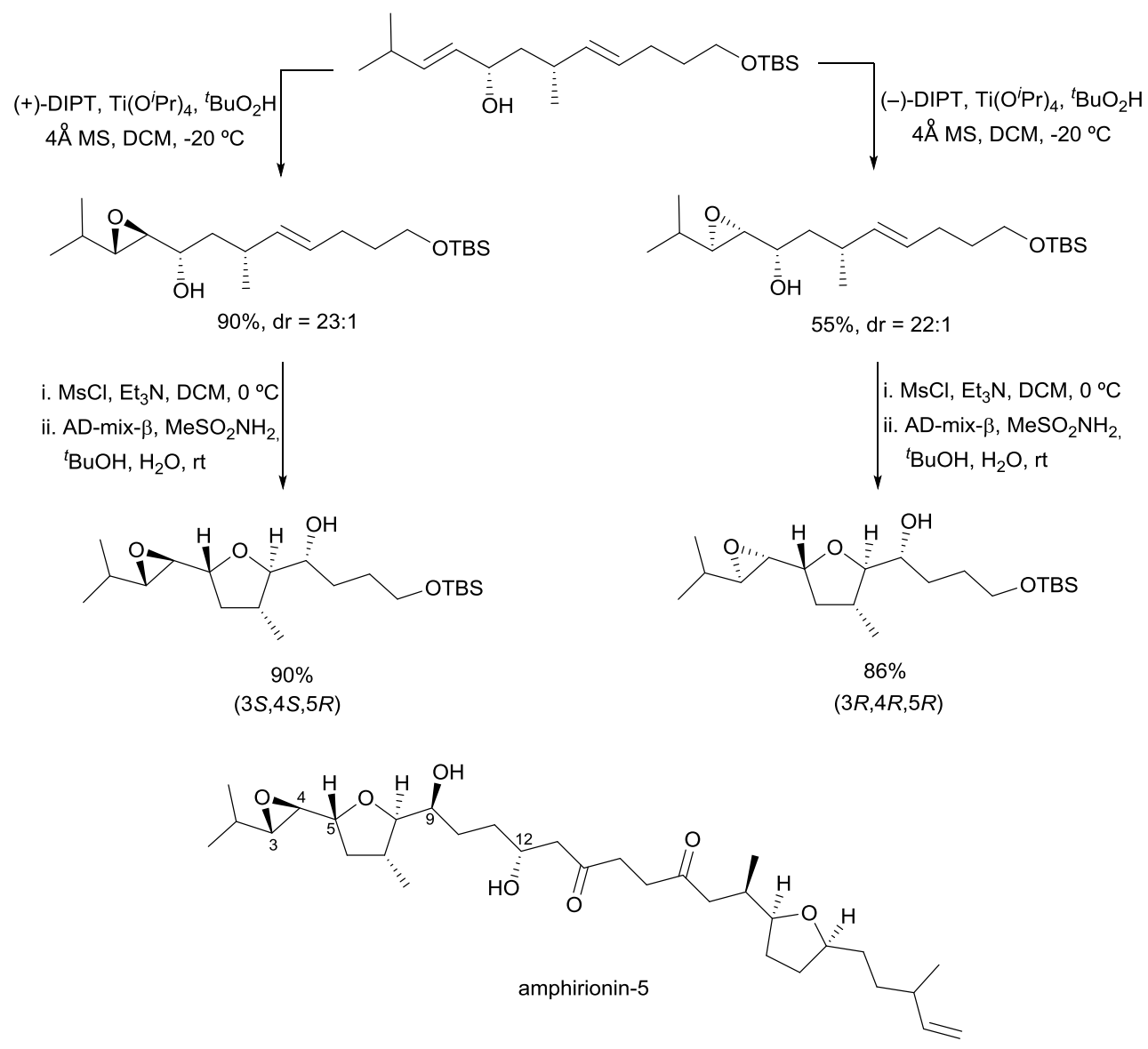

Scheme 1 Diastereodivergent routes to C-1-C-12 fragments of amphirionin-5.

Medium ring ethers as oxepanes are the core of $(+)$-isolaurepinnacin and (+)-neoisoprelaurefucin, isolated from species of the genus Laurencia. Both enantiomers of the oxepane derivatives, isolaurepans, were prepared by the Gómez and Fall group starting from $O$-acetyl-D-glucal. ${ }^{5}$ Enantiodivergent routes from this tetrahydropyran aldehyde as common chiral building block involved multistep procedures. Wittig reaction of this aldehyde, followed by hydrogenation, introduced the $n$-hexyl chain at the 2-position of the tetrahydropyran. After removal of the silyl group and protection of the primary alcohol, followed by oxidation, resulted the ketone precursor of the oxepanone ring by treatment with $\mathrm{Me}_{3} \mathrm{SiCHN}_{2}$ in the presence of $\mathrm{BF}_{3} \cdot \mathrm{Et}_{2} \mathrm{O}$. Wolf-Kishner reaction gave the oxepane with a hydroxymethyl group at the 6-position, which was converted by functional group transformations into the $n$-propyl chain providing (+)-isolaurepan (Scheme 2). A similar synthetic sequence was used for (-)-isolaurepan, the first step being the Wittig reaction to form the $n$-propyl chain. 


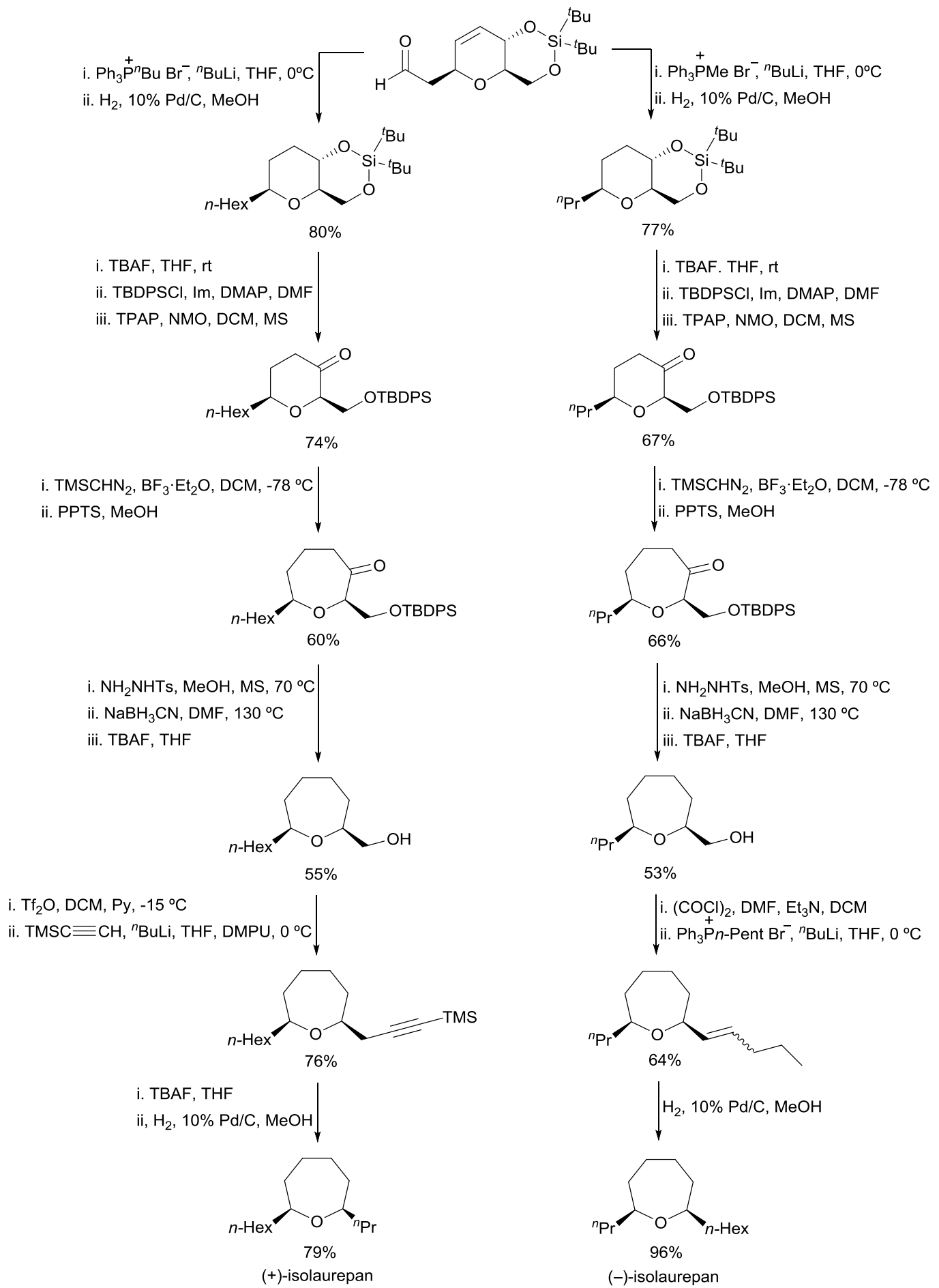

Scheme 2 Enantiodivergent routes to (+)- and (-)-isolaurepans.

Enantiodivergent routes to cis-lauthisan, the saturated oxocane core of (+)laurencin, isolated from the extracts of Laurencia glandulifera red alga, have been developed by Solladié and coworkers. ${ }^{6}$ A chiral $\beta$-keto sulfoxide, prepared from dimethyl pimelate, was used as starting building block. The asymmetric synthesis of (-)-cis-lauthisan started with the reduction of the keto group with DIBALH in the presence of $\mathrm{ZnBr} 2$ to provide the corresponding hydroxy sulfinyl ester, which was desulfinated with Ra-Ni. After preparation of the Weinreb amide, the 
corresponding ketone was obtained by reaction with $n$-hexylmagnesium bromide. The reductive cyclization was carried out with $\mathrm{TMSOTf} / \mathrm{Et} 3 \mathrm{SiH}$ giving the oxocane (-)-cis-lauthisan (Scheme 3). The same staring sulfoxide was reduced with DIBALH to afford mainly the $(S)$ - instead of the $(R)$-alcohol. Following the same synthetic sequence, $(+)$-cis-lauthisan was obtained.

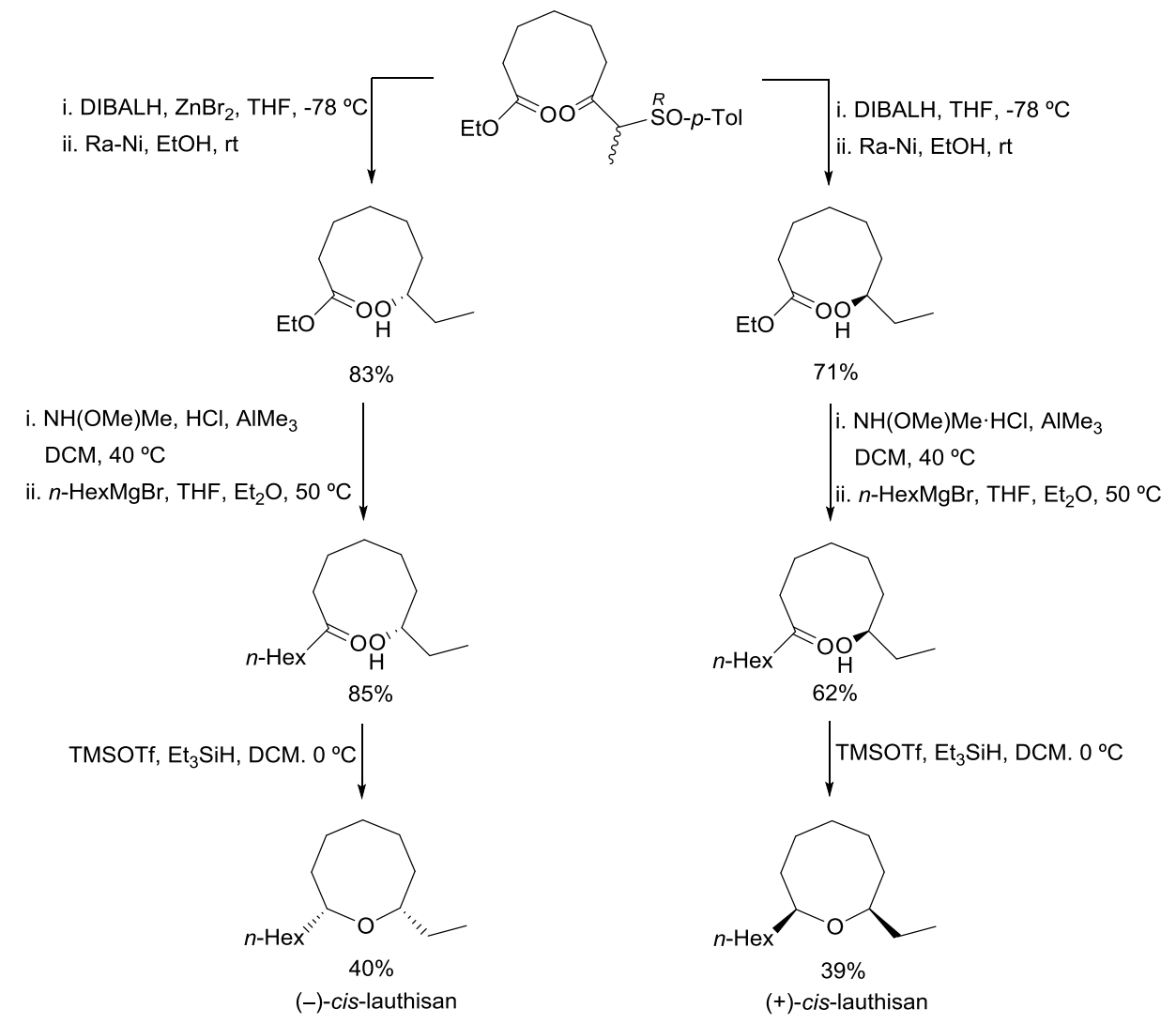

Scheme 3 Enantiodivergent routes to (-)- and (+)-cis-lauthisans.

Lactones, and specially macrolides, are abundant structures in marine natural products. Pietruszka and co-workers ${ }^{7}$ have prepared four diastereomers of the proposed structure for solandelactone $I$ in order to assign its stereochemical features. Marine oxylipins solandelactone A-I were isolated from the hydroid Solanderia secunda showing promising bioactivity. The western part of solandelactone I was enantiodivergently prepared starting from (Z)-1-iodohept1-ene, which was allowed to react with lithium and $\mathrm{CuCN}$, and the resulting alkenyllithiumcyanocuprate was allowed to react with the $(R)$ - or $(S)$-epoxide to give the two enantiomeric esters (Scheme 4). These a-hydroxy esters were transformed into the phosphonates, used as building blocks in the HWE reaction with a cyclopropyl lactone to form the two unsaturated ketones in a diastereodivergent manner (Scheme 5). These isomeric intermediates gave, after reduction with $\mathrm{Zn}\left(\mathrm{BH}_{4}\right)_{2}$ or $\mathrm{NaBH}_{4} / \mathrm{CeCl}_{3}$, the four diastereomers with two vicinal syn- or anti-diols, respectively. The first syn-isomer was identified as solandelactone I. 

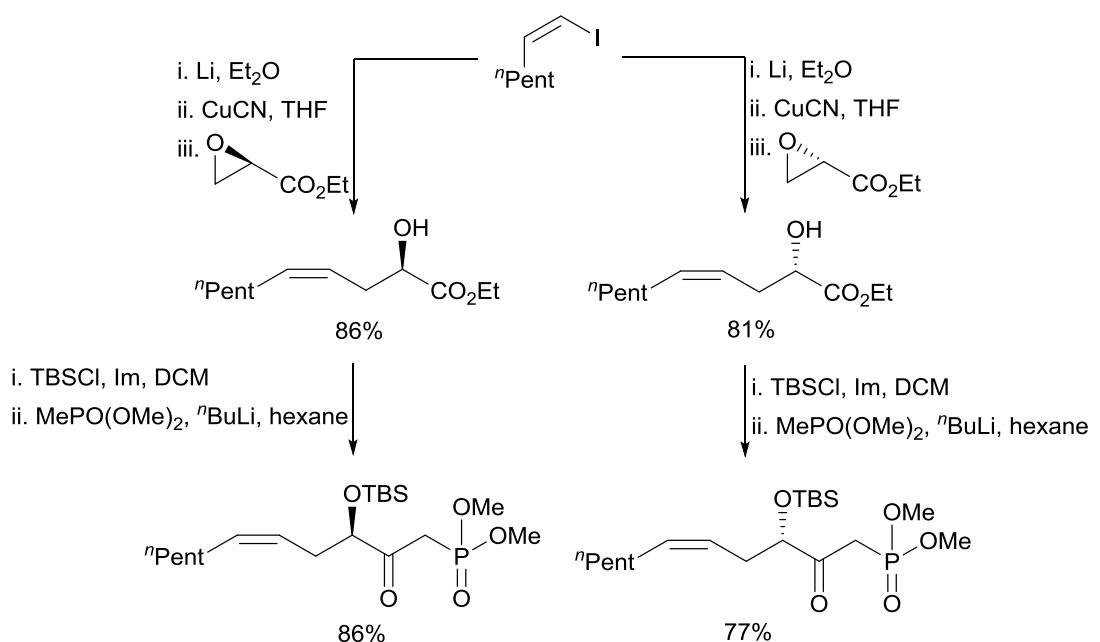

Scheme 4 Enantiodivergent routes to $(R)$ - and $(S)$-keto phosphonates, western part of solandelactone I isomers. 


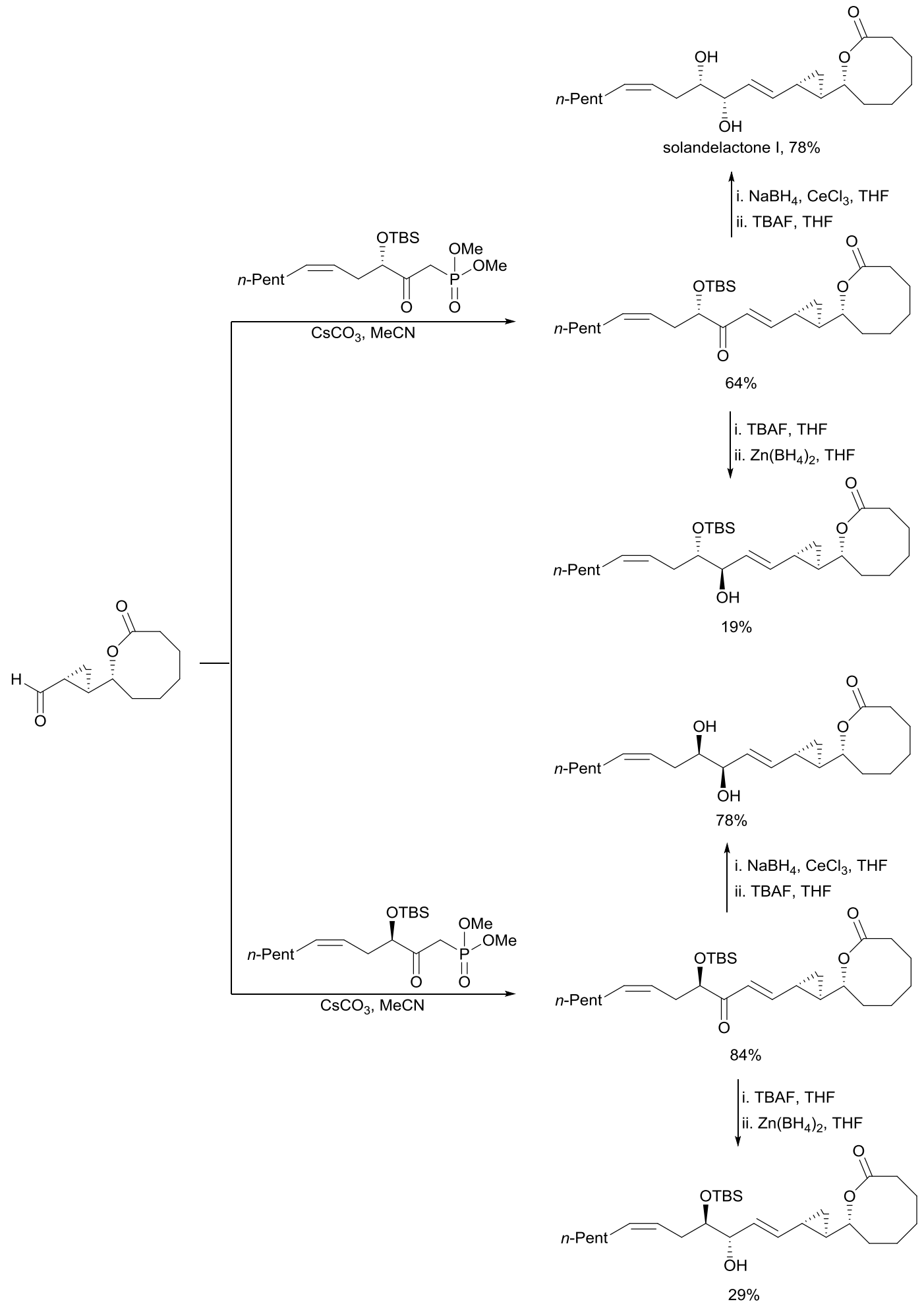

Scheme 5 Diastereodivergent routes to all four isomers of solandelactone I.

In the case of the stereochemical assignment of topsentolide $\mathrm{C}_{2}$, a cytotoxic nine-membered lactone isolated from the marine sponge Topsentia sp., its four isomers were synthesized. Kuwahara and co-workers ${ }^{8}$ reported diastereodivergent routes starting from a common chiral seco-acid by the combined use of the Yamaguchi and Mitsunonu lactonizations. This seco-acid 
gave, after Yamaguchi lactonization, followed by deprotection of the PMB group, the nine-membered lactone topsentolide $C_{2}$ in $90 \%$ overall yield (Scheme 6 ). However, under Mitsunobu conditions the seco-acid gave, after PMB deprotection, 8-epi-topsentolide $\mathrm{C}_{2}$ in $56 \%$ overall yield. From these two compounds 12-epi- and 8,11-bis-epi-topsentolide $\mathrm{C}_{2}$ have been prepared by Mitsunobu inversion of the $\mathrm{C}-12$ hydroxy group.

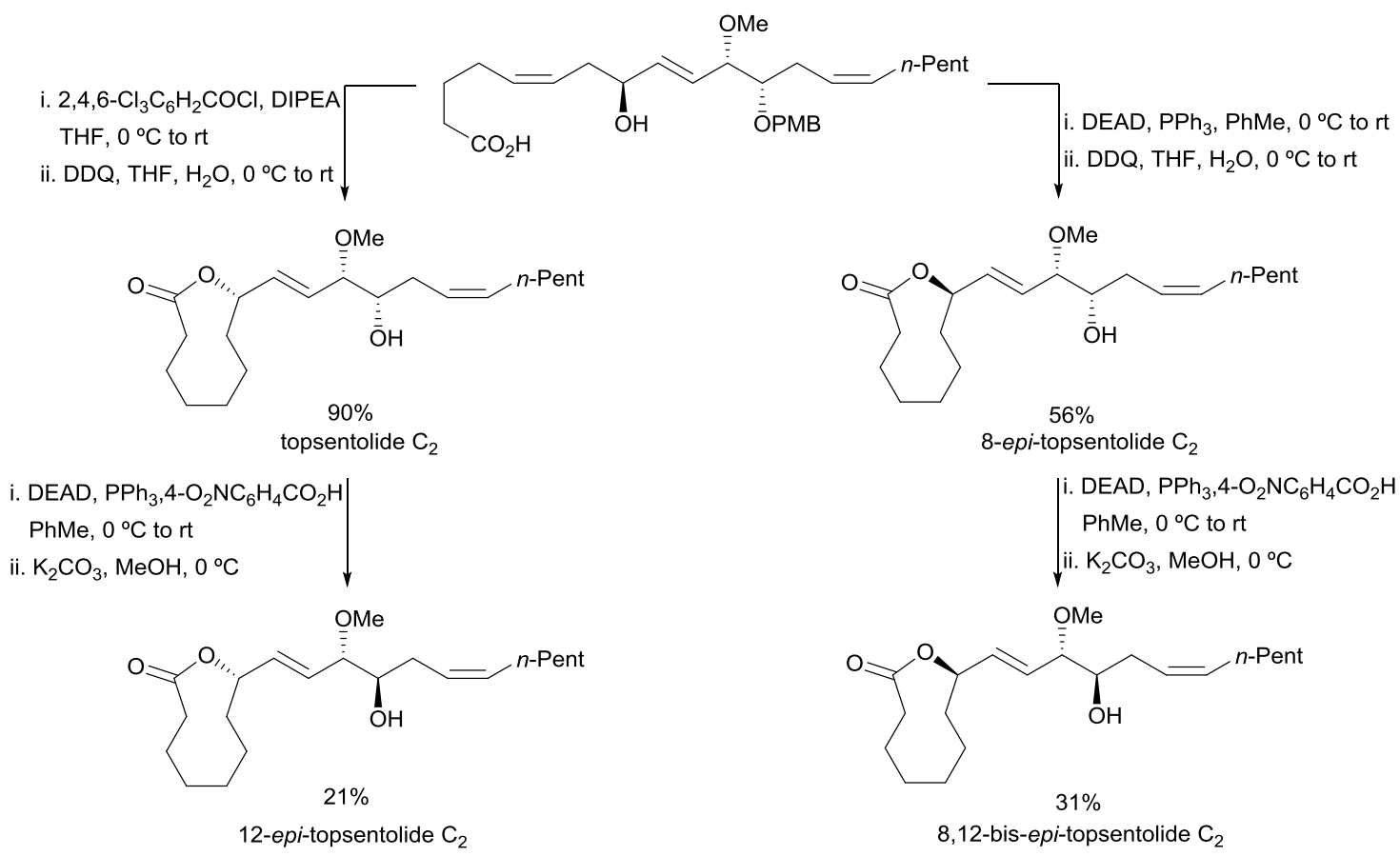

Scheme 6 Diastereodivergent routes to four isomers of topsentolide $C_{2}$.

The family of resorcylic lactones containing benzo-fused 14-membered ring have a wide range of activities. Among then, argialomycin $D$ is a moderate kinase inhibitor, which was originally isolated from the marine mangrove fungus Aigialus parvus. It displays moderate growth inhibitory activity against the human epidermoid carcinoma (KB) and breast cancer (BC-1) cell lines. Harvey and coworkers ${ }^{9}$ have synthesized several analogues of this natural product in order to study the growth inhibitory activity against the HL-60 leukaemic cell line. Starting from D-ribose, enantiodivergent routes allow the synthesis of two dienes which were used as chiral building blocks. D-Ribose was transformed into methyl 2,3$O$-isopropylidene- $\beta$-D-ribofuranoside and the primary alcohol converted into an iodide followed by a Vasella-Wittig reaction sequence to afford the required diene (Scheme 7). For the synthesis of its enantiomer, the hemiacetal of protected Dribose was submitted to Wittig olefination and then to a diol cleavage with $\mathrm{NalO}_{4}$ and final Wittig reaction. 


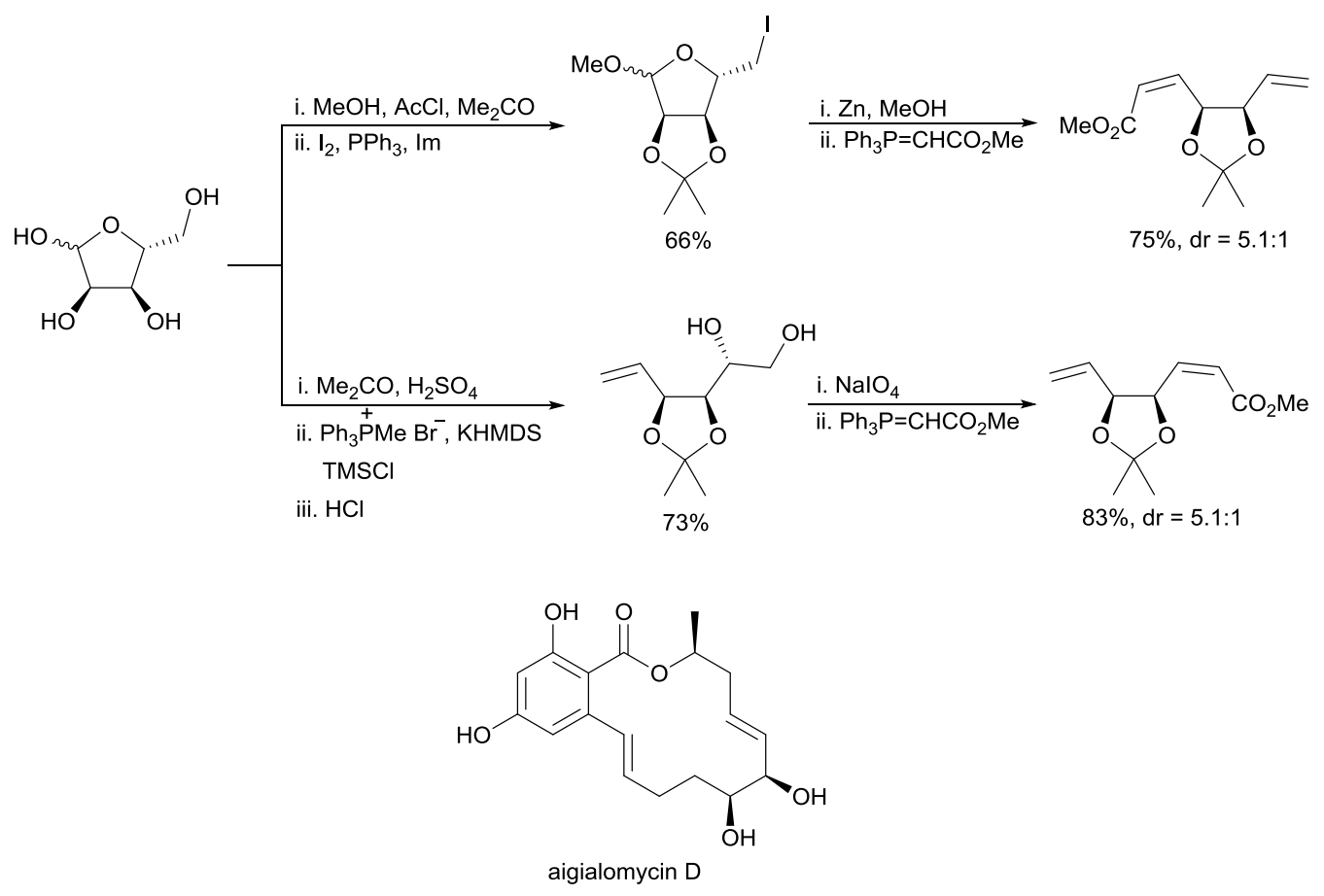

Scheme 7 Enantiodivergent routes to dienes, building blocks of aigialomycin $D$ analogues.

Symbiodinolide, a 62-membered polyol macrolide marine natural product, isolated from the cultured dinoflagellate Symbiodinium sp., exhibits voltagedependent $\mathrm{N}$-type $\mathrm{Ca}^{+2}$ channel-opening activity and COX-1 inhibition effect. Takamura and co-workers ${ }^{10}$ have performed diastereodivergent routes for the synthesis of four possible isomers of the C-1-C-13 fragment in order to stablish an unambiguous configurational assignment. Diastereodivergent routes to two C1-C-13 fragments are depicted in Scheme 8. The starting common intermediate was desilylated followed by selective deprotection of the primary alcohol and TEMPO oxidation. The resulting aldehyde, after $\mathrm{OH}$ deprotection, gave the corresponding tetraol with $(3 R, 5 R, 6 S, 7 S)$ absolute configuration. For the other diastereomer, the primary alcohol was first silylated and the free $\mathrm{OH}$ oxidized to a ketone. The reduction took place with inversion of the $\mathrm{OH}$ group at $\mathrm{C}-6$. Further deprotection-oxidation of the primary alcohol to an aldehyde, followed by stepwise deprotection afforded the $(3 R, 5 R, 6 R, 7 S)$-diastereomer, which is the fragment of the natural product. Following analogous functional group transformations, isomers $(3 S, 5 R, 6 S, 7 S)$ and $(3 S, 5 R, 6 R, 7 S)$ were also prepared using similar diastereodivergent routes. 


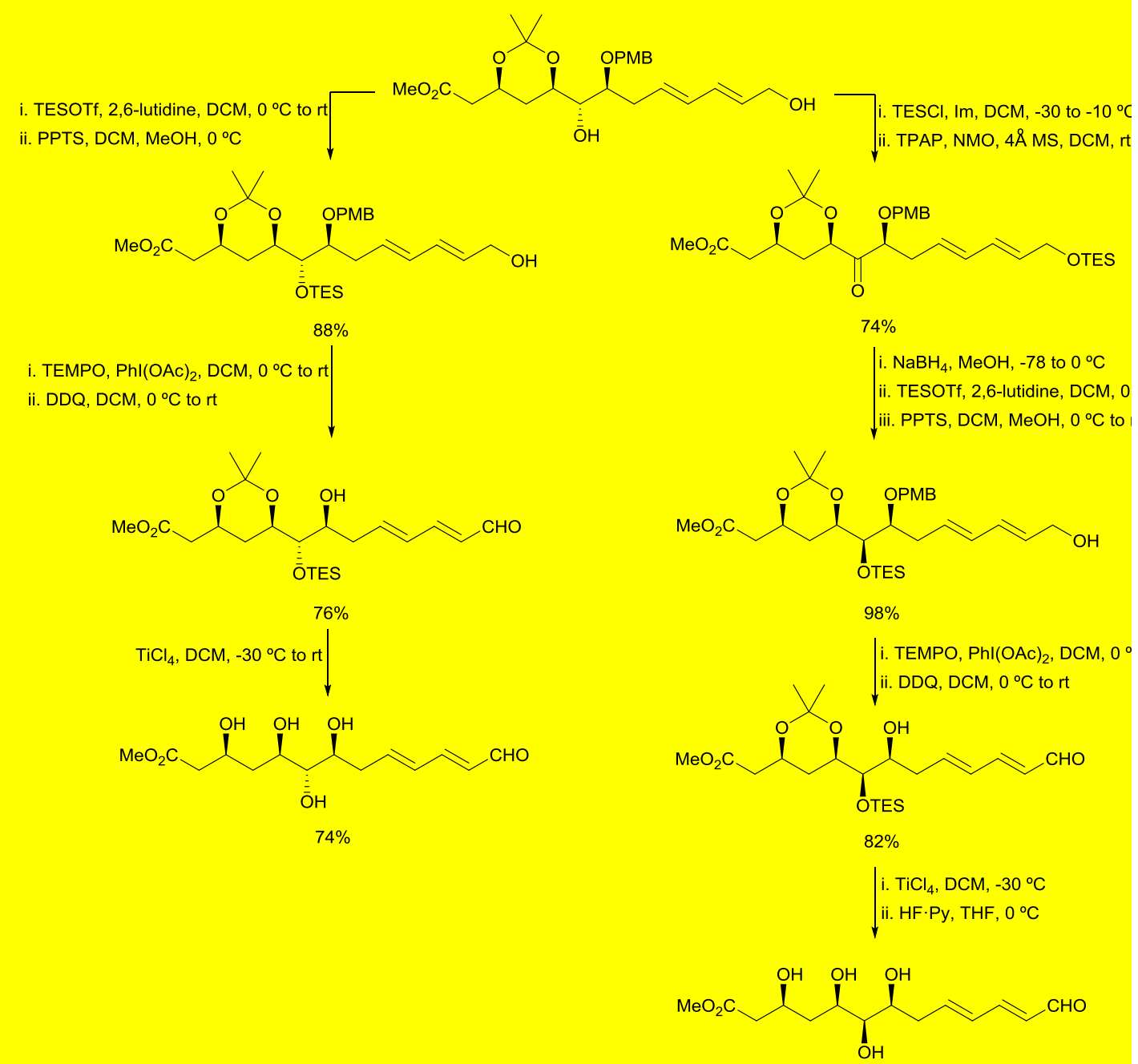

$63 \%$

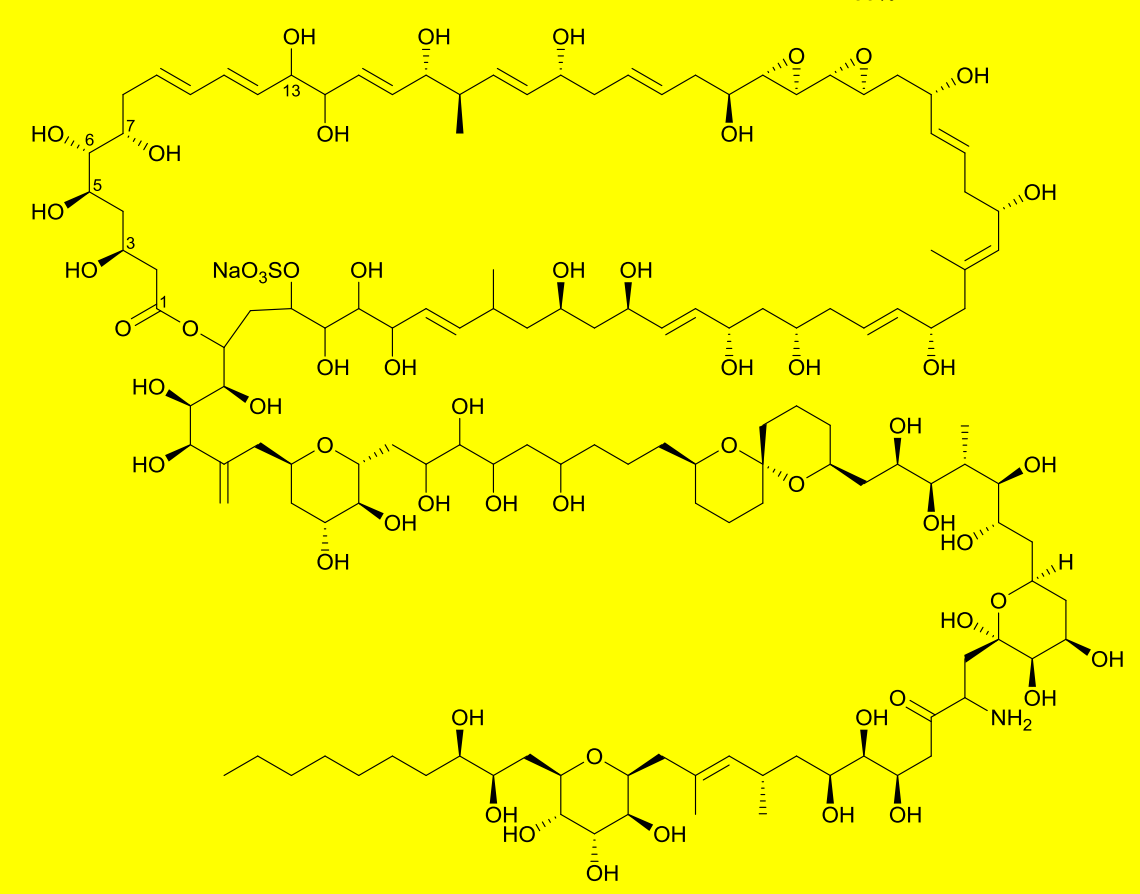

HE CORREGIDO EL NH2 de abajo a la derecha. Los grupos OH del centro, un metilo y el sulfonato no tienen configuración absoluta. Se conoce? 
Scheme 8 Diastereodivergent routes to C-1-C-13 isomeric fragments of symbiodinolide.

Kainoid amino acids include kainic acid, domoic acid, isodomoic acids, domoilactones, and acromelic acids. They are marine-origin neuroexcitatory compounds acting as mimics of glutamic acid targeting ionotropic glutamate receptors. Isodomonic acids $\mathrm{G}$ and $\mathrm{H}$, found in the Japanese red alga Chondria armata, have been prepared by Denmark and co-workers ${ }^{11}$ by diastereodivergent routes. The common intermediate is an alkenylsilane prepared from Lmethionine, which was transformed into the key $(E)$ - and (Z)-alkenyl iodides by desilylative iodination. For the synthesis of isodomoicacid $\mathrm{H}$, in the starting alkenylsilane the primary alcohol was converted into the corresponding carboxylic acid by $\mathrm{CrO}_{3}$-catalyzed oxidation with periodic acid, and then it was esterified with diazomethane. By treatment with iodine monochloride an unexpected complete inversion of the double bond configuration, through intermediate I, took place giving the (Z)-alkenyl iodide, which was coupled with an alkenylsilanol under Pd-catalysis using TBAF. After saponification of the three methyl esters and $\mathrm{N}$-desulfonylation with sodium amalgam, isodomoic acid $\mathrm{H}$ was obtained (Scheme 9 ). However, by silylation of the primary alcohol in the starting alkenylsilane, a subsequent desilylative iodination occurred with retention of the configuration, probably through intermediate II without anchimeric participation of the ester group. After desilylation of the primary alcohol, the same synthetic steps described above provided isodomoic acid G. 


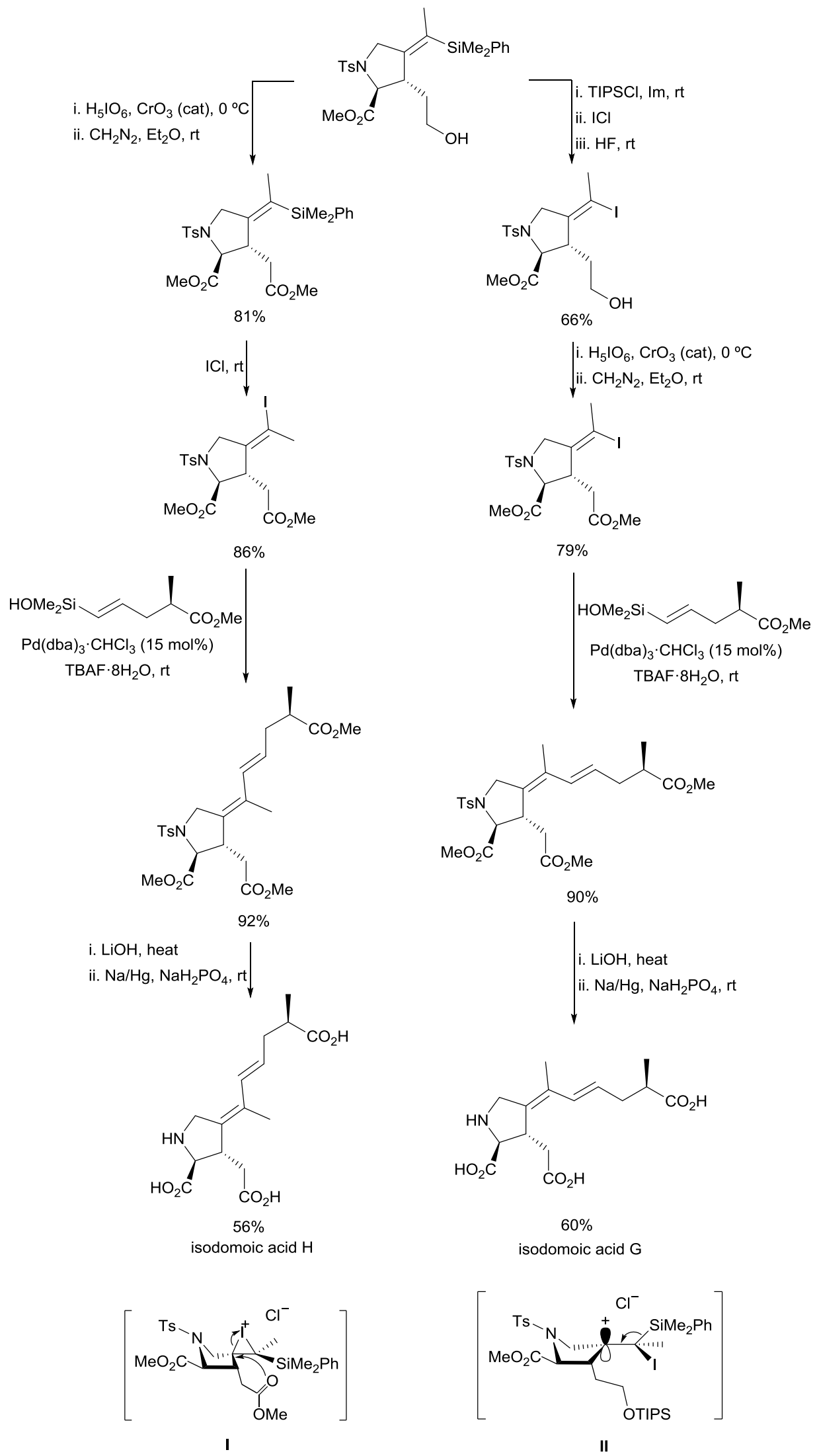

Scheme 9 Diastereodivergent routes to isodomic acids $\mathrm{H}$ and $\mathrm{G}$. 
Enantiodivergent routes to dragmacidin $\mathrm{F}$, a bis(indole) alkaloid isolated from the Mediterranean sponge Halicortex sp., have been reported by Stoltz and co-workers. ${ }^{12}$ This marine-origin alkaloid exhibits in vitro antiviral activity against herpes simple virus and human immunodeficiency virus. A bicyclic lactone intermediate was the common starting material, which was prepared from (-)quinic acid. This exo-methylene lactone gave, after standard catalytic hydrogenation conditions, the unsaturated carboxylic acid. This acid was transformed into the Weinreb amide and then to the ketone by reaction with SEMprotected 1-lithiopyrrole. This ketone was the precursor of (+)-dragmacidin (Scheme 10). The enantiomeric ketone precursor of (-)-dragmacidin $\mathrm{F}$ was prepared by reaction of the exo-methylene lactone with $\mathrm{N}$-SEM-1-lithiopyrrole and silylation of the hydroxy group at the $\mathrm{C}-5$ position to provide a bis(silyl) ether. After selective mono-desilylation of the other $\mathrm{OH}$ group at the 3-position, the corresponding carbonate was prepared by reaction with $\mathrm{CDI}$ and, after hydrogenation, the enantiomeric ketone was obtained.

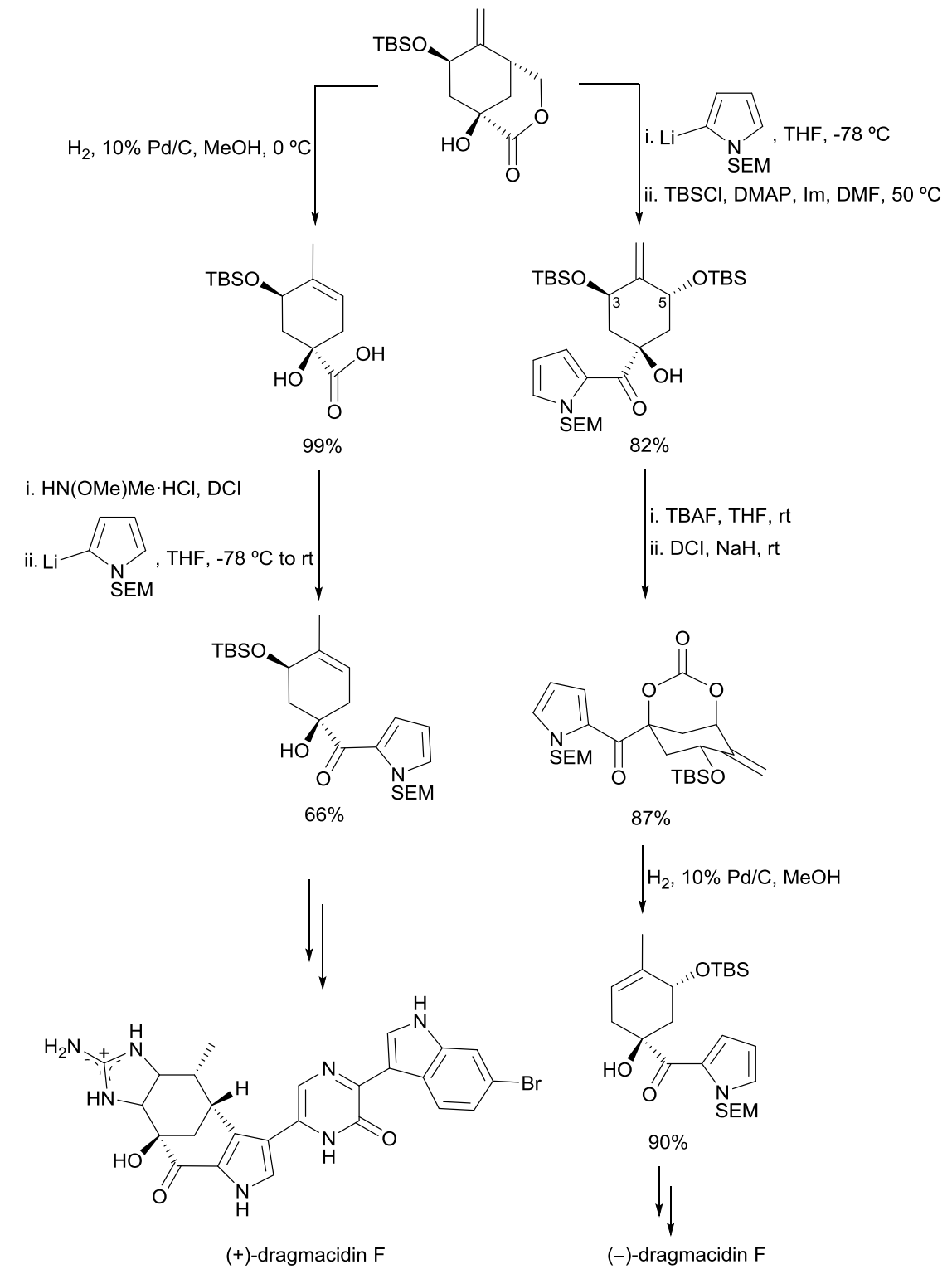


Scheme 10 Enantiodivergent routes to (+)- and (-)-dragmacidin F.

Some marine natural products contain a tetrahydrobenzofuran unit such as hippospongin $A$ and several furanoterpenes. Honda and Ogino ${ }^{13}$ described enantiodivergent routes to prepare the key intermediate in the preparation of a marine natural furanoterpene starting from a $(R)$-acid-ester, obtained by enzymatic hydrolysis with PLE of the corresponding malonate derivative. Reduction of the mixed anhydride gave an alcohol, which was further tosylated and finally reduced with LAH to give the (-)-isomer (Scheme 11). Alternatively, reduction of the ester with $\mathrm{LiBH}_{4}$ afforded the $(R)$-alcohol-acid, which was esterified and the methylalcohol transformed as above into a methyl substituent furnishing the (+)-enantiomer. This last enantiomer was previously transformed into the enantiomer of a furanoterpene. ${ }^{14}$

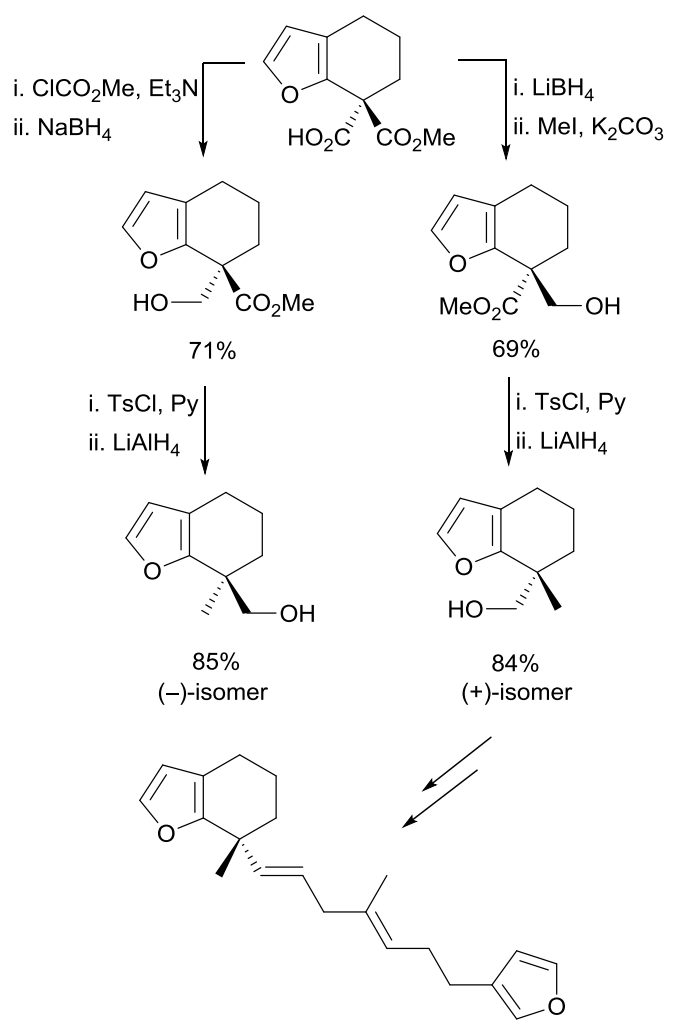

Scheme 11 Enantiodivergent routes to key intermediates of a marine furanoterpene.

Agelastatins A-D possess a fused tetracyclic ring structure and belong to the family of oroidin alkaloids. Agelastatin $A$ and $B$ were isolated from the deepwater marine sponge Agelas dendromorpha near New Caledonia. Agelastatin A exhibit nanomolar activity against a broad number of cancer cell lines and also as osteopontin-mediated adhesion, invasion and colony formation, NO LO ENTIENDO BIEN and other biological properties. As starting common material a bisallylic carbonate was used for the preparation of pyrrolopiperazinones through enantiodivergent routes such as it was reported by Trost and Dong. ${ }^{15} \mathrm{By} \mathrm{Pd}-$ 
catalyzed asymmetric allylic alkylation (AAA) of the bisallylic carbonate with methyl 5-bromopyrrolecarboxylate using $(R, R)$ - $\mathrm{L}$ as chiral ligand, the $\mathrm{N}$-alkyl pyrrole was obtained in $83 \%$ yield and $92 \%$ ee (Scheme 12 ). After transformation of the carboxylate ester into a $\mathrm{N}$-methoxy amide an intramolecular AAA was performed with the same chiral ligand to provide the piperazinone precursor of $(+)$-agelastatin A. By development of a Pd-catalyzed one-pot cascade AAA, using the $\mathrm{N}$-methoxy amide of 5-bromopyrrolecarboxylic acid, the corresponding enantiomeric piperazinone precursor of $(-)$-agelastatin A was obtained in $82 \%$ yield and $97.5 \%$ ee.
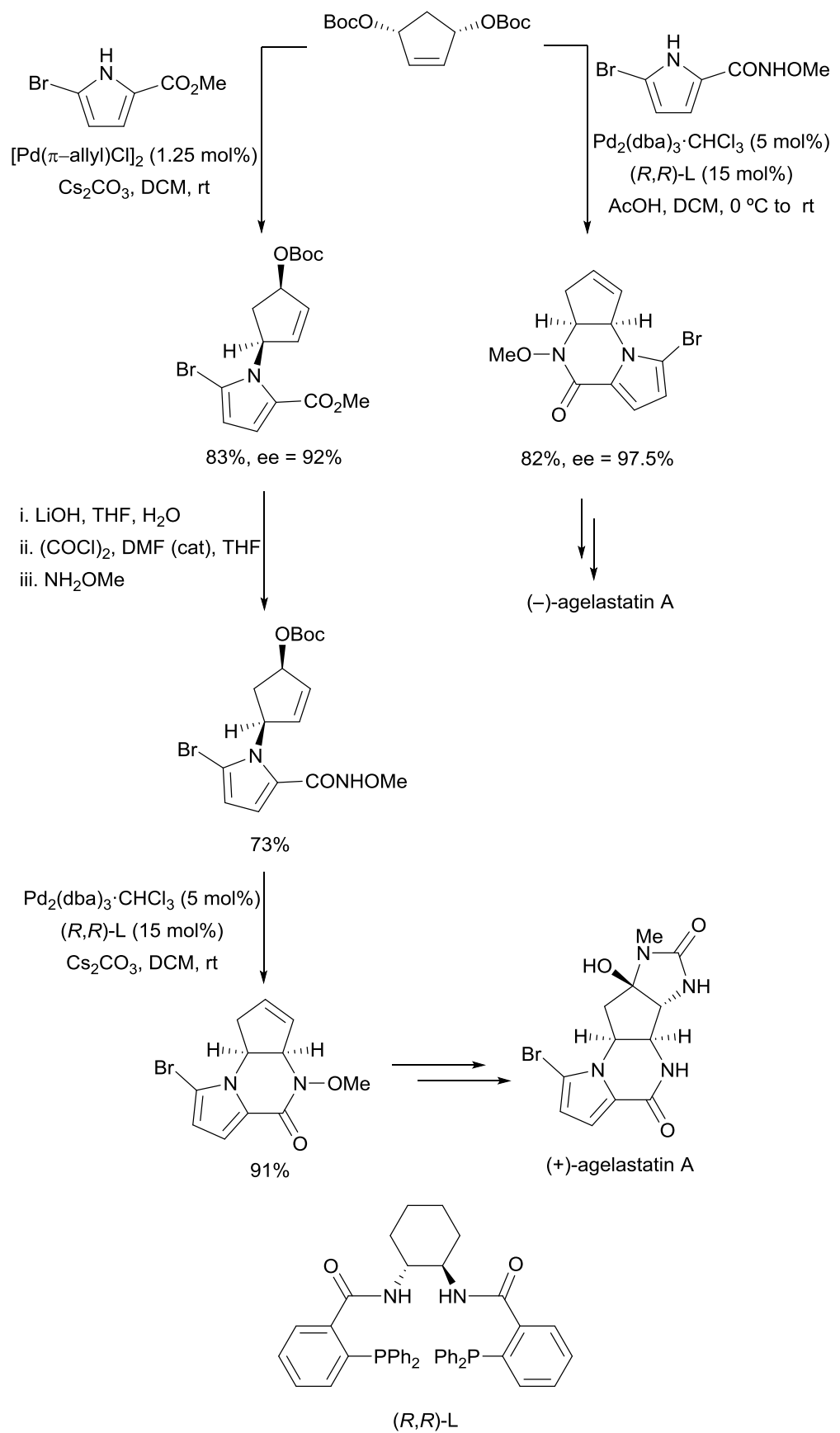

Scheme 12 Enantiodivergent routes to piperazinones precursors of (+)- and (-)-agelastatins A. 


\section{Lactones}

Natural products containing a $\mathrm{y}$-butyrolactone unit are ubiquitous and exhibit a wide range of biological activities. ${ }^{16}$ Enantiodivergent routes to (+)- and (-)-transquercus lactones, also known as whisky lactones, were reported by Inomata and co-workers ${ }^{17}$ using a chiral bicyclic lactone as starting common material. The (+)and (-)-trans-lactones were isolated together with a (-)-isomer from oak woods. The starting lactone, prepared from D-manitol, ${ }^{18}$ was reduced with DIBALH to give a lactol followed by addition of $n$-BuMgBr providing a diol (Scheme 13). After oxidation with TPAP and NMO to the corresponding bicyclic butanolide, followed by a retro-Diels-Alder reaction, afforded the (-)-butenolide precursor of $(+)$ quercus lactone. On the other hand, performing first the addition of $n$-BuLi and then reduction of the resulting ketone with L-Selectride gave the epimeric alcohol, which was treated with the same reagents to provide the (+)-butenolide precursor of $(-)$-quercus lactone, after addition of dimethylcuprate.

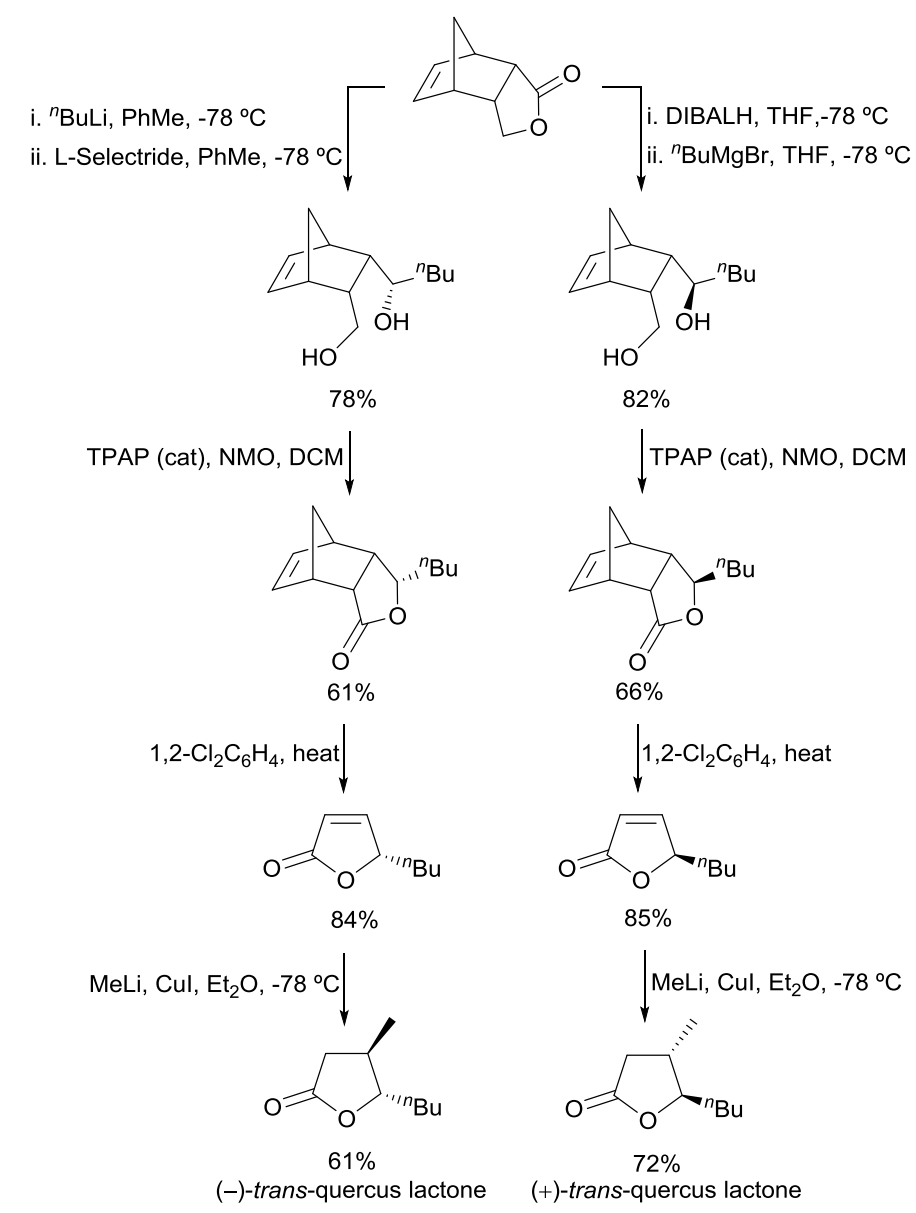

Scheme 13 Enantiodivergent routes to (+)- and (-)-trans-quercus lactones.

5-Hydroxyalkylbutyrolactones are naturally occurring compounds with different biological activity. Muricatacin, an acetogenin derivative isolated from 
the seeds of the tropical plant Anona muricata, shows strong cytotoxic activity against certain human tumor cell lines. The isolated example is a mixture of enantiomers showing the same antitumor activity. Popsavin and co-workers ${ }^{19}$ reported enantiodivergent routes toward (+)- and (-)-muricatacin from D-xylose. The common starting material was the benzylated 5-O-benzoyl-1,2-Ocyclohexylidene- $\alpha$-D-xylafuranose, ${ }^{20}$ which was deprotected with $\mathrm{AcOH}$ to give the corresponding lactol. Wittig olefination provided a $\alpha, \beta$-unsaturated ester, which was hydrogenated and hydrolyzed to form a lactone. Oxidative cleavage of the diol with $\mathrm{NaIO}_{4}$ gave the aldehyde-lactone precursor of (+)-muricatacin ${ }^{21}$ and the related 5-hydroxyalkylbutyrolactones (Scheme 14). The starting xylofuranose was hydrolyze to a primary alcohol, which was oxidized to an aldehyde with DCC and then submitted to a Wittig olefination giving a Z/E-mixture of unsaturated esters. Catalytic hydrogenation followed by deprotection of the acetal and oxidative cleavage gave to corresponding formate. After treatment with aqueous TFA resulted the enantiomeric aldehyde-lactone precursor of $(-)$ muracatacin and related 5-hydroxyalkylbutyrolactones. 


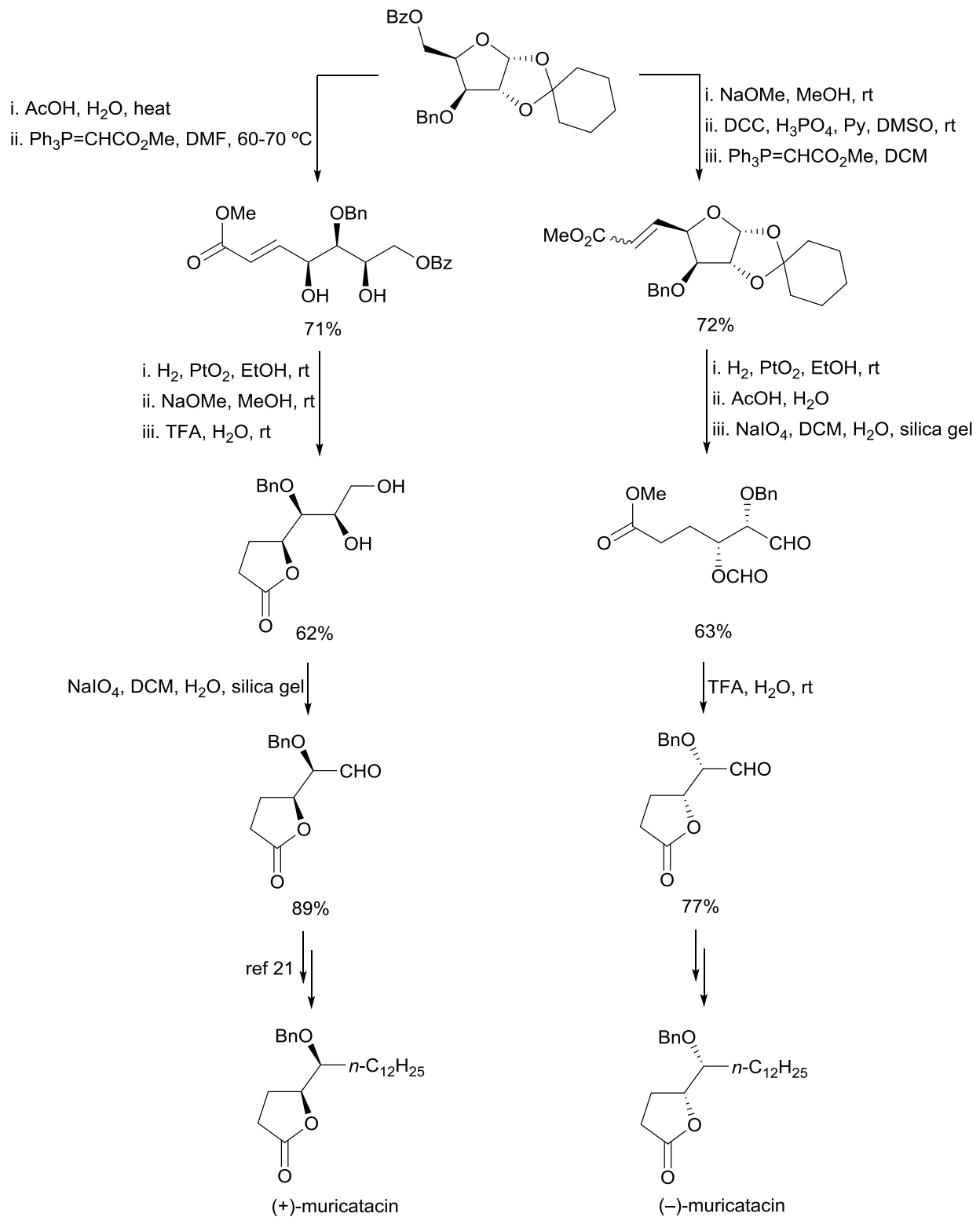

Scheme 14 Enantiodivergent routes to aldehyde-lactones precursors of (+)- and (-)-muricatacins.

The same group has reported enantio- and diastereodivergent routes to several styryl lactones also from D-xylose..$^{22}$ These lactones, which are a group of secondary metabolites, mainly isolated from Asian trees of the genus Goniothalamus of the plant family Annonacae, exhibit high cytotoxic activity specific on neoplastic cells. Diastereodivergent routes to (+)-goniofufuranone and 7-epi-(+)-goniofufuranone have been elaborated from the same chiral building block. This intermediate was submitted to Mitsunobu conditions giving a benzoate with inversion of the configuration at the $\mathrm{C}-5$ followed by deprotection of the alcohol. Removal of the cyclohexylidene protecting group, gave a sixmembered lactol, which was condensed with Meldrum's acid using $\mathrm{Et}_{3} \mathrm{~N}$ as catalyst to yield $y$-lactone. Final hydrogenolysis furnished (+)-goniofufuranone (Scheme 15). On the other hand, acidic hydrogenolysis of the starting furanose 
(giving the pyranose) followed by condensation with Meldrum's acid and final debenzylation afforded 7-epi-goniofufuranone.

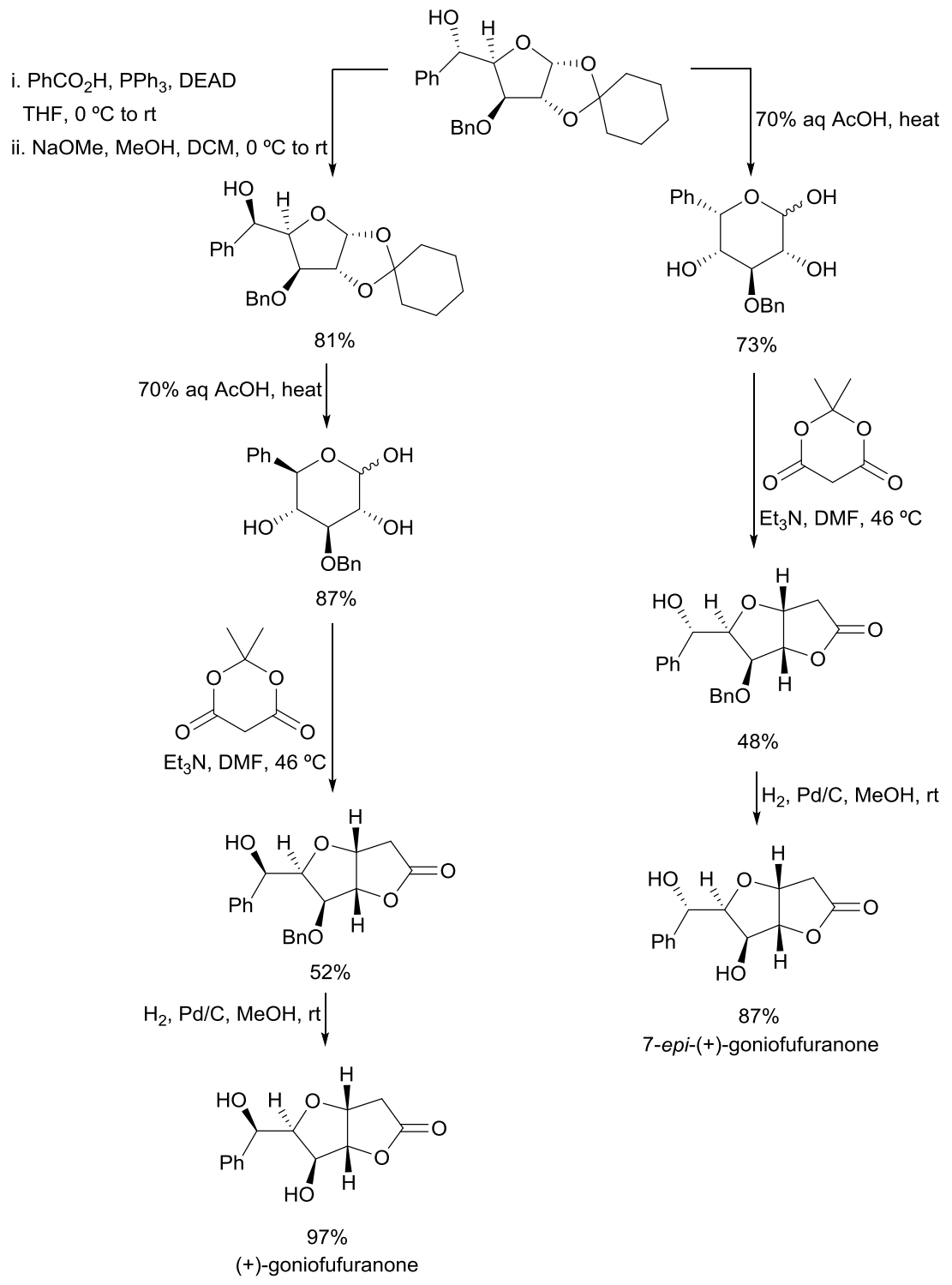

Scheme 15 Diastereodivergent routes to (+)-goniofufuranone and its 7-epi-isomer.

Their enantiomers have been prepared from a more elaborate intermediate lactone through diastereodivergent routes (Scheme 16). This butyrolactone gave by hydrogenolysis 7-epi-goniofufuranone, whereas by oxidation with PCC, followed by reduction with $\mathrm{NaBH}_{4}$ and debenzylation provided (-)-goniofufuranone. In addition, (+)- and (-)-crassalactones $\mathrm{C}$ were synthesized following enantiodivergent routes from the aldehyde precursor of the intermediate used for (+)-goniofufuranone and 7-epi-goniofufuranone. Comparable antiproliferative activities of the six compounds were observed against a large number of tumor cell lines. 


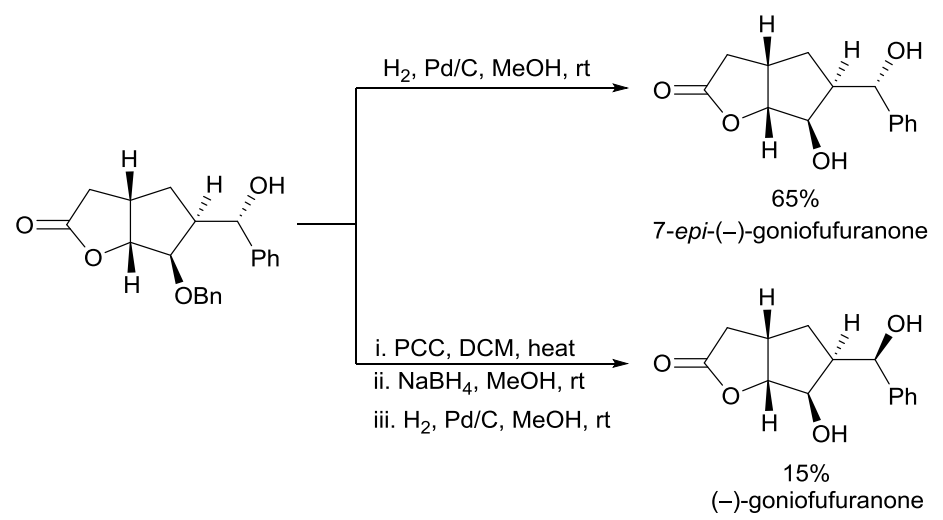

Scheme 16 Diastereodivergent routes to 7-epi-(-)-goniofufuranone and (-)-goniofufuranone.

Substituted $\gamma$-butyrolactones with a carboxylic acid at the $\beta$-position, known as paraconic acids, ${ }^{23}$ are ubiquitous natural products. In particular, methylenolactocin exhibits strong antitumor and antibiotic activities. Gosh and coworkers $^{24}$ have reported enantiodivergent routes to the natural (-)-enantiomer and $(+)$-methylenolactocin from D-mannitol. This starting hexaol was transformed into masked enantiomeric succinates, according to previously described protocols, ${ }^{25}$ which were further oxidized to the corresponding aldehydes. Subsequent addition of pentylmagnesium bromide gave $y$-lactones that were $\alpha$ methylated with formaldehyde and protected to give (-)-and (+)methylenolactocin, respectively (Scheme 17). 


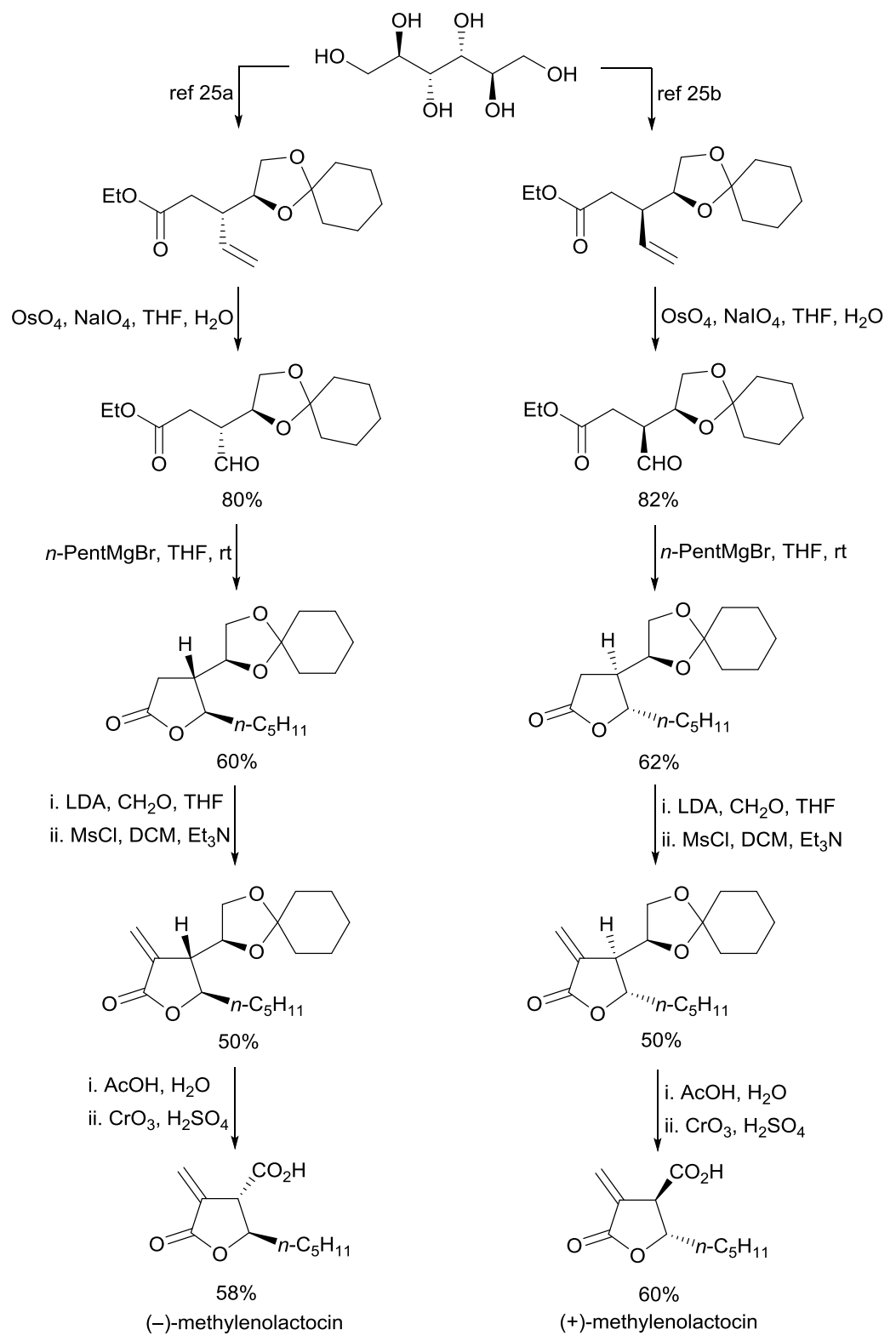

Scheme 17 Enantiodivergent routes to (-)- and (+)-methylenolactocins.

Kinase inhibitors ( \pm )-frenolicin $B$ and $( \pm)$-epi-frenolicin $B$ are pyranonaphthoquinone antibiotics first isolated from a strain of Streptomyces roseofulvus, which exhibit excellent anticoccidial activity. Donner ${ }^{26}$ reported diastereodivergent routes to these benzopyran- $y$-lactone-fused tricyclic compounds starting from a benzo-fused $\mathrm{y}$-lactone. By oxidation of the dimethoxyphenyl unit with CAN to benzoquinone and subsequent reported transformations, ${ }^{27}$ epi-frenolicin B was formally prepared (Scheme 18). Access to frenolicin $\mathrm{B}$ requires epimerization at $\mathrm{C}-5$ by means of $\mathrm{BBr} 3$, followed by oxidation with CAN and further already described transformations. ${ }^{27}$ 


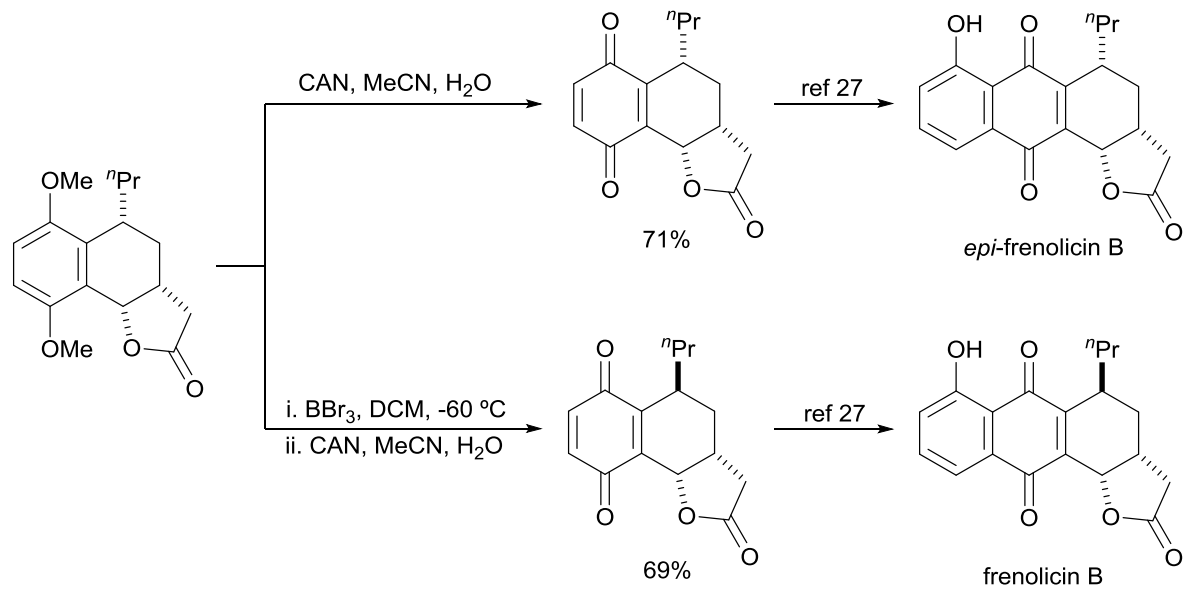

Scheme 18 Diastereodivergent routes to racemic epi- and frenolicin B precursors.

Few 6-membered lactones have been synthesized using stereodivergent routes. (+)-Altholactone (goniothalenol) is a natural cis-fused furanopyrone with antitumor activity isolated from Polyalthea sp., as well as from Goniothalmus giganteus. Gesson and co-workers ${ }^{28}$ reported enantiodivergent routes to (+)- and $(-)$-altholactones from D-glucose. As starting common material, a tetrahydrofurancarbaldehyde was allowed to react with phenylmagnesium bromide giving mainly the expected alcohol through a chelation-controlled addition. This alcohol was tosylated and then treated with PTSA in ethylene glycol giving a new tetrahydrofuran. The remaining hydroxy group at C-4 was benzoylated and, after debenzylation the $\mathrm{OH}$ at $\mathrm{C}-3$, was also benzoylated. Subsequent acetal hydrolysis followed by Wittig olefination and hydrolysis, the resulting dihydroxy acid gave a pyrone ring and consequently (+)-altholactone (Scheme 19). For the obtention of the (-)-enantiomer, the synthesis of the pyrone was firstly performed. The aldehyde was submitted to a Reformatsky condensation with ethyl bromoacetate to provide a single alcohol. The ester was hydrolyzed and after debenzylation to the dihydroxy acid, it was lactonized with DCC and the other hydroxy groups acetylated. The resulting lactone was transformed into the unsaturated lactone by treatment with DBU. Final treatment with $\mathrm{HF}$ in benzene allowed the introduction of a phenyl group at the anomeric center to afford mainly (-)-altholactone. These pyrones show interesting cytotoxicity in vitro against L1210 leukemia, specially the (+)-isomer. 

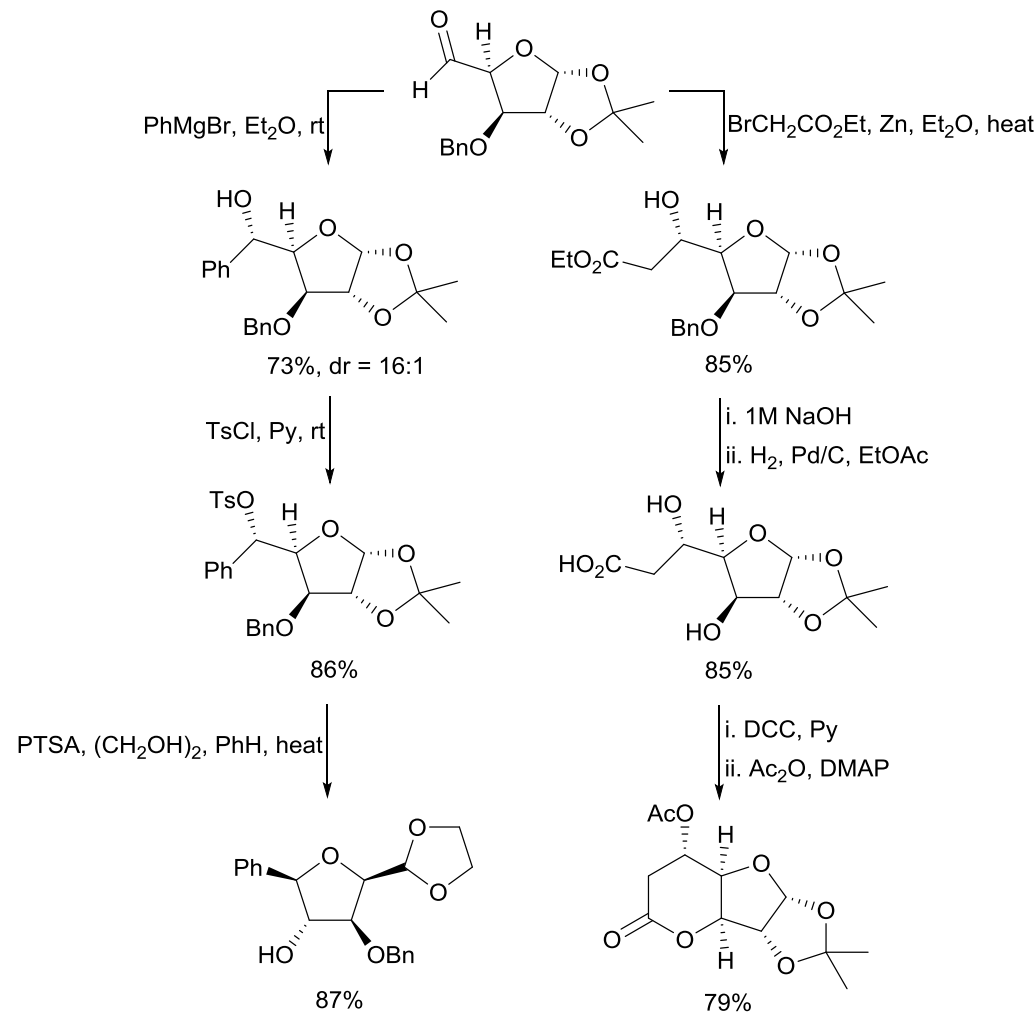

i. $\mathrm{BzCl}, \mathrm{Py}, \mathrm{rt}$
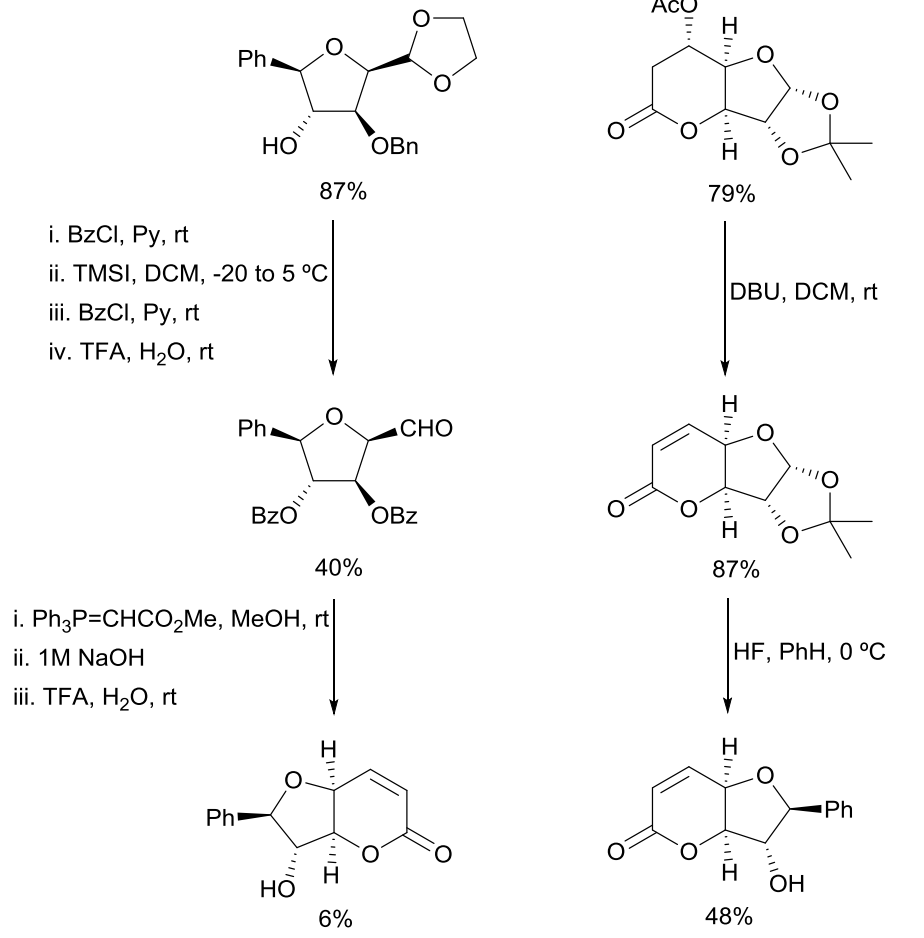

(+)-altholactone

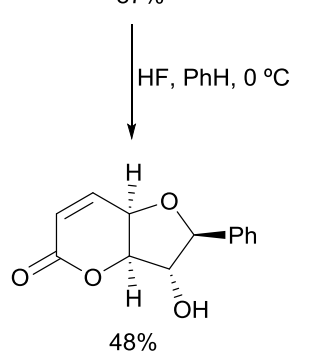

(-)-altholactone

Scheme 19 Enantiodivergent routes to (+)-and (-)-altholactones.

Hurem and Dudding described diastereodivergent routes to erythro- and threo-6-acetoxy-5-hexadecanolides. ${ }^{29}$ The first $(5 R, 6 S)$-lactone is the major chemical component of Culex sp. egg rafts responsible for the potent and selective attraction of gravid Culex mosquitos. The racemic threo-isomer can be used as oviposition traps, the corresponding enantiomer being inactive. A diastereodivergent acetylation strategy was employed starting from the threohydroxylactone. By mesylation of the C-6 hydroxy group, followed by substitution with acetate, the racemic erythro-lactone was obtained (Scheme 20). However, just acetylation of this alcohol gave the threo-lactone. 


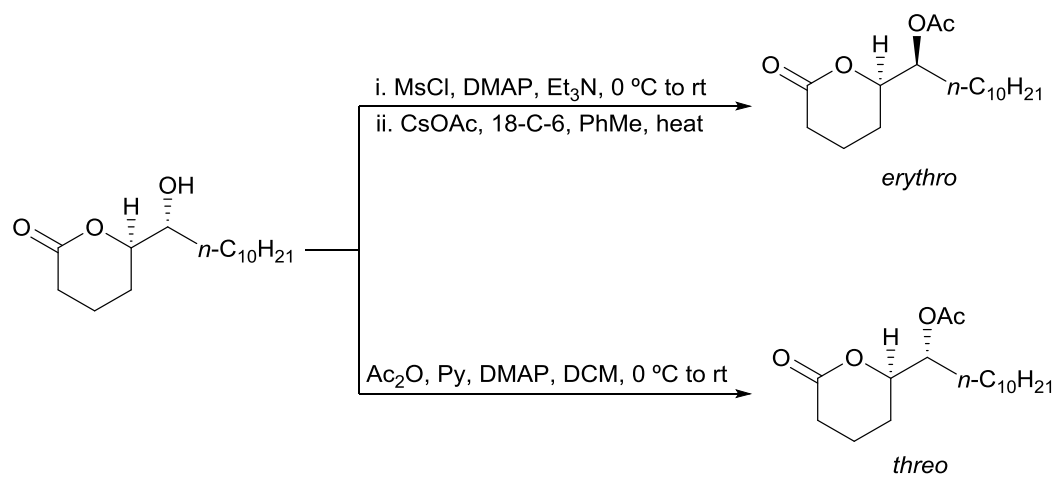

Scheme 20 Diastereodivergent routes to erythro- and threo-6-acetoxy-5-hexadecanolides.

The syntheses of macrolides are mainly based on classical lactonization of the corresponding seco-acids. ${ }^{30}$ Other efficient methods such as ring-closing metathesis, intramolecular Mitsunobu esterification, and others have been employed. Bracher and Schulte ${ }^{31}$ have reported enantiodivergent routes to $(R)$ and $(S)$-lasiodiplodin. The $(R)$-isomer is a 12-membered orsellinic acid type lactone constituent of the fungus Lasiodiplodia theobromae and of the wood of Euphorbia splendens and Euphorbia fidjiana, which showed significant antileukemic activity. The two enantiomers have been prepared from a seco-acid by macrolactonization with either Gerlach's modification ${ }^{32}$ of the Corey lactonization or a Mitsunobu lactonization. The $(S)$-lactone was obtained using di-(2-pyridyl) disulfide- $\mathrm{PPh}_{3}-\mathrm{AgClO}_{4}$ in $61 \%$ yield, which was debenzylated and desulfurized with Raney-Nickel (Ra-Ni) to provide (-)-lasiodiplodin (Scheme 21). Naturally occurring lasiodiplodin was prepared with inversion of the chiral centre under Mitsunobu conditions followed by treatment with Ra-Ni.

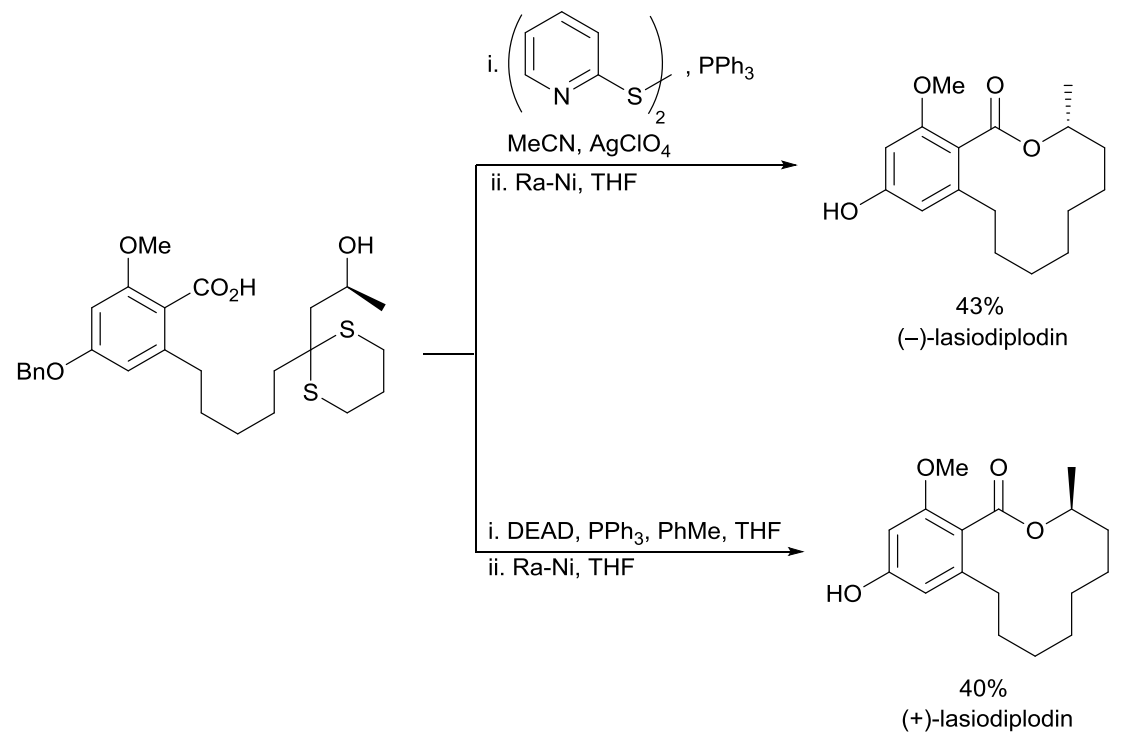

Scheme 21 Enantiodivergent routes to (-)- and (+)-lasiodiplodins. 
The macrocyclic lactone (S)-curvularin, a polyketide metabolite of various Curvularia, Penicillum, Alternaria and Cochliobolus species, has attracted considerable interest because of its cytotoxic and antimicrobial activities. Enantiodivergent routes to both enantiomers have been reported by Bracher and Schulte. ${ }^{33}$ Starting from (3,5-dibenzyloxyphenyl)acetic acid, its esterification with (S)-methyl-7-hydroxyoctanolide gave the (S)-ester, which was further transformed into the corresponding acid followed by treatment with trifluoroacetic anhydride and concomitant Friedel-Crafts acylation giving a ketone that, after hydrogenolysis, provided (S)-curvularin (Scheme 22). On the other hand, esterification of the starting common acid with (S)-methyl-7-hydroxyoctanoate under Mitsunobu conditions provided the enantiomeric ester, which was further transformed into $(R)$-curvularin according to the above-mentioned steps.

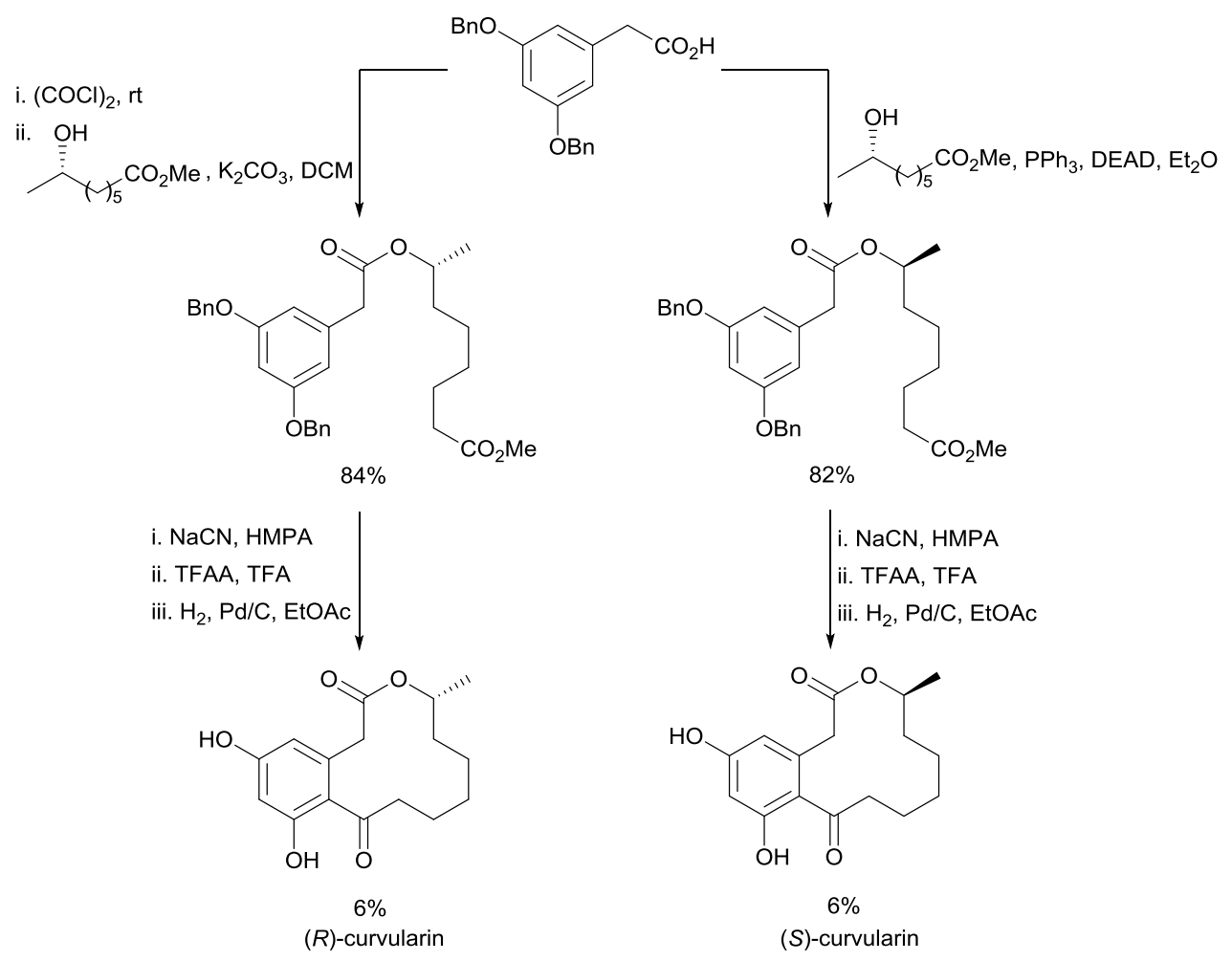

Scheme 22 Enantiodivergent routes to $(R)$ - and $(S)$-curvularins.

The same group has reported ${ }^{34}$ enantiodivergent routes to the 14membered macrocyclic lactone zearalane. The natural precursor zearalenone was isolated from the fungus Gibberella zeae with strogenic and anabolic activities. In this case, the seco-acid was subjected to lactonization either under Mitsunobu conditions or with a Gerlach's modification ${ }^{32}$ of the Corey method (Scheme 23). Final debenzylation provided $(R)$ - and (S)-zearalane. The last compound showed strogenic, anabolic, anthelminthic and immunomodulating properties. 


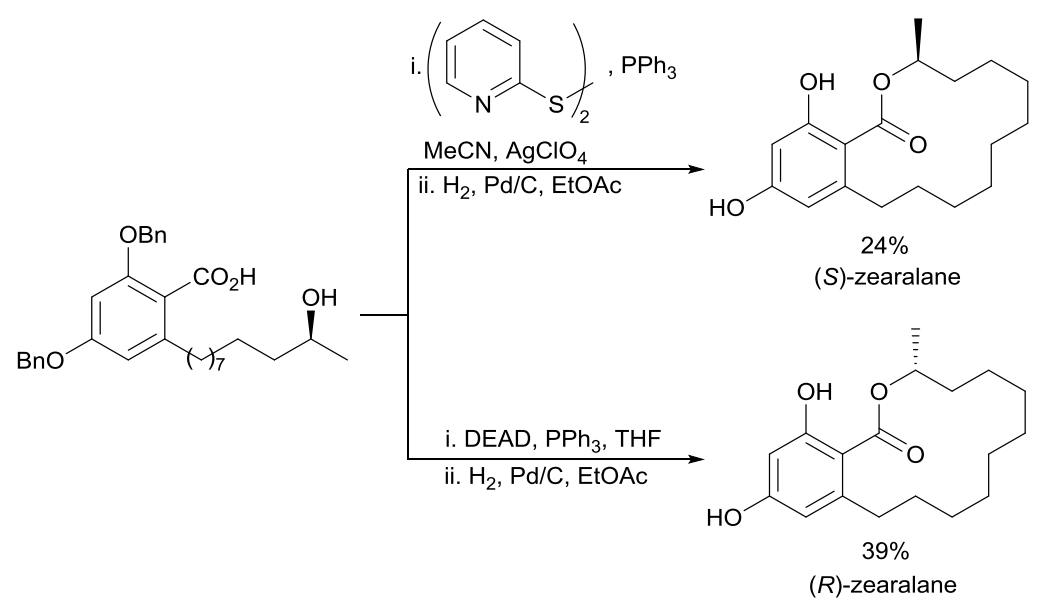

Scheme 23 Enantiodivergent routes to $(S)$ - and $(R)$-zaeralanes.

Aspercyclides A-C are 11-membered biaryl ether lactones isolated from the fermentation broth of Asperigillus sp. They exhibit moderate activity in $\lg \mathrm{E}$ receptor binding related to allergic disorders. Prasad and co-workers ${ }^{35}$ described enantiodivergent routes to aspercyclide $\mathrm{C}$ enantiomers from L-tartaric acid. The key common intermediate is the protected allylic alcohol $(3 R, 4 R)-4$ (methoxymethoxy)non-1-en-3-ol, which after protection as PMB ether and MOM deprotection, the configuration of the alcohol was inverted under Mitsunobu conditions (Scheme 24). For the synthesis of its enantiomer, the starting MOMmonoprotected diol was submitted to Mitsunobu conditions and then to PMBprotection and final MOM deprotection. For the completion of the formal synthesis of aspercyclide $\mathrm{C}$, the homoallylic alcohol was coupled with a biaryl acid ${ }^{36}$ and after ring-closing metathesis (RCM) the biaryl lactone was obtained. Deprotection of the PMB ether and of the aryl methyl ether ${ }^{37}$ gave the natural product. An analogous reaction sequence employing the enantiomeric homoallylic alcohol afforded the enantiomer of aspercyclide $\mathrm{C}$. 


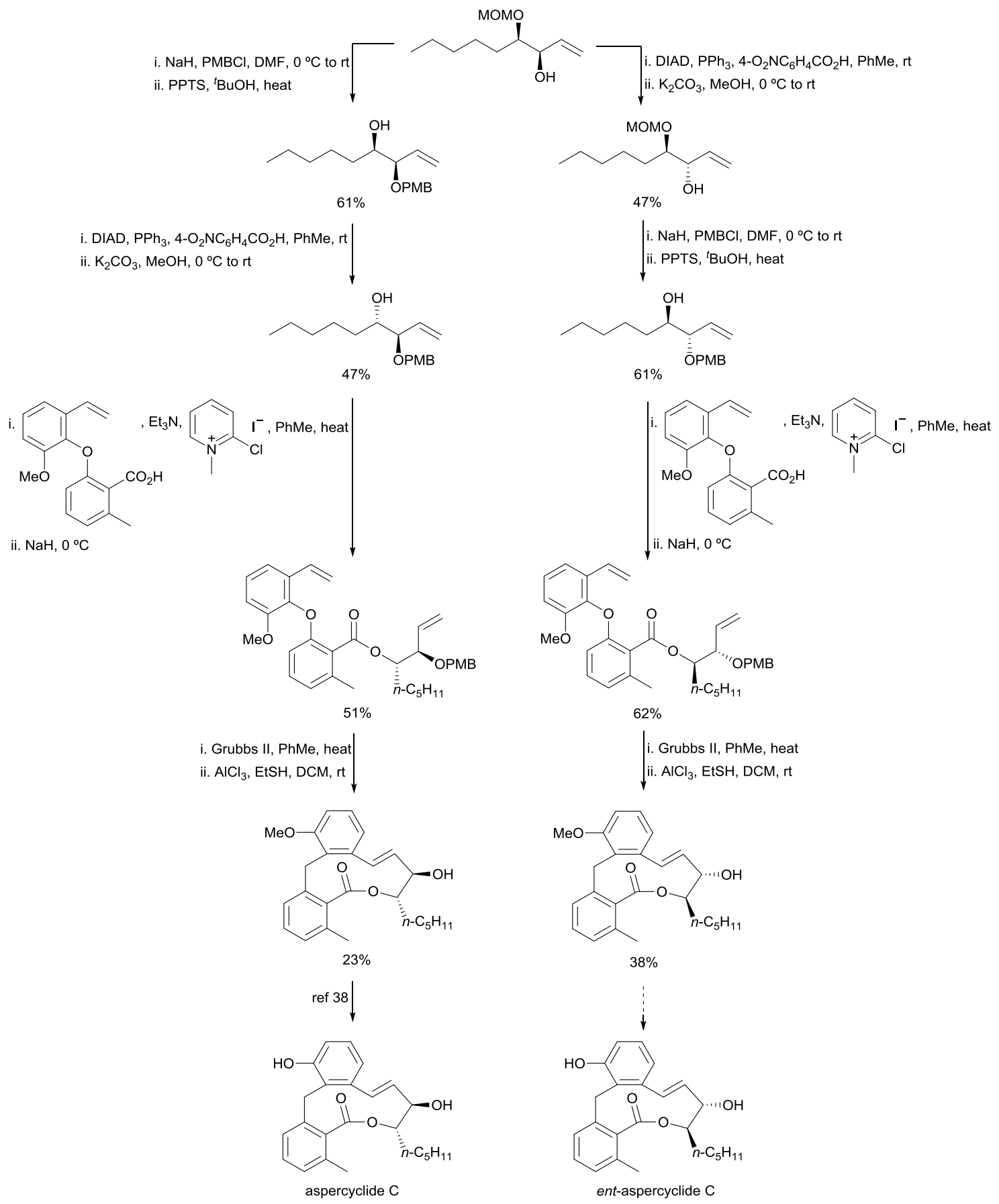

Scheme 24 Enantiodivergent routes to aspercyclide $C$ and its enantiomer.

Microcarpalide is a 10-membered lactone isolated from the fermentation broths of endophytic fungi. It was found to be weakly cytotoxic to mammalian cells and acts as a microfilament disrupting agent. Also, the Prasad group has developed enantiodivergent routes to (-)-microcarpalide and its enantiomer from L-tartaric acid. ${ }^{38}$ As starting common material a known alcohol ${ }^{39}$ was transformed into a homoallylic alcohol by successive formation of its tosylate, reaction with $n$ pentylmagnesium bromide, acetonide deprotection, tosylation of the primary alcohol, epoxide formation and final opening of the epoxide with vinylmagnesium cuprate (Scheme 25). For the other enantiomer, the starting alcohol was 
transformed into a diol. ${ }^{40}$ This diol was submitted to oxidative cleavage with $\mathrm{NalO}_{4}$ to give an aldehyde, which was reduced with $\mathrm{NaBH}_{4}$, then tosylation of this primary alcohol, reaction with $n$-pentylmagnesium cuprate and deprotection of the MOM ether gave a homoallylic alcohol. For the synthesis of (-)microcarpalide the obtained homoallylic alcohol was esterified with $(4 R, 5 R)-4,5-$ bis(benzyloxy)hept-6-enoic acid and the macrolactone was synthesized by a RCM reaction followed by debenzylation..$^{41} \mathrm{~A}$ similar reaction sequence, starting from the enantiomeric alcohol, gave (+)-microcarpalide. 
i. TsCI, DMAP, DCM, rt

ii. $n$-PentMgBr, $\mathrm{CuBr}, \mathrm{THF}, 0^{\circ} \mathrm{C}$ to rt

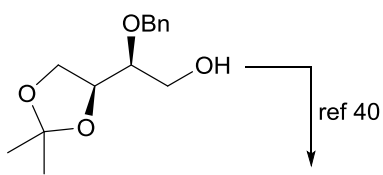<smiles>CCCCCC[C@H](OCc1ccccc1)[C@H]1COC(C)(C)O1</smiles><smiles>C=CC[C@@H](OC)[C@@H](OC)[C@@H](O)CO</smiles>

i. $\mathrm{FeCl}_{3} \cdot 6 \mathrm{H}_{2} \mathrm{O}, \mathrm{DCM}$, $\mathrm{rt}$

ii. $\mathrm{TsCl} \mathrm{Et}_{3} \mathrm{~N}, \mathrm{DMAP}, \mathrm{DCM}, \mathrm{O}^{\circ} \mathrm{C}$ to $\mathrm{rt}$

iii. $\mathrm{K}_{2} \mathrm{CO}_{3}, \mathrm{MeOH}$, rt<smiles>CCCCCCOC(CCCC)OC1CO1</smiles>

$61 \%$

$\mathrm{MgBr}, \mathrm{CuCN}, \mathrm{THF},-78^{\circ} \mathrm{C}$ to $\mathrm{rt}$<smiles>C=CC[C@@H](O)[C@@H](CCCCCC)OCC</smiles>

$88 \%$<smiles>C=C[C@H](OC(=O)OCc1ccccc1)[C@H](CCC(=O)O)OC(=O)OCc1ccccc1</smiles>

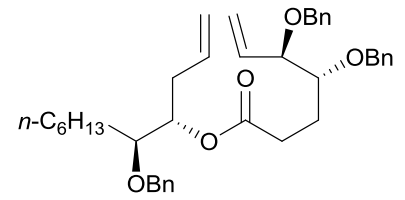

$43 \%$

Grubbs I, DCM, rt $\mid$ ref 41

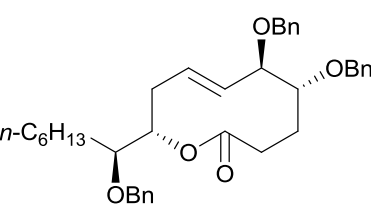

ref 41

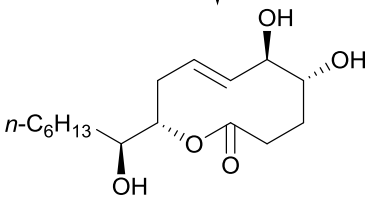

(-)-microcarpalide i. $\mathrm{NalO}_{4}, \mathrm{MeCN}, \mathrm{H}_{2} \mathrm{O}$, rt ii. $\mathrm{NaBH}_{4}, \mathrm{MeOH}, 0^{\circ} \mathrm{C}$ to $r$

$80 \%$

i. TsCl, DMAP, DCM, rt ii. $n$-PentMgBr, $\mathrm{CuBr}, 0^{\circ} \mathrm{C}$ iii. PPTS, $\mathrm{MeOH}$, heat<smiles>C=CC[C@H](O)[C@H](CCCCCC)OCc1ccccc1</smiles>

$61 \%$

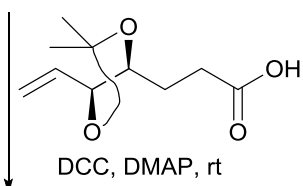

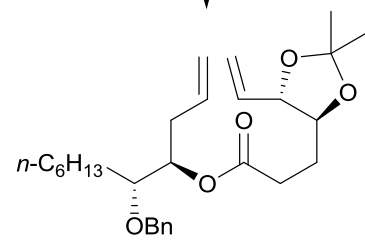

$96 \%$

Grubbs I, DCM, heat

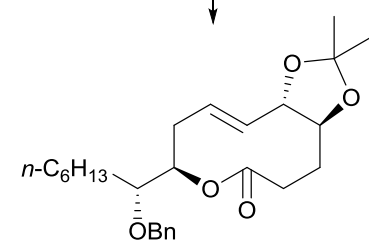

$49 \%$ $\mid \mathrm{TiCl}_{4}, \mathrm{DCM}, 0^{\circ} \mathrm{C}$

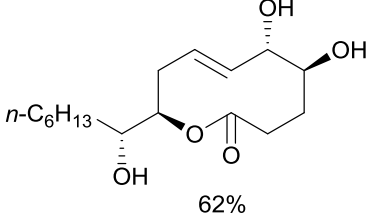

(+)-microcarpalide

Scheme 25 Enantiodivergent routes to (-)- and (+)-microcarpalides. 
The 16-membered macrolides FD-891 and FD-892 were isolated from the fermentation broth of Streptomices graminofaciens A-8890. FD-891 shows more than 100 times cytotoxic activity than FD-892. Kanoh and co-workers ${ }^{42}$ reported diastereodivergent routes to the $\mathrm{C}-1-\mathrm{C}-18$ macrolactone fragments of these natural products and their analogues, based on RCM. The advanced common intermediate pentaene was submitted to RCM followed by desilylation and Katsuki-Sharpless asymmetric epoxidation to afford a $\beta$-epoxide (Scheme 26). For the synthesis of the $\alpha$-epoxide, the pentaene intermediate was desilylated and the primary alcohol was regioselectively TBS-silylated. Next, the epoxidation provided the corresponding a-epoxide, which was submitted to desilylation and RCM. This last lactone is a precursor of FD-891, as described by Crimmins and Yadav total synthesis. ${ }^{43}$

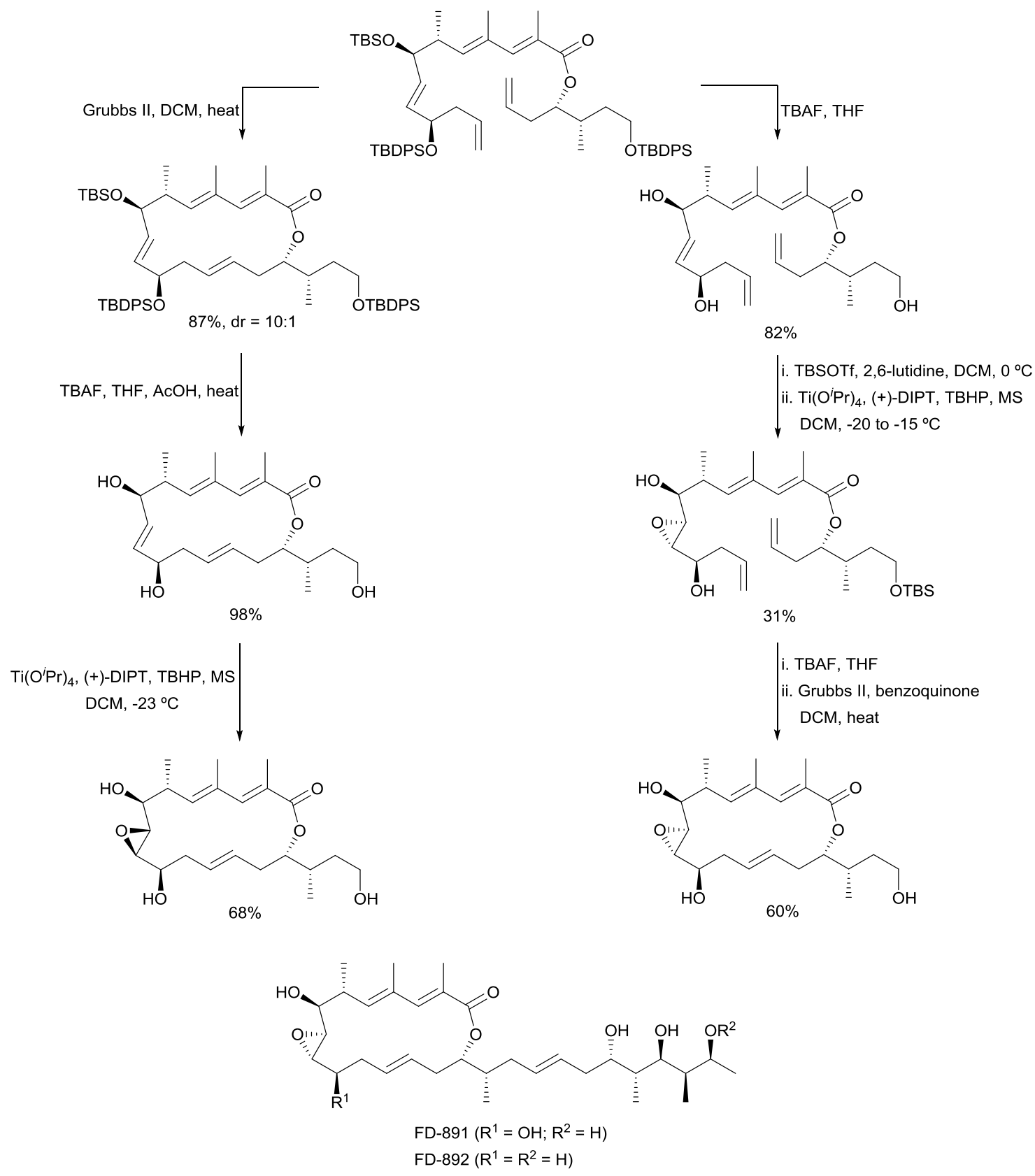


Scheme 26 Diastereodivergent routes to C-1-C-18 macrolactone fragments.

Diastereodivergent routes to a 14-membered macrodiolide library from the corresponding seco-acids are possible using Yamaguchi and Mitsunobu macrolactonizations as key steps such as it has been reported by Ömura, Sunazuka and co-workers. ${ }^{44}$ 14-Membered macrolides are present in many natural products and are considered to be the most important ones in medicinal chemistry. In Scheme 27 selected seco-acids have been depicted: under Yamaguchi conditions retention of $\mathrm{C}-13$ configuration took place, whereas Mitsunobu reaction occurs with inversion at this stereocenter giving 32 stereoisomers.

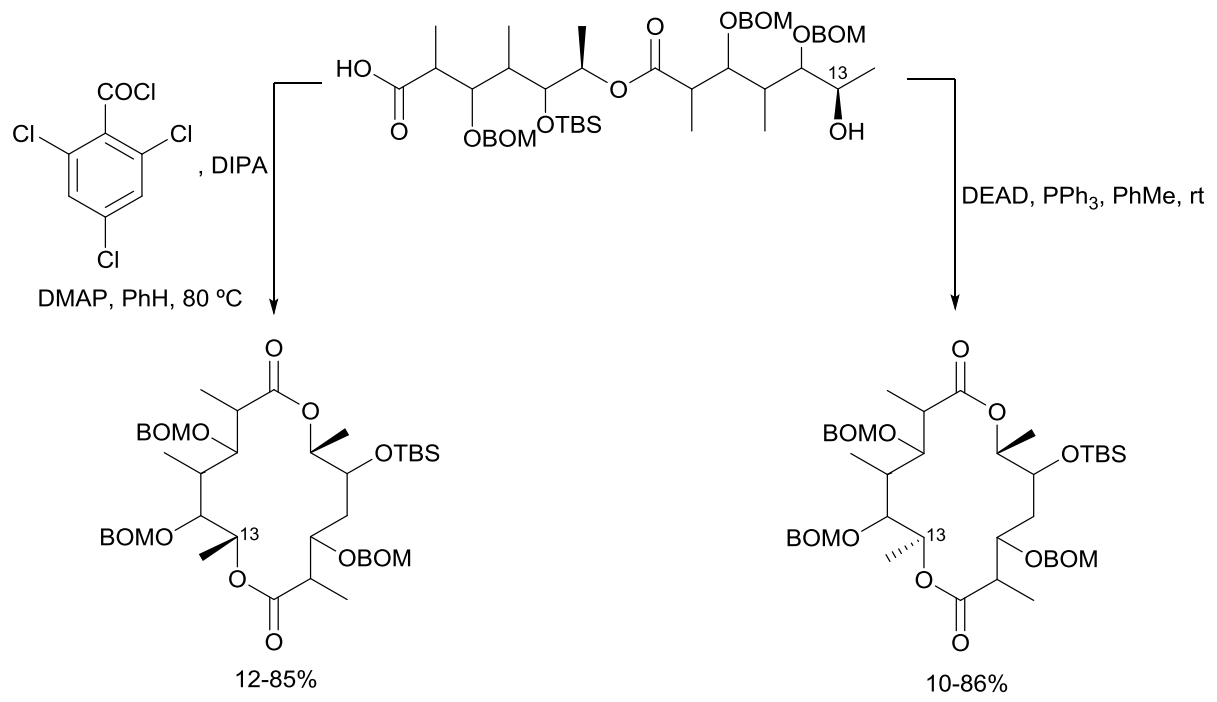

Scheme 27 Diastereodivergent routes to a 14-membered macrolide library.

The family of macrosphelide-type natural products ${ }^{45}$ are 15- or 16membered macrotriolides and have been isolated from Microsphaeropsis sp. FQ5050. Some members of this family inhibit cell-cell adhesion of NH-60 cells to human umbilical vein endothelial cells (HUVECs), a key step within the metastasis process. Häcker and Plietker ${ }^{46}$ developed diastereodivergent routes to macrotriolides $A$ and $E$ and macrosphelides $D$ and $M$ using a chiral cyclic sulfate as common material, which was prepared from tert-butyl sorbate (Scheme 28). Esterification with the sulfate-containing building bock gave the trimester, which after saponification of the tert-butyl ester, gave a seco-acid which was lactonized using Shiina protocol ${ }^{47}$ to the 15 -membered macrotriolide D. Using $\mathrm{Ti}\left(\mathrm{O}^{\prime} \mathrm{Pr}\right)_{4}$ the 16-membered macrosphelide $\mathrm{A}$ was obtained. When the same reaction steps were carried out with the epimeric acid, the diastereomeric 15membered macrotriolide $\mathrm{M}$ and 16-membered macrosphelide $\mathrm{E}$ were obtained. Parallel synthetic protocols have been carried out using the same cyclic sulfate and other acids to provide diastereomeric macrosphelides $\mathrm{C}$ and $\mathrm{F}$. 


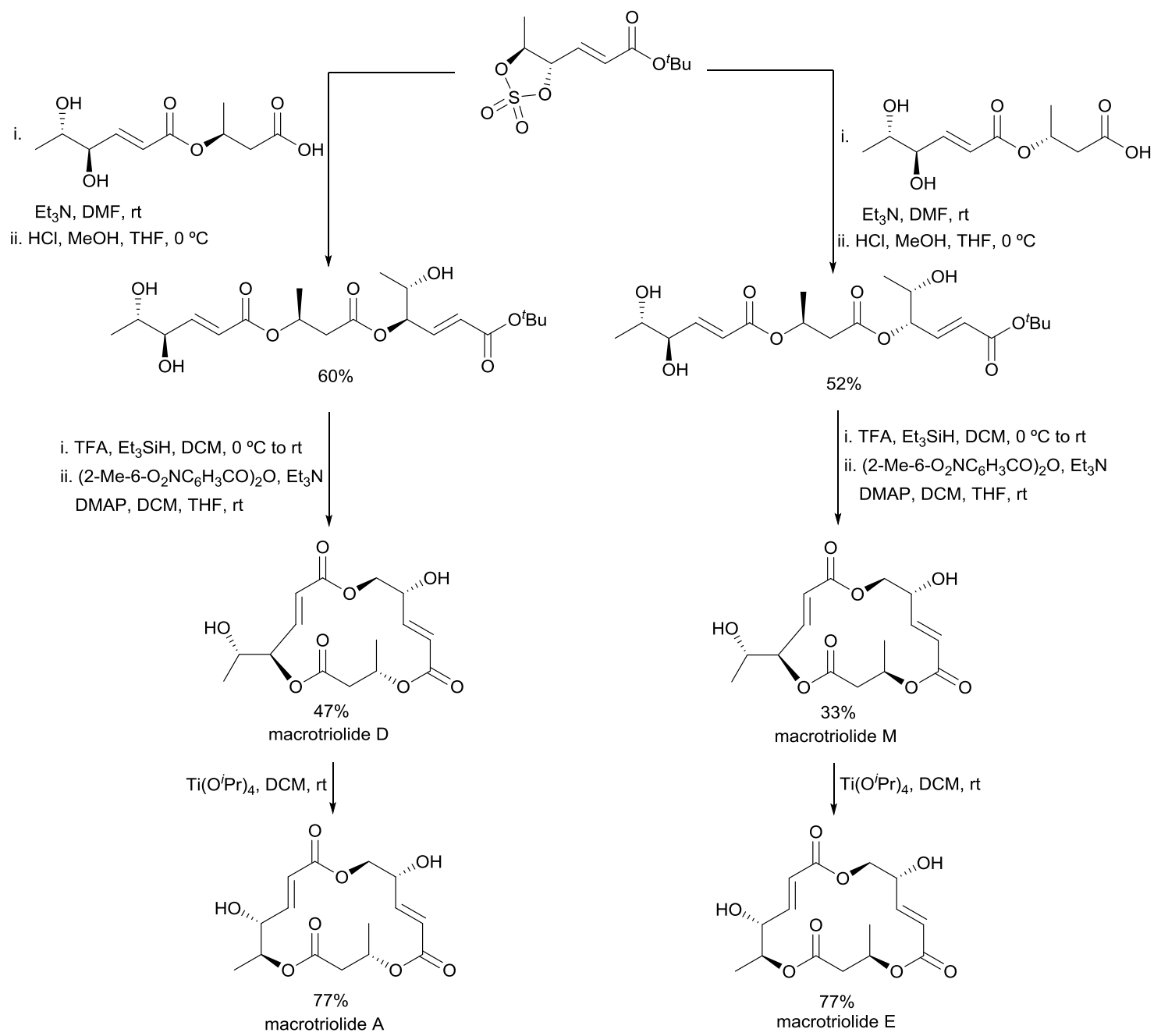

Scheme 28 Diastereodivergent routes to macrosphelides $A$ and $E$ and macrotriolides $D$ and $M$.

Haprolid, a polyketide-peptide hybrid, has been isolated from myxobacterium Byssovorax cruenta (cell line Har1). Kalesse and co-workers ${ }^{48}$ have recently reported diastereodivergent routes to $(7 S, 11 S)$ - and $(7 R, 11 S)$ isomers of haprolid using the seco-acid lactonization as key step. Via Shiina ${ }^{47}$ lactonization the $(7 S, 11 S)$-diastereomer of haprolid was isolated in $32 \%$ yield (Scheme 29). On the other hand, under Mitsunobu conditions the same secoacid afforded the $(7 R, 11 S)$-diastereomer. 


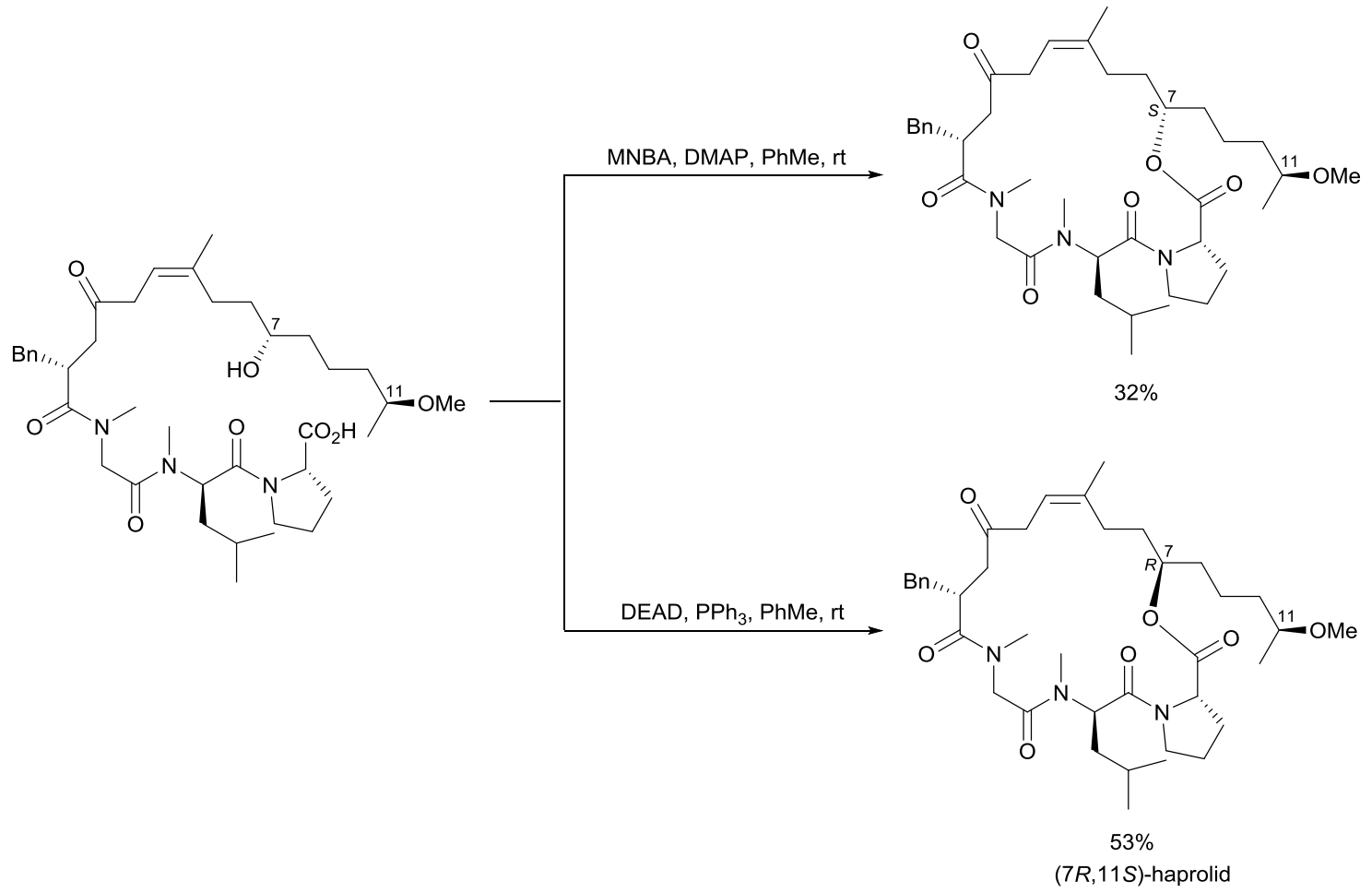

Scheme 29 Diastereodivergent routes to $(7 S, 11 S)$ - and (7R,11S)-haprolid diastereomers. 32 no tiene nombre debajo?

Recently, Machara, Kyjaková and co-workers ${ }^{49}$ have described enantiodivergent routes to 10-pentyl-3,4,5,8,9,10-hexahydro-2H-oxencin-2-one enantiomers from $(S)$-glycidyl tosylate. The $(5 Z, 9 S)$-tetradec-5-en-9-olide was discovered to be the queen-specific volatile pheromone of the termite Silvestritermes minutus, after preparation of both enantiomers. By opening of the epoxide with allylmagnesium bromide in the presence of catalytic amount of $\mathrm{Li}_{2} \mathrm{CuCl}_{4}$ the corresponding alcohol was obtained (Scheme 30 ). The tosylate was then substituted by $n$-butylmagnesium bromide in the presence of $\mathrm{CuCl}$ and, after esterification with hex-5-enoic acid, the ester was submitted to RCM using Hoveyda-Grubbs second generation catalyst under high dilution to provide the 4:1 (E/Z)-mixture of macrolides. For the synthesis of the (9S)-enantiomer the glycidyl tosylate was allowed to react with $n$-butylmagnesium bromide and 5 mol\% of $\mathrm{Li}_{2} \mathrm{CuCl}_{4}$ and then with allylmagnesium bromide under $\mathrm{CuCl}$ catalysis. After esterification, RCM and final addition of morpholinoethyl isocyanate as ruthenium scavenger, a 4:1 mixture of $(E / Z)$-macrolides was obtained. As it was mentioned above, the (5Z,9S)-tetradec-5-en-9-olide matched with the isolated natural product. 


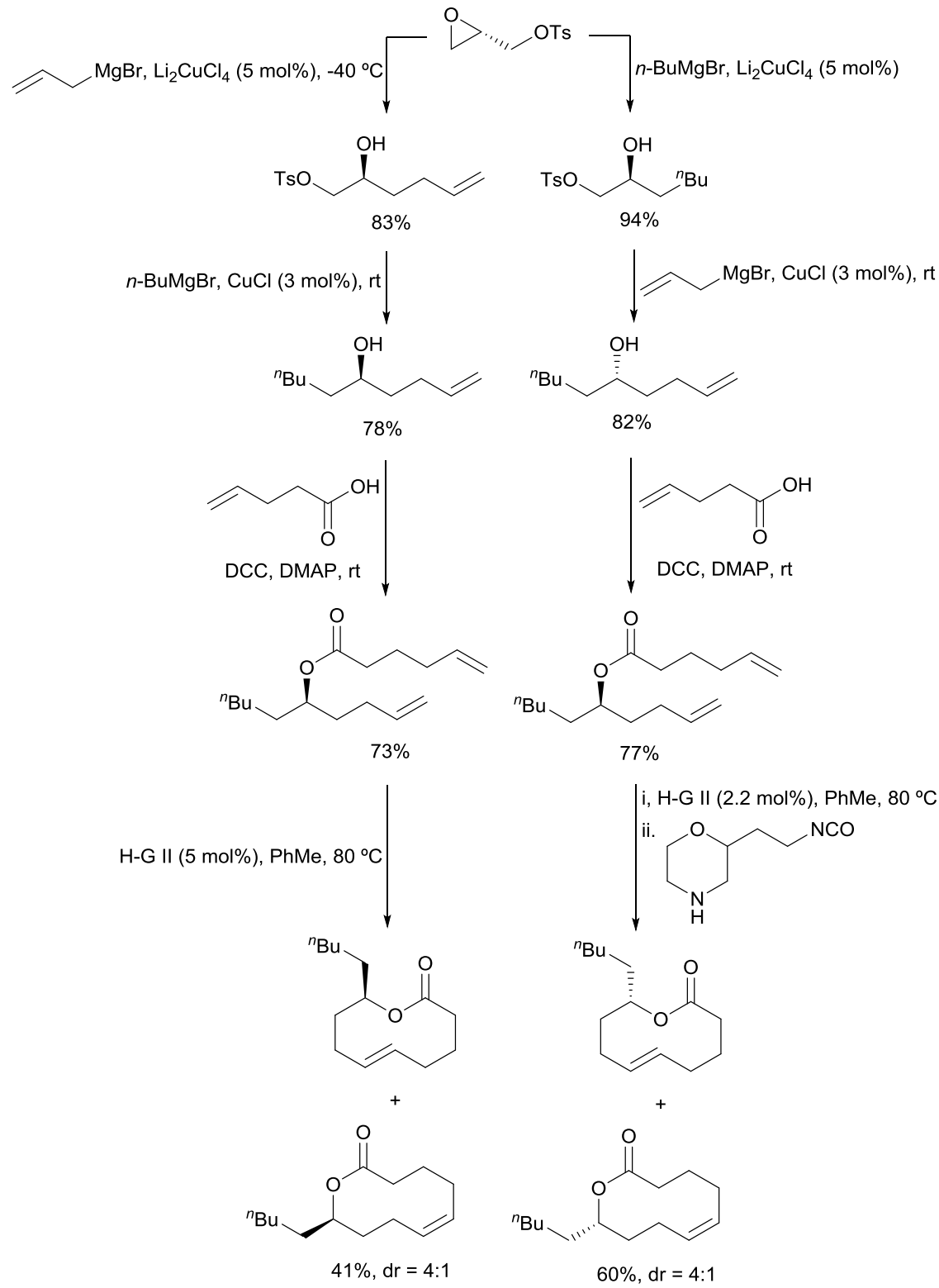

Scheme 30 Enantiodivergent routes to $(5 Z, 9 R)$ - and $(5 Z, 9 S)$-tetradec-5-en-9-olides.

\section{Other natural products}

$(+)$-Sesamin and (-)-asarinin are typical diastereomeric furofurans. Samizu and Ogasawa ${ }^{50}$ reported diastereodivergent routes to these lignans via a dioxepin as common intermediate. Treatment of this dioxepin with $\mathrm{Ti}(\mathrm{O} / \mathrm{Pr})_{2} \mathrm{Cl}_{2}$ followed by reduction with $\mathrm{NaBH}_{4}$ afforded 2,3-trans:3,4-cis-tetrahydrofurans, which were further transformed into (+)-sesamine (Scheme 31). When the same dioxepin was treated with TBSOTf and then with $\mathrm{NaBH}_{4}$ 2,3-cis:3,4-transtetrahydrofurans, precursor of (-)-asarinin, were formed. The diastereodivergent formation of these trisubstituted tetrahydrofurans was rationalized by participation of a titanium chelating complex I in the first case and a non-chelating one II in the last case. 

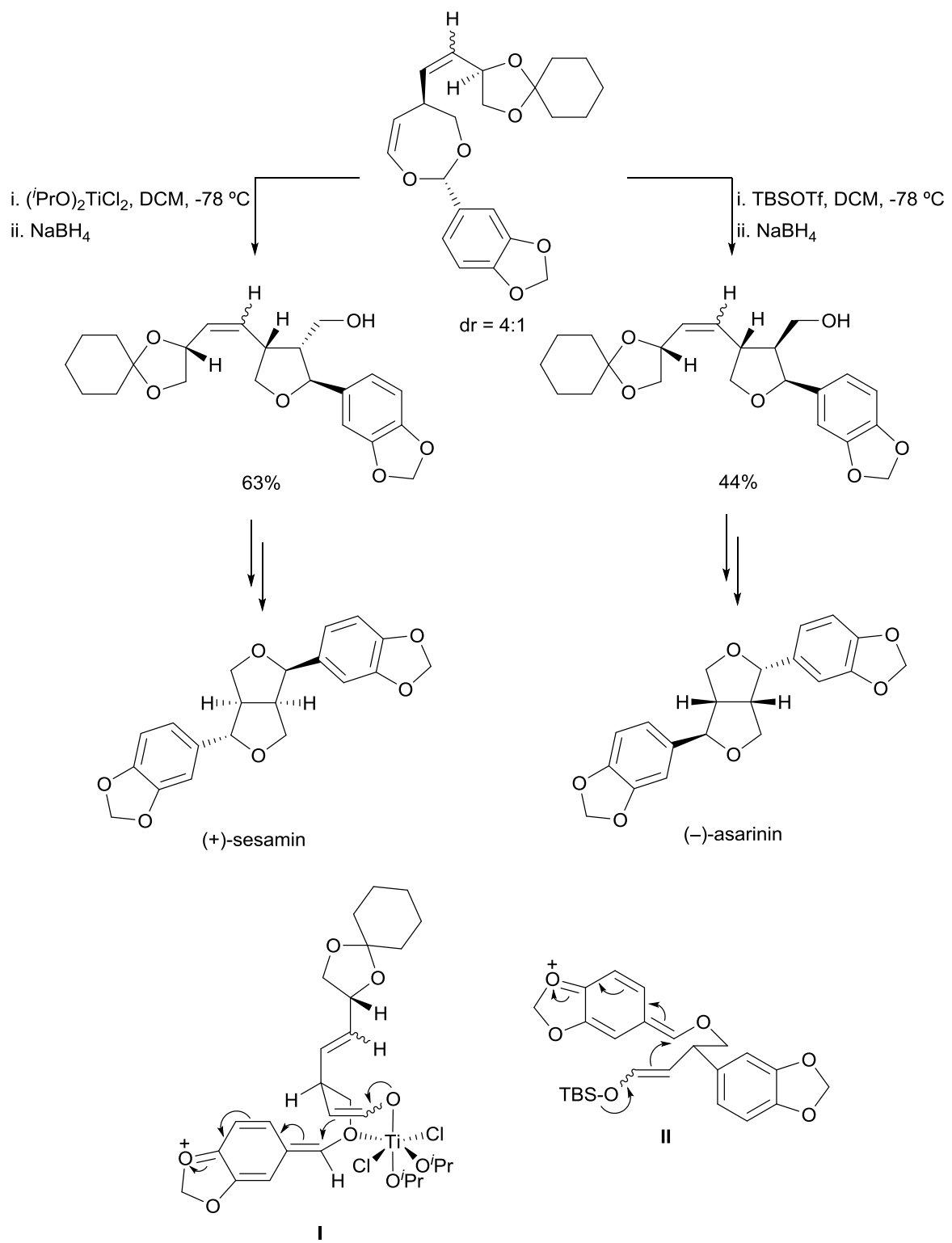

Scheme 31 Diastereodivergent routes to tetrahydrofurans precursors of natural lignans (+)sesamin and (-)-asarinin.

Annonaceous acetogenins are a class of natural products with oligotetrahydrofuran structure and potent biological activities such as cytotoxic, antitumor immunosuppressive, pesticidal, antifeedant and antimalarial effects. Tanaka and co-workers ${ }^{51}$ described diastereodivergent routes to tetrahydrofuran cores in acetogenins from a common syn-propargylic alcohol prepared from Dmannitol. Hydrogenation of this intermediate to a saturated triol and subsequent sulfonylation of the primary alcohol was followed by tetrahydrofuran ring formation via an epoxide, giving the trans-threo isomer (Scheme 32). On the other hand, the trans-erythro isomer was synthesized by hydrogenation followed by tosylation of the secondary alcohol, subsequent reductive deacetylation and final intramolecular $S_{N} 2$ reaction. Starting from the anti-propargylic alcohol cis-erythro and cis-threo-isomers were prepared following the same described diastereodivergent protocols. 


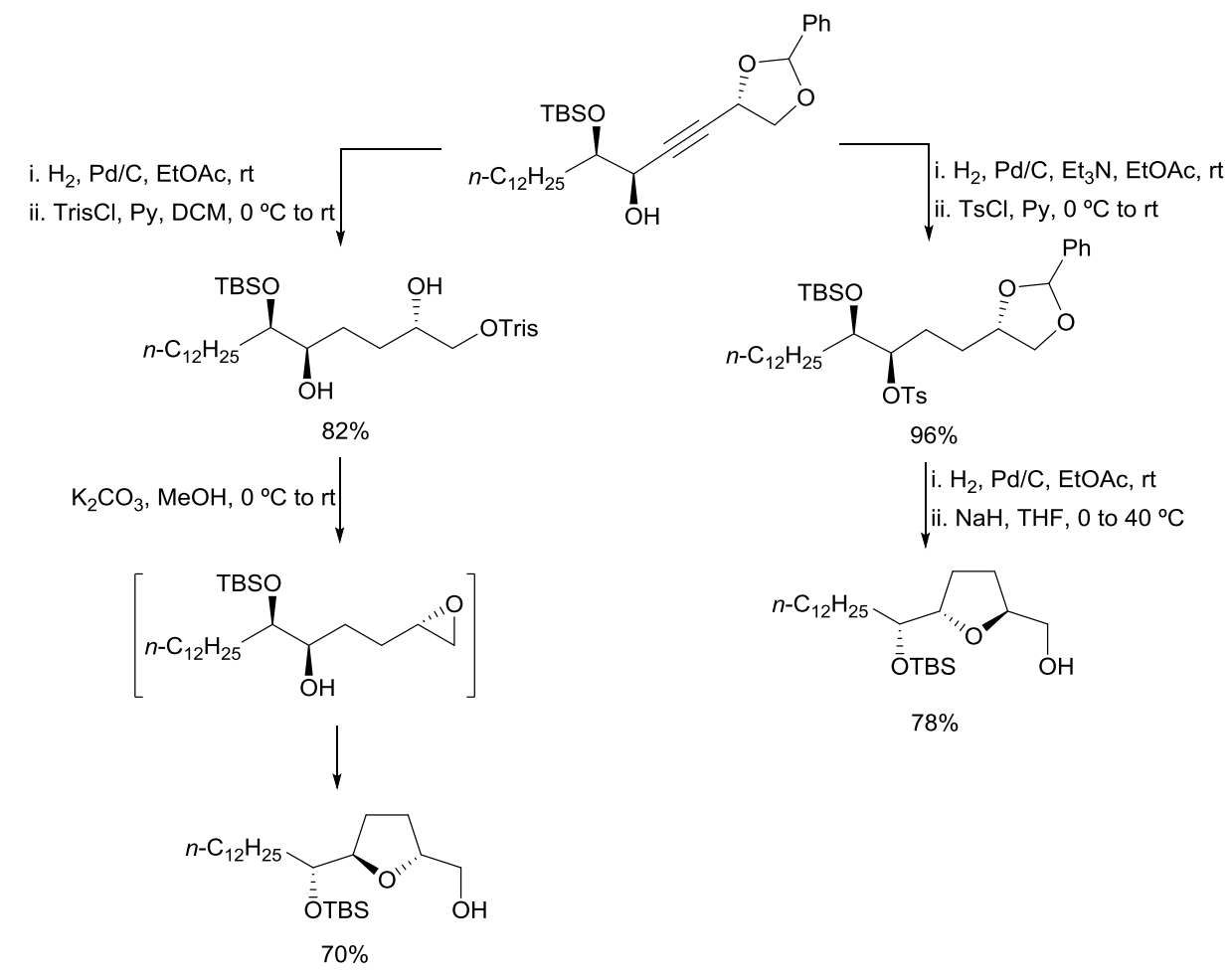

Scheme 32 Diastereodivergent routes to trans-threo- and trans-erythro-tetrahydrofuran cores in acetogenins.

Similar reiterative methodology has been reported by the same group for the diastereodivergent synthesis of bis-tetrahydrofuran cores of acetogenins. ${ }^{52}$ Starting from a tetrahydrofuran-containing threo-propargylic alcohol as common intermediate, the trans-threo-trans-threo- and trans-erythro-trans-threo-bistetrahydrofurans were obtained (Scheme 33). On the other hand, in a similar manner, starting from the erythro-propargylic alcohol cis-erythro-rans-threo-and cis-threo-trans-threo-bis-tetrahydrofurans were also prepared diastereodivergently in 57 and $70 \%$ yield, respectively.

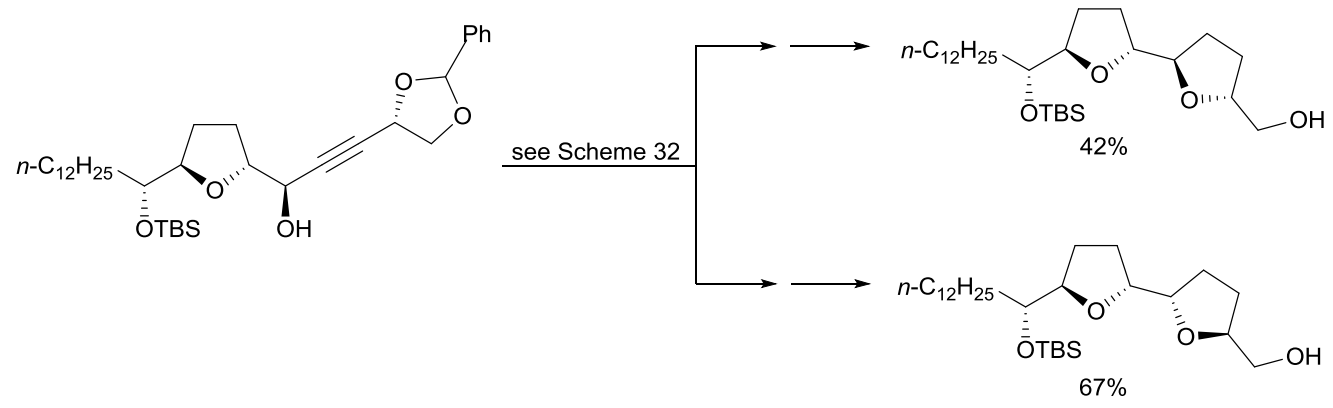

Scheme 33 Diastereodivergent routes to trans-threo-trans-threo- and trans-erythro-trans-threobis-tetrahydrofuran ring core in acetogenins. 
Both enantiomers of the natural product centrolobine have been found in different species. (-)- Centrolobine was isolated from the tree Centrolobium tormentosum, whereas its (+)-enantiomer occurs in Centrolobium robustum. Both enantiomers exhibit antibiotic and antifungal activity, which suggests that they play a role in the plants own pest control mechanism. Schmidt and Hölter ${ }^{53}$ reported enantio- and diastereodivergent synthesis of all stereoisomers of centrolobine starting from 3-(4-TBSO)phenylpropanal. Enantioselective allylation using Leighton's method ${ }^{54}$ gave both enantiomeric homoallylic alcohols, which were further transformed into TBS-protected tetrahydropyans. Deprotection of the $(3 S, 7 S)$-tetrahydropyran with $\mathrm{HCl}$ in $\mathrm{MeOH}$ induces epimerization and desilylation giving (+)-centrolobine, whereas using TBAF only desilylation occurred to provide (-)-epi-centrolobine (Scheme 34$)$. The same route was performed with $(3 R, 4 R)$-tetrahydropyran affording $(+)$-epi-centrolobine and $(-)$ centrolobine.

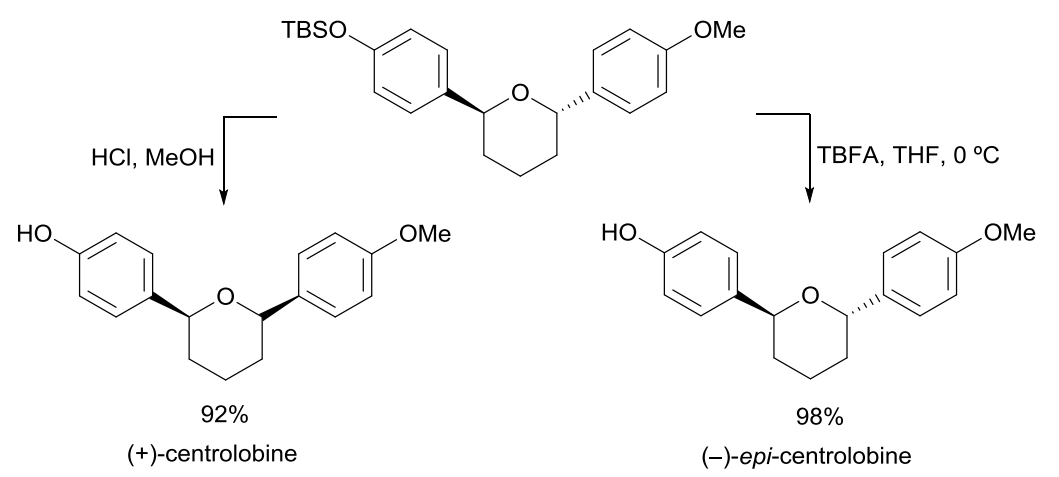

Scheme 34 Diastereodivergent routes to (+)-centrolobine and (-)-epi-centrolobine.

Enantiodivergent routes to both enantiomers of sulcatol from $(R)$ epichlorohydrin have been described by Takano and co-workers. ${ }^{55}$ Sulcatol is an aggregation pheromone of the insect Gnathotrichus sulcatus, which was prepared from the $(R)$-epoxide as common starting material. Reduction with $\mathrm{LiAlH}_{4}$ gave (S)-sulcatol in $75 \%$ overall yield from $(R)$-epichlorohydrin (Scheme $35)$. On the other hand, dissolving metal reduction provided $(R)$-sulcatol in $30 \%$ overall yield.

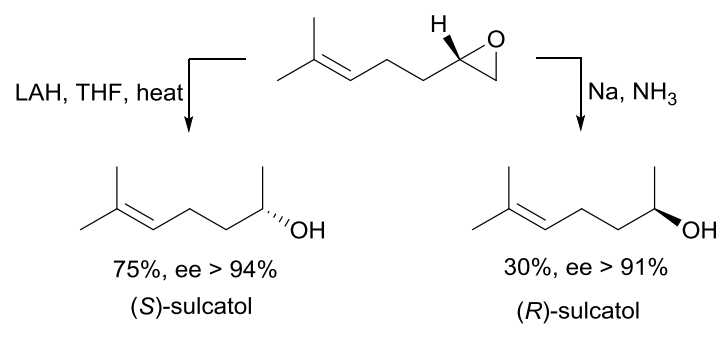

Scheme 35 Enantiodivergent routes to $(S)$ - and $(R)$-sulcatol. 
Huffman and co-workers ${ }^{56}$ described enantiodivergent routes to the synthetic cannabinoid nabilone -used clinically as antiemetic in cancer chemotherapy- from an enone as common intermediate, prepared from (+)apoverbenone. Dissolving metal reduction of the starting enone gave a saturated ketone, that after ether cleavage with sodium thiopropoxide and treatment with $\mathrm{SnCl}_{4}$ gave the rearranged ketone (Scheme 36). Isomerization using $\mathrm{AlCl}_{3}$ and other ether cleavage gave (-)-nabilone. On the other hand, demethylation of the starting enone and rearrangement using $\mathrm{AlCl}_{3}$ gave an enone, which was reduced with $\mathrm{Li} / \mathrm{NH}_{3}$ and finally demethylated to yield (+)-nabilone.

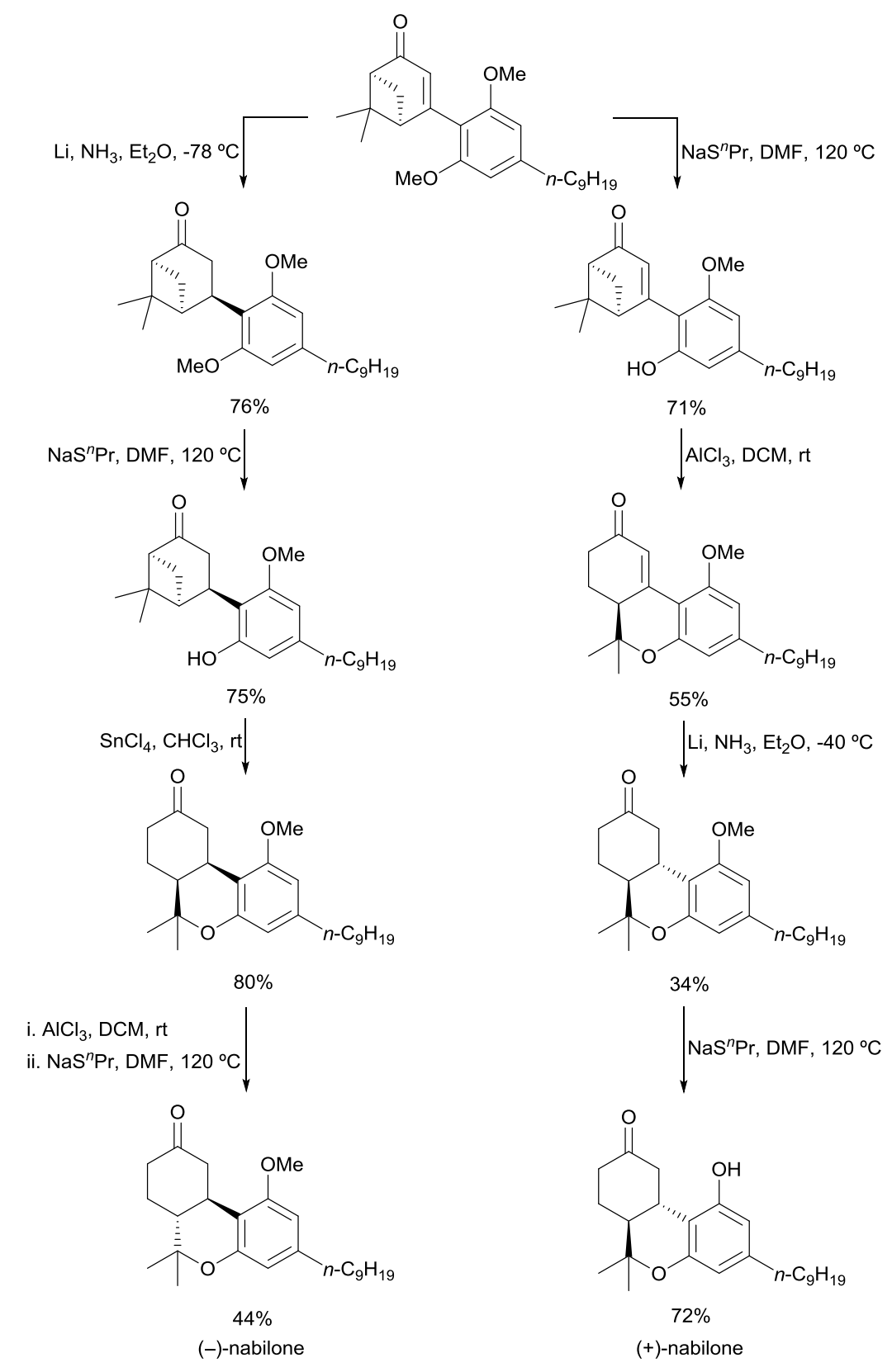

Scheme 36 Enantiodivergent routes to (-)- and (+)-nabilones. 
Methyl jasmonate is a natural fragrance which has been prepared by Montforts and co-workers ${ }^{57}$ following enantiodivergent routes. Pd-Catalyzed alkylation of hydroxycyclopent-2-enyl acetate, obtained by enzymatic hydrolysis of the diacetate, with dimethyl sodiomalonate gave the corresponding cisderivative with retention of the configuration (Scheme 37). This intermediate was further transformed into (-)-methyl jasmonate. Starting from the same monoacetate by protection of the alcohol as ethyl carbonate, followed by Pdcatalyzed alkylation with dimethyl sodiomalonate, provided after hydrolysis the enantiomeric cis-derivative, which was further transformed into (+)-methyl jasmonate.

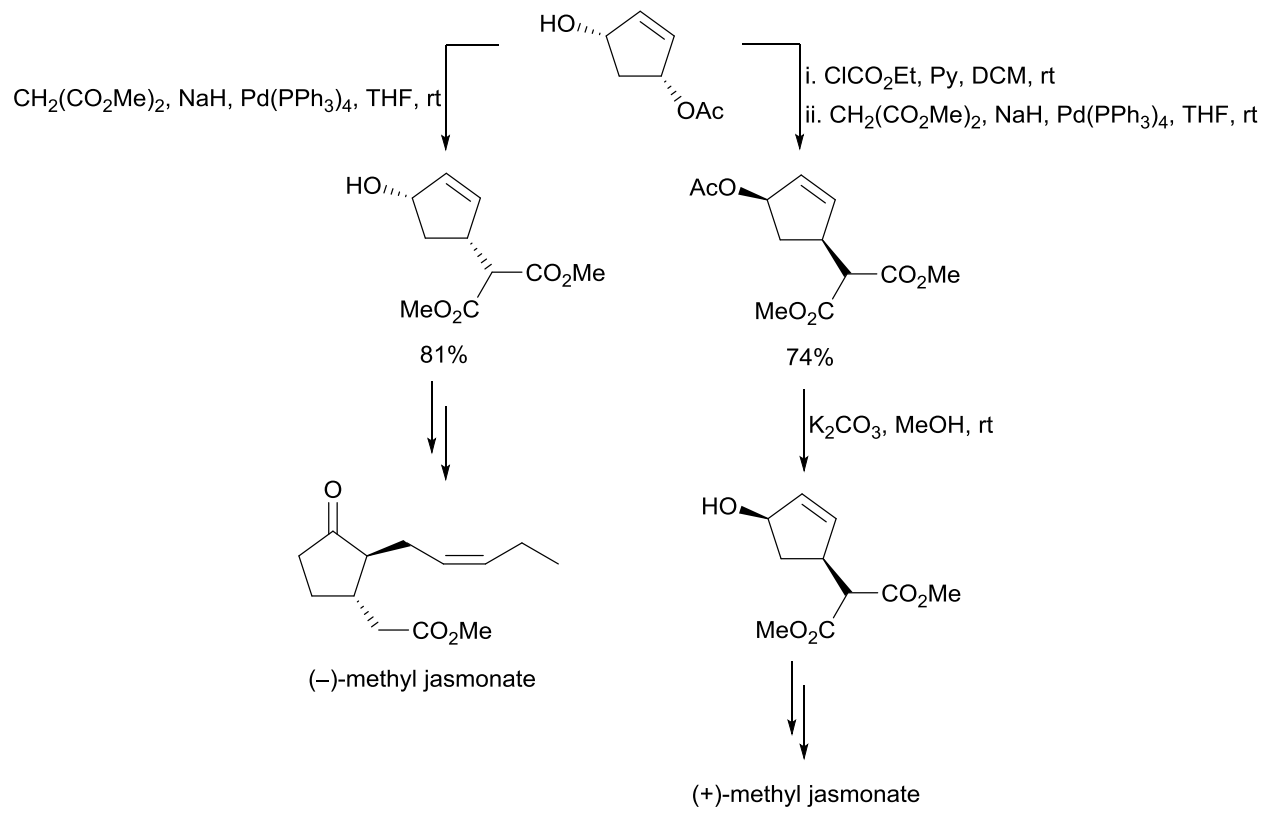

Scheme 37 Enantiodivergent routes to (-)- and (+)-methyl jasmonates.

Enantiodivergent routes to both enantiomers of $A B C D E$ rings of an analogue of antitumor antibiotic fredericamycin $\mathrm{A}$ have been reported by Kita and co-workers. ${ }^{58}$ As common starting material monoprotected $(R)$-diol, prepared by lipase-catalyzed desymmetrization of the diol, was used. By silylation of the hydroxy group, followed by saponification, the monosilyl ether was obtained (Scheme 38). After Dess-Martin periodinane (DMP) oxidation and then with $\mathrm{NaClO}_{2}$, the corresponding carboxylic acid was obtained, which was desilylated and treated with MeLi to give a methyl ketone. Final DMP oxidation gave a $(R)$ aldehyde which was further transformed into the $(R)$-unnatural analogue of $A B C D E$ rings of fredericamycin $A$. The other $(S)$-enantiomer was obtained by oxidation of the primary alcohol under DMP conditions and then $\mathrm{NaClO}_{2}$, followed by addition of MeLi and final DMP to yield the $(S)$-aldehyde precursor of the natural $A B C D E$ rings analogue of fredericamycin $A$. 


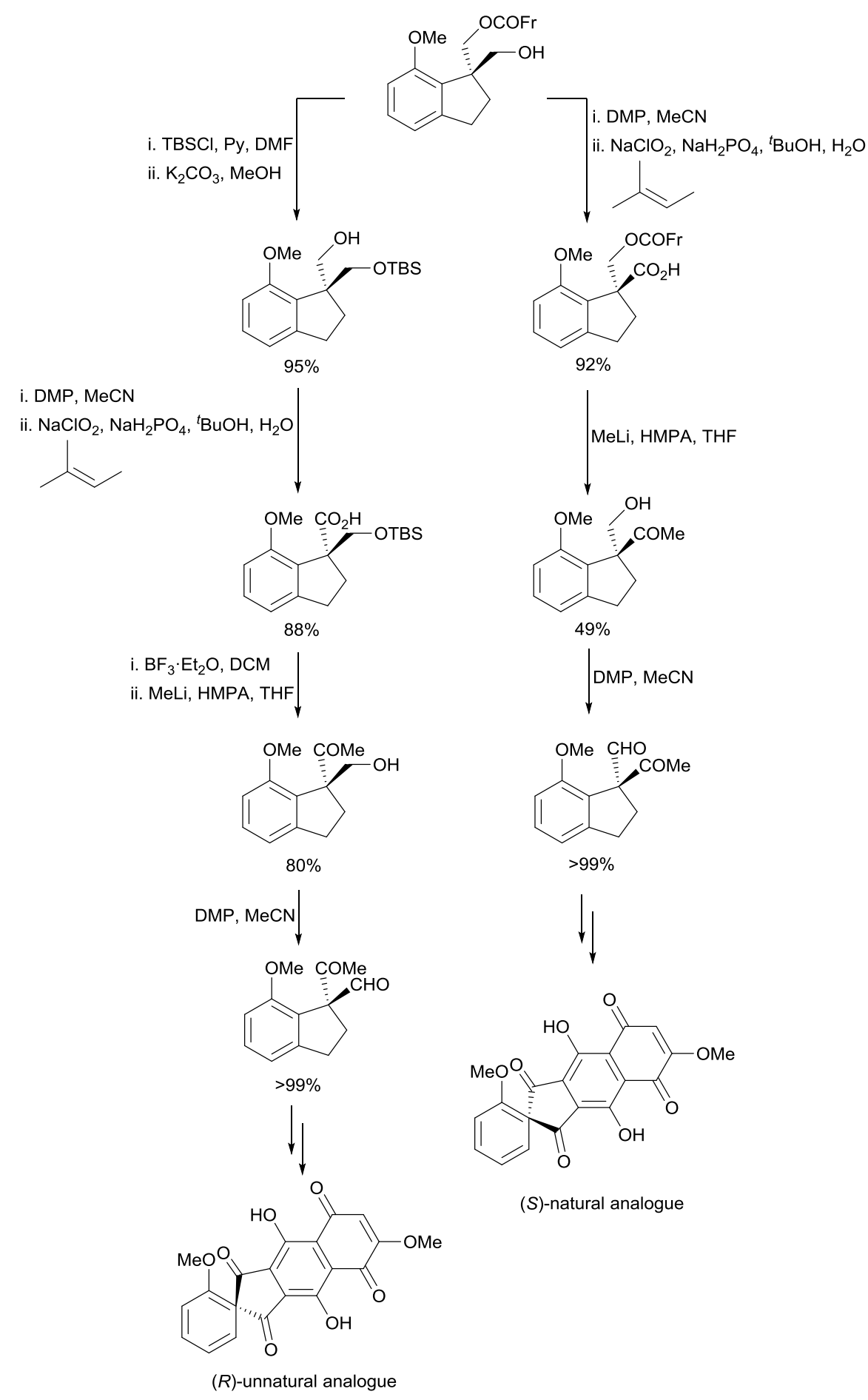

Scheme 38 Enantiodivergent routes to precursors of $(R)$ - and $(S)$-ABCDE rings analogues of fredericamycin A.

Ambroxol is an active metabolite of bromhexine, both being used clinically for various respiratory problems. Diastereodivergent routes to cis- and transambroxol have been reported by Bäckvall and co-workers ${ }^{59}$ using cis-1-acetoxy4-chlorocyclohex-2-ene ${ }^{60}$ as common intermediate. The Pd-catalyzed amination with 2-amino-3,5-dibromobenzylamine gave the cis-isomer after hydrolysis and 
hydrogenation of the double bond (Scheme 39). The corresponding noncatalyzed substitution provided the trans-isomer.

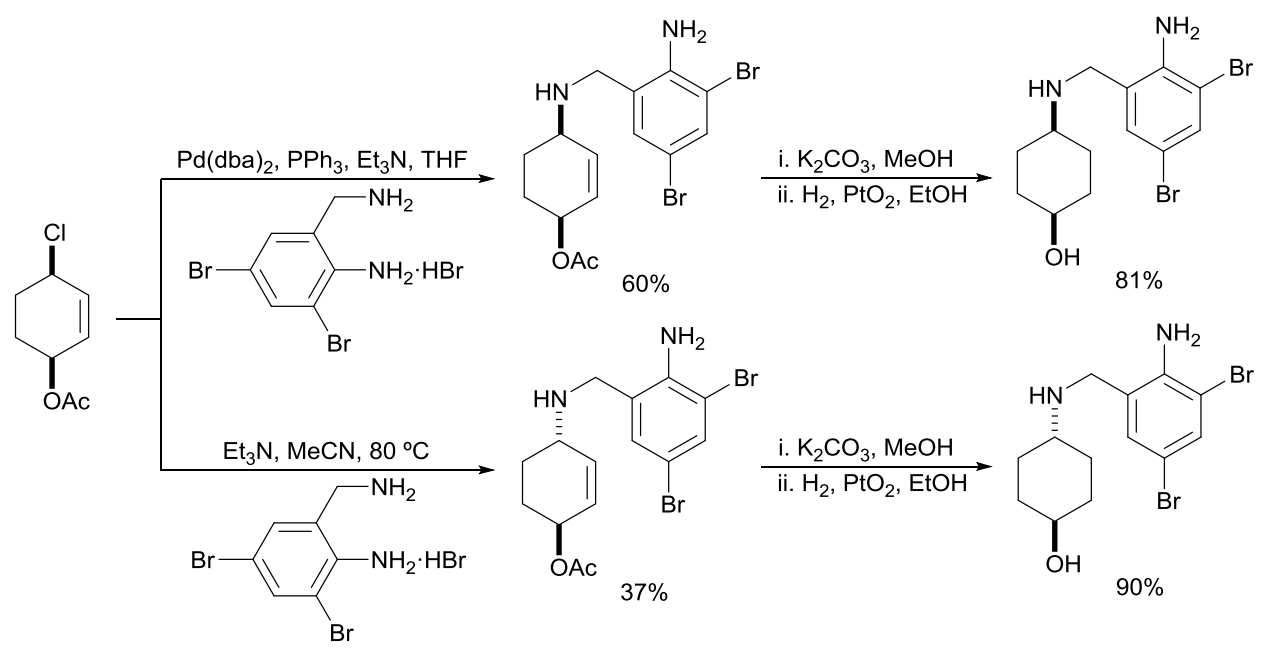

Scheme 39 Diastereodivergent routes to cis- and trans-ambroxol.

Andrés and Pedrosa ${ }^{61}$ reported diastereodivergent routes to syn- and anti$\mathrm{N}, \mathrm{N}$-dibenzyl sphingosines from (S)-N,N-dibenzyl-OTBS-serinal.62 By synaddition of pentadec-1-enyl ethyl zinc to this serinal followed by desilylation, debenzylated syn-(2S,3S,4E)-sphingosine was obtained in $44 \%$ overall yield (Scheme 40). For the preparation of the debenzylated anti-(2S,3R,4E)sphingosine, the serinal was treated with pentadecynylmagnesium bromide followed by reduction of the triple bond with $\mathrm{LiAlH}_{4}$.

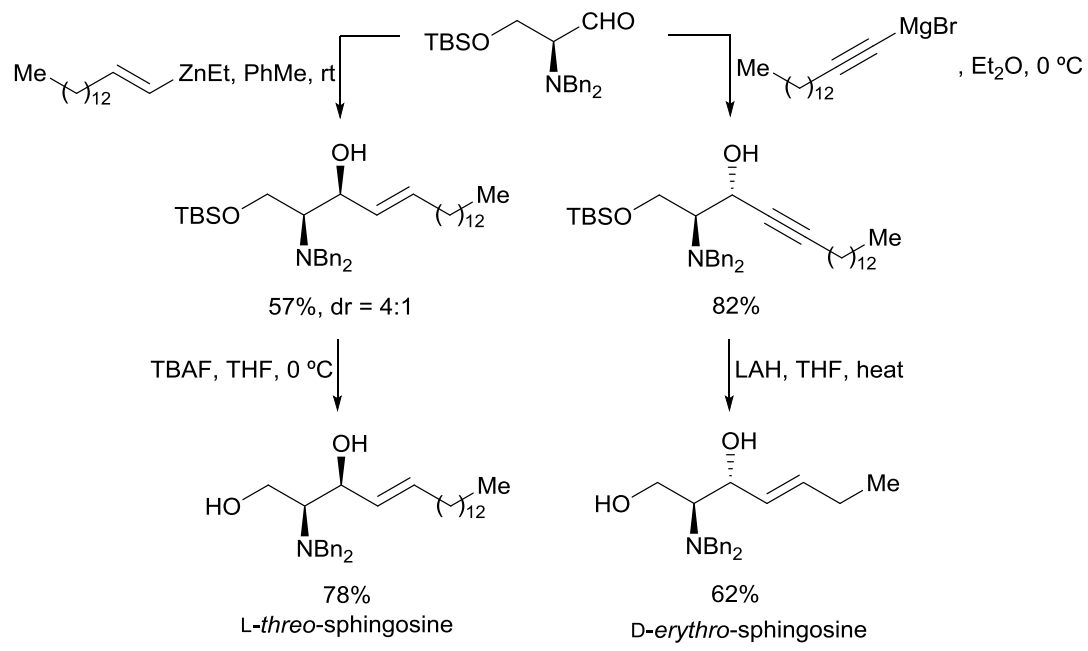

Scheme 40 Diastereodivergent routes to $\mathrm{N}, \mathrm{N}$-dibenzyl syn-and anti-sphingosines.

Diastereodivergent routes to syn- and anti-sphingosines from a $\beta$-keto sulfoxide as common intermediate have been reported by the Khiar and Martín- 
Lomas group ${ }^{63}$ starting from L-serine. Reduction with DIBALH at $-78{ }^{\circ} \mathrm{C}$ gave the (S)- $\beta$-hydroxysulfoxide precursor of anti-sphingosine (Scheme 41). However, the same reduction performed in the presence of $\mathrm{ZnCl}_{2}$ gave the corresponding epimer, which was further elaborated to give syn-sphingosine.

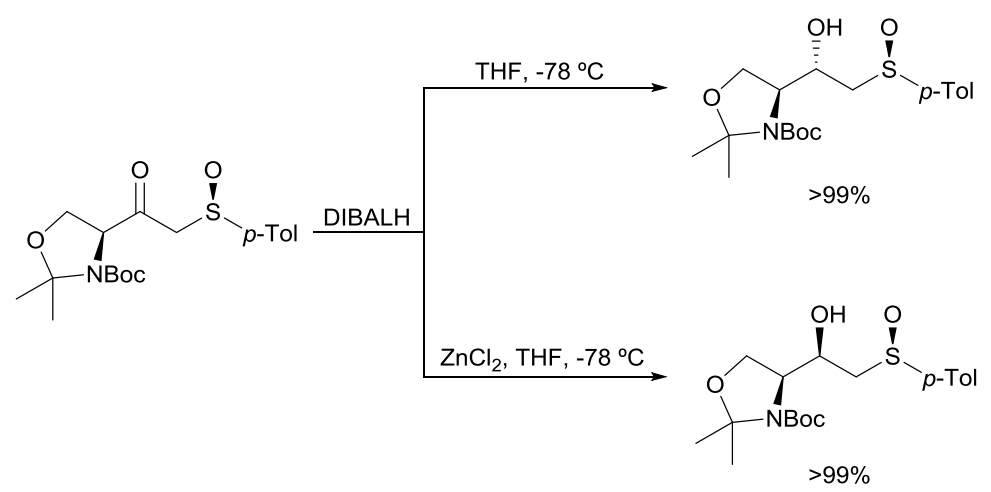

Scheme 41 Diastereodivergent routes to precursors of anti- and syn-sphingosines.

Another diastereodivergent approach to D-erythro- and L-threosphingosines is based on the ring-opening of a vinylaziridine as common starting material, and has been published by Olofsson and Somfai. ${ }^{64}$ Direct opening of the aziridine took place using TFA giving the O-benzyl D-erythro-sphingosine (Scheme 42). For the threo-diastereomer the aziridine was $\mathrm{N}$-acetylated and opened by treatment with $\mathrm{BF}_{3} \cdot \mathrm{Et}_{2} \mathrm{O}$ followed by deacetylation.

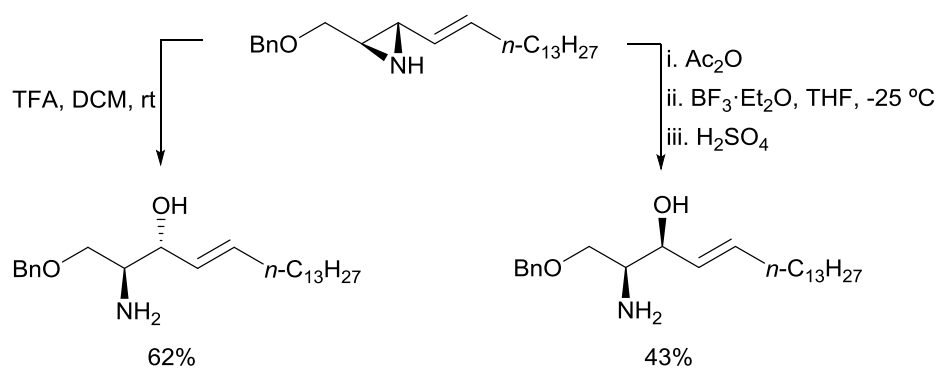

Scheme 42 Diastereodivergent routes to O-benzyl D-erythro- and L-threo-sphingosines.

Isoprostanoids and prostaglandins are naturally occurring metabolites derived from an oxidation of polyunsaturated fatty accids. ${ }^{65}$ In Nature, the oxidation of arachidonic acid by cyclooxygenase and non-enzymatic free radical peroxidation leads to prostaglandins and isoprostanes, respectively. As a consequence of these two different pathways, the relative stereochemistry of the two side chains, trans and cis, are characteristic features of these two types of compounds. Schrader and Snapper described diastereodivergent routes to all $15-\mathrm{F}_{2}$ isoprostanes. ${ }^{66}$ Starting from an enantioenriched enone ( $85 \%$ ee), asymmetric reduction with (S)-2-methyl-CBS-oxazaborolidine produced mainly 
the $(15 R)$-allylic alcohol, which was submitted to hydroboration with 9-BBN followed by oxidation giving the corresponding enantiomerically pure diol (Scheme 43). On the other hand, using ( $R$ )-2-methyl-CBS-oxazaborolidine, and then hydroboration-oxidation the (15S)-diol was obtained. A similar strategy was used for the synthesis of their respective enantiomers. These four diols were further transformed into $15-F_{2 t}$ and $15-F_{2 c}$ isoprostanes.

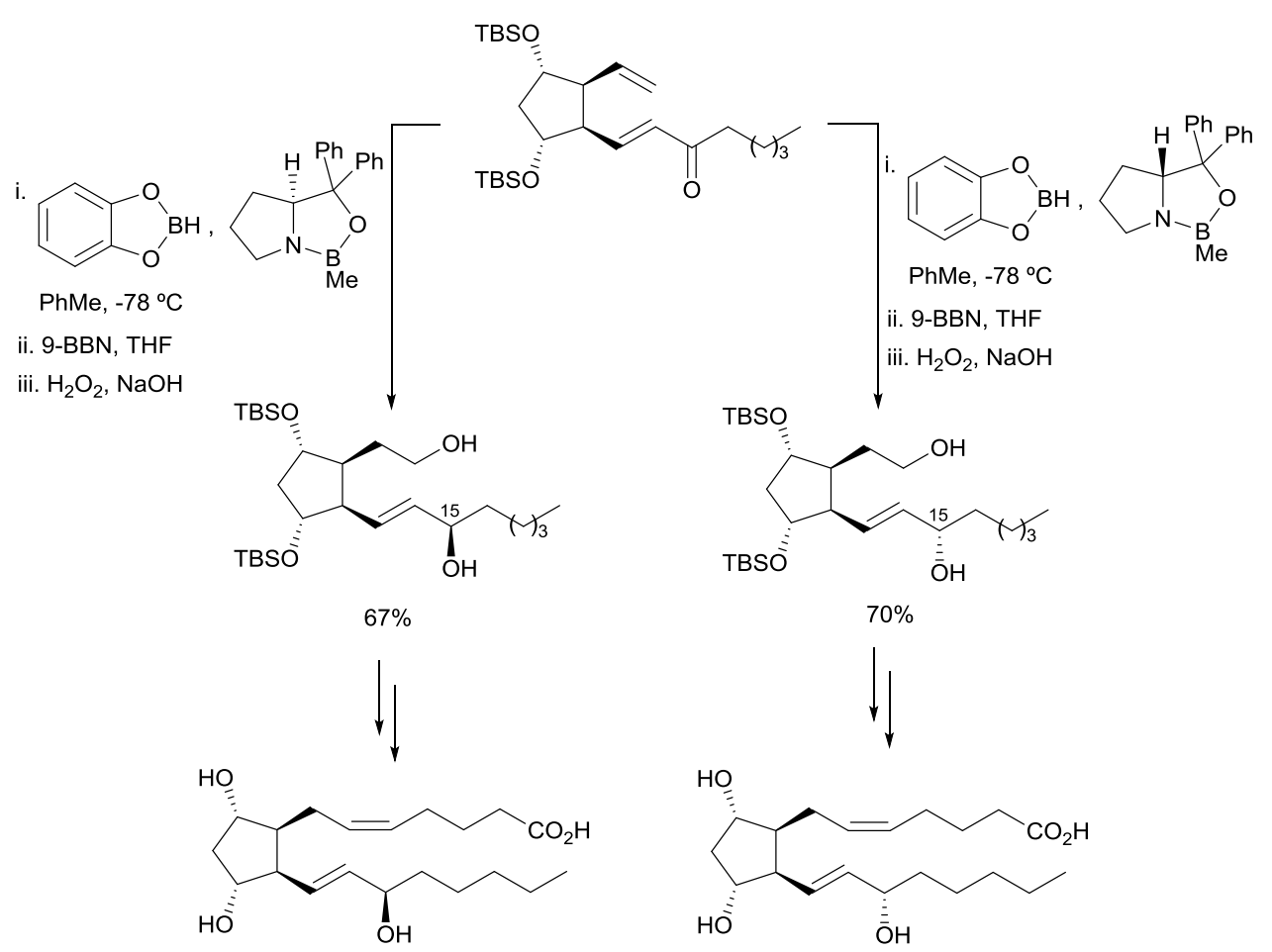

Scheme 43 Diastereodivergent routes to diols precursors of $15-F_{2 t}$ and $15-F_{2 c}$ isoprostanes.

Isofurans are produced by human metabolism of arachidonic acid. ${ }^{65}$ Taber and co-workers ${ }^{67}$ reported diastereodivergent routes to $\Delta^{13}$-9-isofurans starting from 4-bromocrotonoate, which was transformed into a dienic diol precursor of diastereomeric epoxides by Katsuki-Sharpless asymmetric epoxidation. The common advanced tetrahydrofuran was transformed into a silylated intermediate precursor of one SC- $\Delta^{13}-9-$ IsoF (Scheme 44). Inversion of the C-8 configuration of the same alcohol was carried out by an oxidation-reduction protocol, whereas under Mitsunobu conditions predominant dehydration was observed. This late diastereomer was further transformed into the other SC- $\Delta^{13}-9-$ IsoF. 


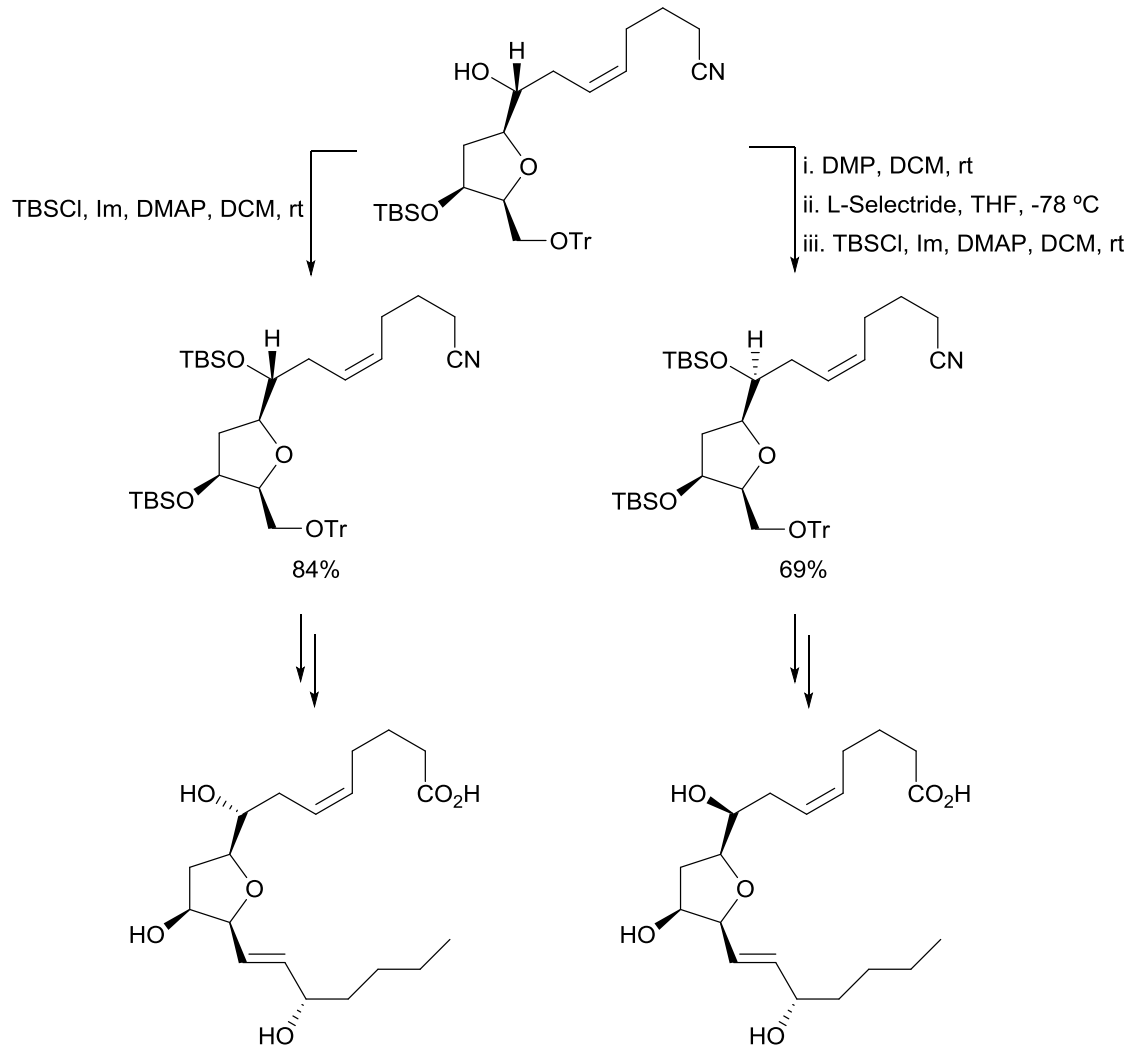

Scheme 44 Diastereodivergent routes to precursors of $\Delta^{13}$-9-isofurans.

Anachelins, siderophores isolated from the freshwater cyanobacterium Anabaena cylindrica, serve as bacterial growth factor facilitating iron uptake. ${ }^{68}$ The total synthesis of anachelin $\mathrm{H}$ was reported by Gademann and Bethuel ${ }^{69}$ starting from L-serine. In order to determine the configuration of four stereogenic centers, diastereodivergent routes of polyketide fragments were carried out. For instance, a hydroxy ketone was used as common starting material, which was reduced to the 3,5-anti-diastereomer using $\mathrm{Me}_{4} \mathrm{NBH}(\mathrm{OAc})_{3}$ followed by TBSprotection (Scheme 45). The 3,5-syn reduction was performed with $\mathrm{NaBH}_{4}$ after precomplexation of the hydroxy ketone with $\mathrm{Et}_{2} \mathrm{BOMe}$. This last polyketide fragment is the precursor of the alkaloid peptide anachelin $\mathrm{H}$. 


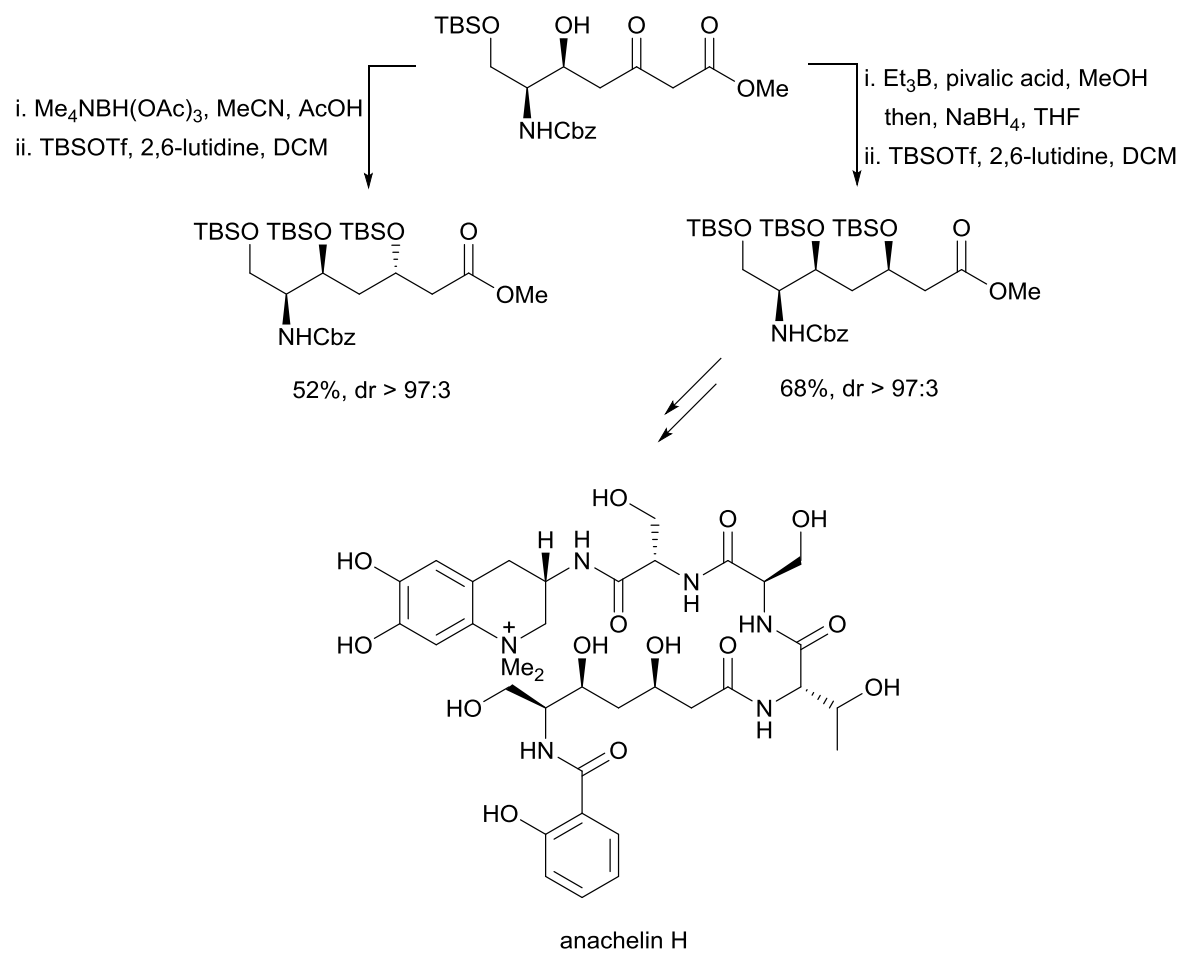

Scheme 45 Diastereodivergent routes to polyketide fragments.

Alkylated 6,8-dioxabicyclo[3.2.1]octane structural units are widespread in bioactive natural products, namely in brevicomin and frontalin. Prasad and Anbarasan have reported enantiodivergent routes to hydroxy exo-brevicomin from L-(+)-tartaric acid. ${ }^{70}$ These pheromones play a crucial role in the communication system of Dendroctonus ponderosae beetle species. ${ }^{71}$ A bisWeinreb amide derived from (+)-tartaric acid was used as common starting material. The synthesis of the (+)-enantiomer was performed by addition of 4pentenylmagnesium bromide, and the resulting keto group was reduced with LSelectride yielding a single diastereomeric alcohol, which was protected as its silyl ether (Scheme 46). Subsequent reduction of the other Weinreb amide unit with $\mathrm{NaBH}_{4}$ and tosylation provided the corresponding tosylate which was reduced with Super hydride. Final Wacker oxidation produced the mentioned (+)hydroxy-exo-brevicomin via a trihydroxy ketone. The corresponding (-)enantiomer was obtained by addition of methylmagnesium bromide to the bisWeinreb amide followed by successive treatment with L-Selectride, TBSOTf, $\mathrm{NaBH}_{4}$ and $\mathrm{TsCl}$, as before. The resulting tosylate was transformed into the corresponding iodide, which by $n$-Bus $\mathrm{SnH} / \mathrm{AIBN}$ mediated radical addition to the methyl vinyl ketone produced a ketone. Simultaneous deprotection of the silyl group and the acetonide followed by cyclization took place in the presence of $\mathrm{FeCl}_{3}$ affording (-)-hydroxy-exo-brevicomin. 


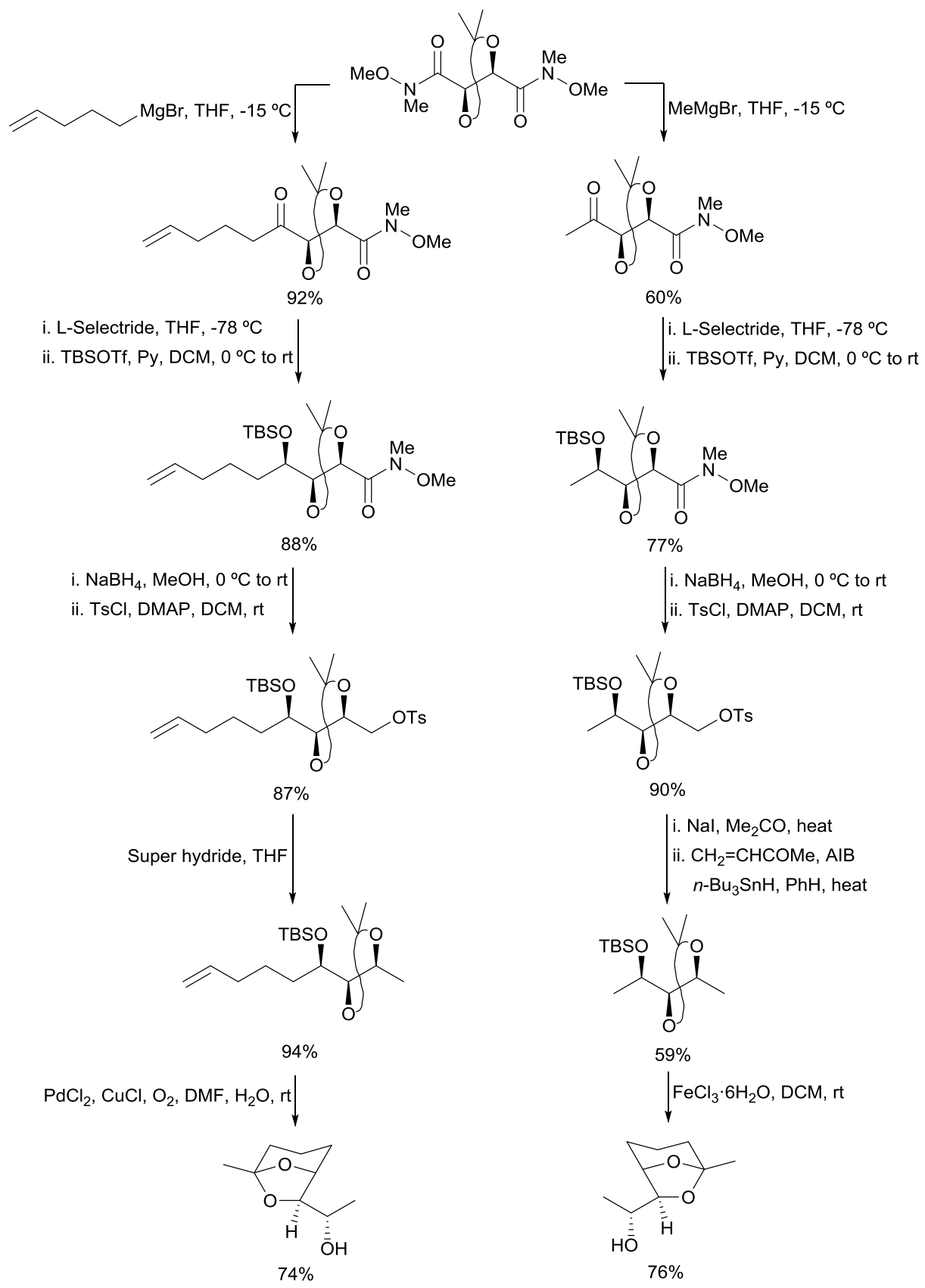

Scheme 46 Enantiodivergent routes to (+)- and (-)-hydroxy-exo-brevicomins.

After isolation of (-)-gummiferol from the leaves of Adenia gummifera by Wall and co-workers, ${ }^{72}$ cytotoxicity studies revealed that this molecule exhibited strong activity against P388 murine leukemia and U373 human glioma cell lines. Kadota and co-workers ${ }^{73}$ reported diastereodivergent routes to two possible isomers of (-)-gummiferol in order to elucidate unambiguously its structure and for evaluation of the structure-cytotoxic activity relationship. The common intermediate, an allylic alcohol monoepoxide, was submitted to a second epoxidation under Katsuki-Sharpless conditions with (+)-DIPT to provide the syndiepoxide, which was the precursor of the natural product (Scheme 47). On the other hand, by Katsuki-Sharpless epoxidation with (-)-DIPT the other 
diastereomer was isolated. The absolute configuration of the diepoxide unit has little influence on the cytotoxicity, the triacetylene unit being the crucial structural element required for the cytotoxic activity.

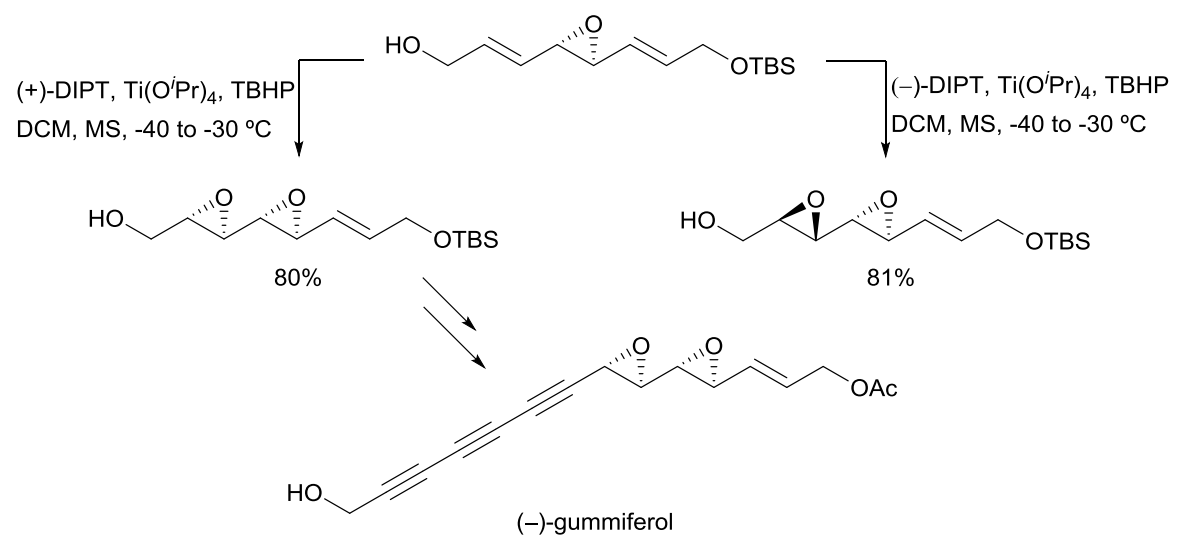

Scheme 47 Diastereodivergent routes to precursor diepoxides of (-)-gummiferol.

Yan and coworkers ${ }^{74}$ have described enantiodivergent routes to (+)- and (-)-shikimic acids, (+)- and (-)-4-epi-shikimic acids and (+)- and (-)-pinitols starting from L-tartaric acid. In Scheme 48 the enantiodivergent strategies to both enantiomers of shikimic acid from a common vinyl epoxide has been depicted. Reduction with LAH and epoxidation of the resulting cyclohexenol with MCPBA afforded the desired epoxide, which was opened with LiCN at the less hindered face. The obtained trans-cyanohydrin was converted into a diacetate and subsequent treatment with DBU yielded an unsaturated nitrile. Final acetate saponification and acetal hydrolysis gave natural (+)-shikimic acid in $36 \%$ overall yield after seven steps (Scheme 48). Addition of sodium malononitrile to the starting epoxide via a $S_{N} 2$ process followed by transformation into a carboxylate ester with magnesium bis(monoperoxy phthalate) (MMPA) afforded an unsaturated ester, which was epoxidated with MCPBA. The resulting epoxide was reductively cleaved by treatment with $\mathrm{H}_{2} / \mathrm{Pd} / \mathrm{C}$. Acetylation followed by DBUpromoted elimination of $\mathrm{AcOH}$, TFA-mediated acetonide deprotection, and final ester hydrolysis provided (-)-shikimic acid in $29 \%$ overall yield. 


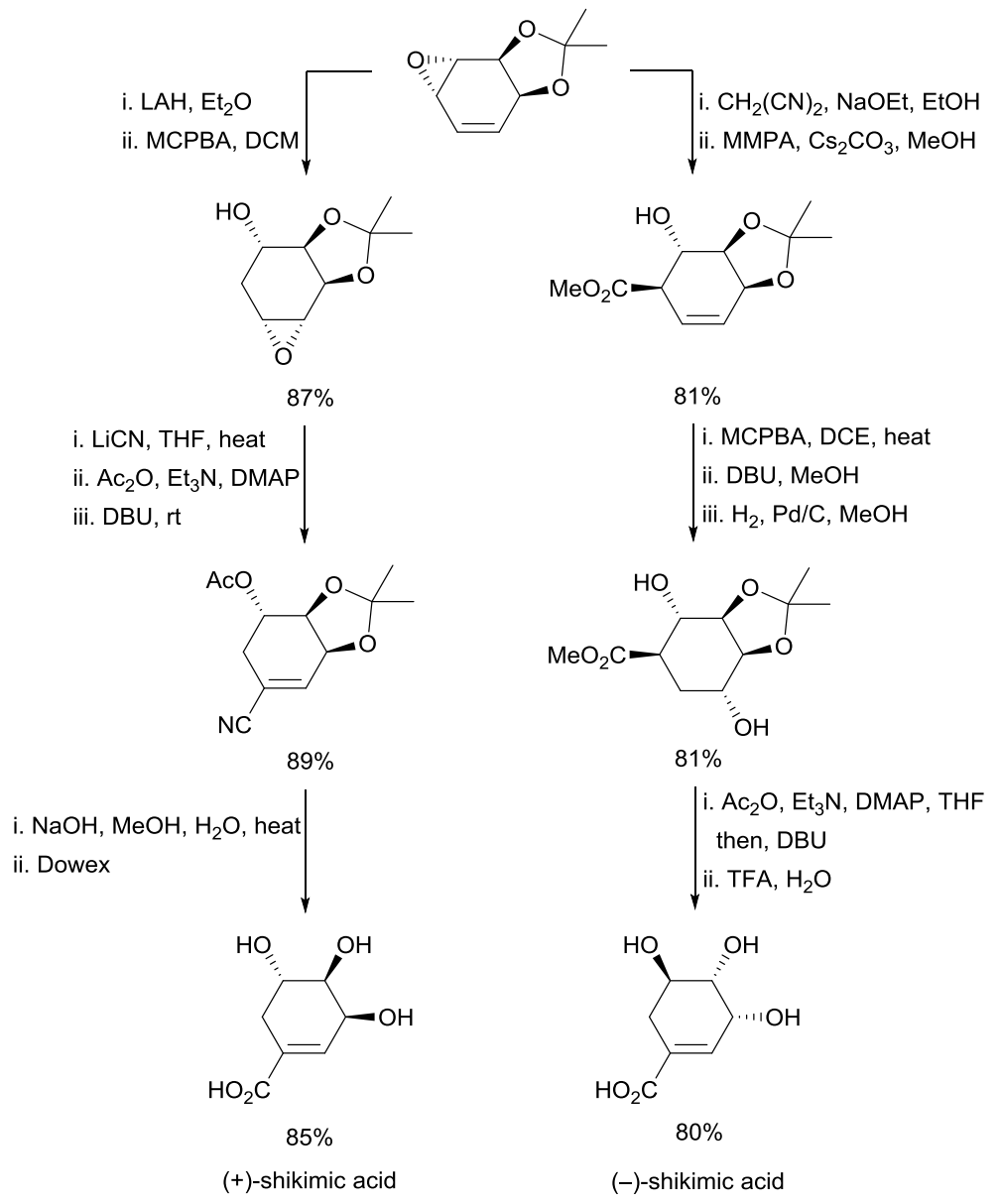

Scheme 48 Enantiodivergent routes to (+)- and (-)-shikimic acids.

The gypsy moth sex-attractant pheromone disparlure is produced by the female moth Porthetria dispar L., a widespread forest pest. ${ }^{75}$ Prasad and Anbarasan ${ }^{76}$ reported enantiodivergent routes to (-)- and (+)-disparlure starting from L-tartaric acid bis-Weinreb amide (Scheme 46). The common starting material was a monobenzylated diol, which was tosylated and then submitted to cross metathesis with 4-methyl-1-pentene. The resulting alkene was hydrogenated and, after treatment with $\mathrm{K}_{2} \mathrm{CO}_{3}$, furnished (-)-disparlure (Scheme 49). For the synthesis of its enantiomer, the starting monoprotected diol was silylated and then allowed to react with 4-methyl-1-pentene using also the Grubbs second generation catalyst. Hydrogenation, followed by tosylation of the resulting alcohol, produced the corresponding tosylate, which was transformed into (+)disparlure after final treatment with TBAF. 


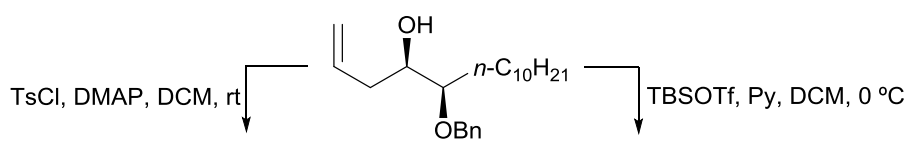

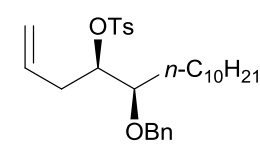

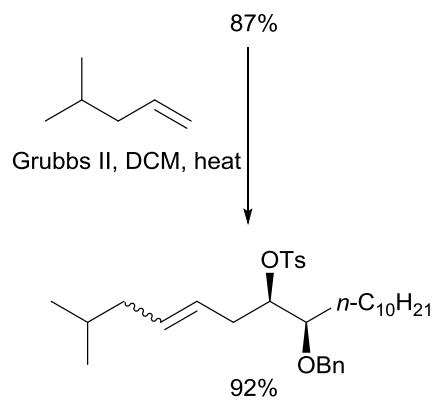

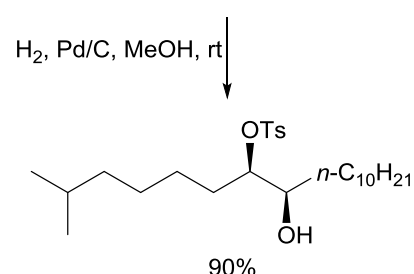<smiles>CC(C)(C)OCOCCI</smiles>
0",

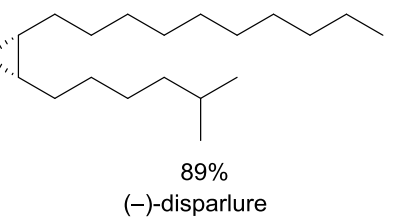

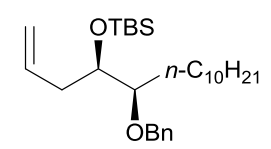

$98 \%$

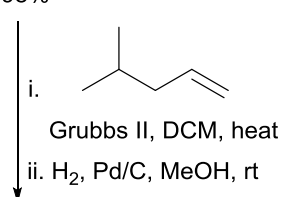

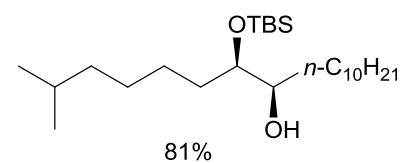

$81 \%$

TsCl, DMAP,DCM, rt<smiles>CCCCCC(O)C(O)CCCCC(C)C</smiles>

$90 \%$

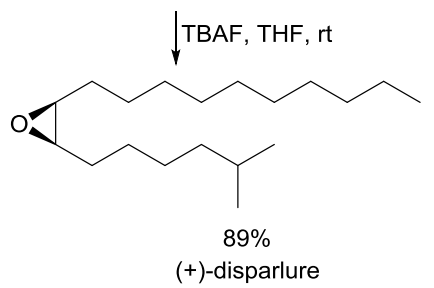

Scheme 49 Enantiodivergent routes to (-)- and (+)-disparlures.

Pandey and co-workers ${ }^{77}$ described recently diastereodivergent routes to cis-(+)- and trans-(+)-disparlure starting from a chiral epoxide obtained by organocatalytic MacMillan's self-aldol reaction of silylated a-hydroxy acetaldehyde. Epimerization of $\mathrm{C}-\mathrm{OH}$ of the starting epoxide under Mitsunobu conditions followed by silylation provided the corresponding protected derivative (Scheme 50). This epoxide was submitted to $\mathrm{Cu}(\mathrm{I})$-catalyzed regioselective ringopening with isohexylmagnesium bromide, and the resulting monosilylated diol was tosylated followed by desilylation to furnish cis-(+)-disparlure. On the other hand, the trans-isomer was prepared by silylation of the hydroxy group in the starting material followed by epoxide opening with the above mentioned Grignard reagent. Final tosylation and desilylation gave the trans-(+)-disparlure. 
i. PNBA, $\mathrm{PPh}_{3}$, DIAD, $\mathrm{PhMe}, 0^{\circ} \mathrm{C}$ to $\mathrm{rt}$

ii. $\mathrm{LiOH} \cdot \mathrm{H}_{2} \mathrm{O}, \mathrm{THF}, \mathrm{MeOH}$, rt

iii. TBSCI, Im, DMAP, DCM, $0^{\circ} \mathrm{C}$ to rt<smiles></smiles>

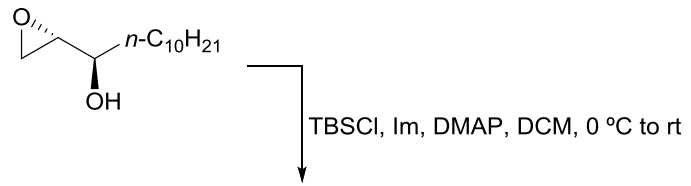<smiles>CCCCCCC(O[SbH2])C(CC1CO1)C1CO1</smiles>
OTBS $87 \%$

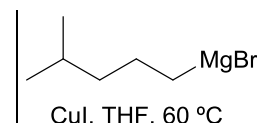
Cul, THF, $60^{\circ} \mathrm{C}$

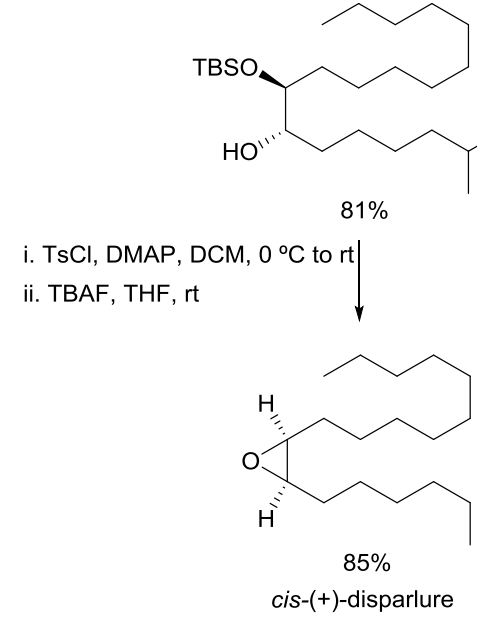<smiles>CCCCCCCCC(O)[C@H](O)CCCCCC(C)C</smiles>

i. TsCl, DMAP, DCM, $0^{\circ} \mathrm{C}$ to $\mathrm{rt}$ ii. TBAF, THF, rt

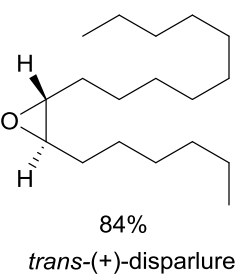

Scheme 50 Diastereodivergent routes to cis-(+)- and trans-(+)-disparlures.

\section{Heterocycles}

Oxygen-containing saturated heterocycles are important synthetic targets, not only as natural products, but also as biologically active compounds (see, Sections 2 and 4) and as building blocks. Chiral epoxides can be prepared using different asymmetric methods specially by asymmetric epoxidation of alkenes, as it has been described along this review article. Aminoalkyl epoxides are useful synthetic intermediates mainly for the preparation of dipeptide isosteres. Moyano and Pericás ${ }^{78}$ reported diastereodivergent routes to erythro- and threo-aminoalkyl epoxides starting from enantiomerically enriched anti- $N$-Boc-3-amino-1,2-diols. These crystalline diols were submitted to an intramolecular Mitsunobu reaction giving the erythro-epoxides (Scheme 51). On the other hand, by silylation of the primary alcohol, followed by mesylation of the secondary one, and final desilylation with TBAF, the corresponding threo-epoxides were isolated. 


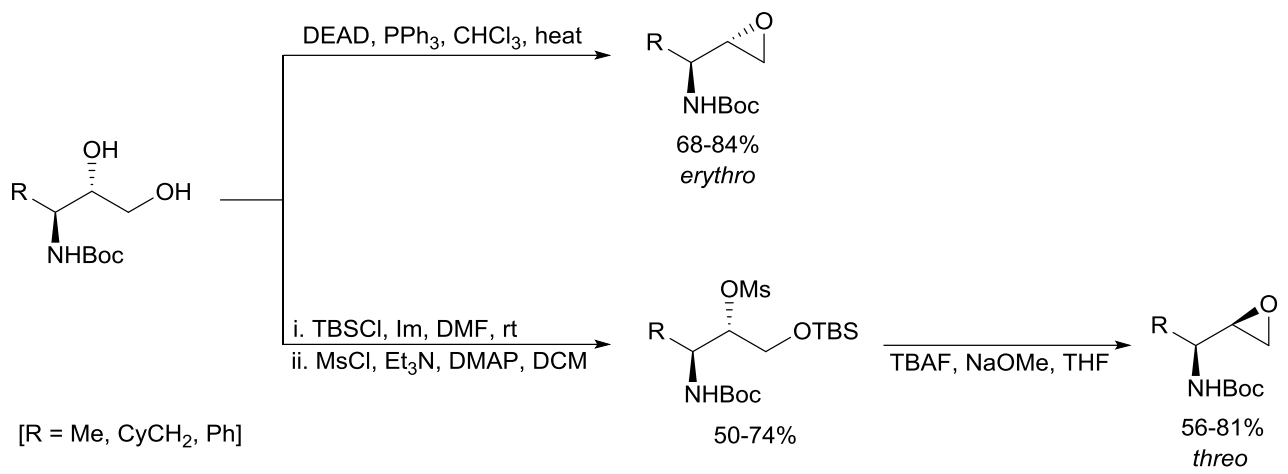

Scheme 51 Diastereodivergent routes to $\mathrm{N}$-Boc-aminoalkyl epoxides.

Enantiodivergent routes to theobroxide, a potato microtuber-inducing substrate isolated from Lasiodiplodia theobromae, have been described by Kamikubo and Ogasawa ${ }^{79}$ starting from a common tricyclic building block. This optically pure cycloadduct, prepared by lipase-mediated desymmetrization of the corresponding meso-diol, was silylated, and after sequential deacetylation and PDC oxidation of the resulting alcohol, provided the corresponding enone (Scheme 52). Chemoselective epoxidation occurred stereoselectively from the convex face giving exclusively the exo-epoxide, which was methylated under basic conditions. After retro-Diels-Alder removal of cyclopentadiene, the resulting enone was reduced with $\mathrm{NaBH}_{4} / \mathrm{CeCl}_{3}$, and after final desilylation and purification by column chromatography, (+)-theobroxide was isolated. For the preparation of the natural (-)-theobroxide, the same tricyclic allylic alcohol was acetylated with pivalic anhydride followed by methanolysis and silylation giving the corresponding protected hydroxy pivalate. Removal of the pivaloyl group with an excess of MeLi afforded a monosilylated diol. Following the same reaction sequence as above, the (-)-natural product was obtained. 


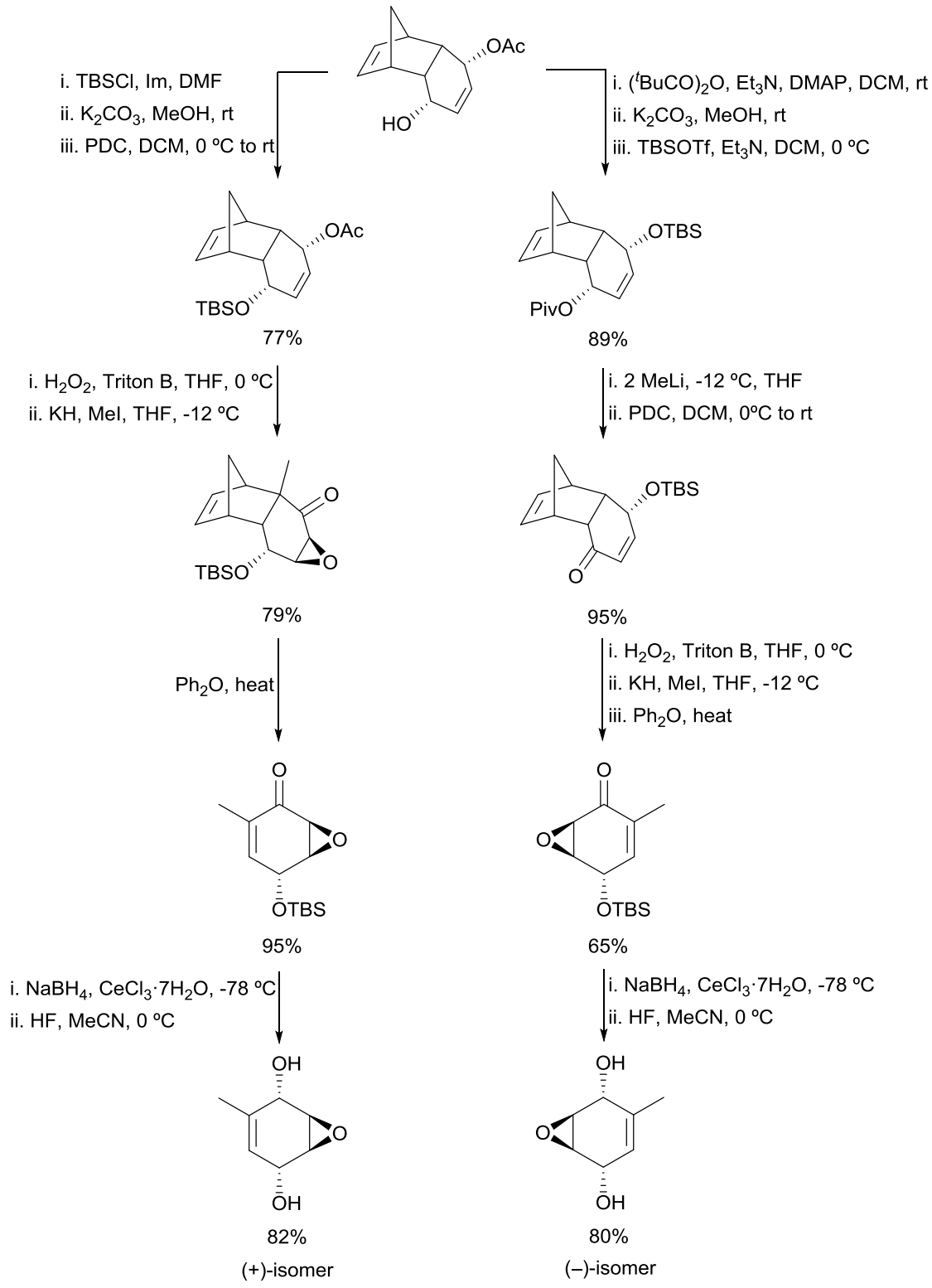

Scheme 52 Enantiodivergent routes to (+)- and (-)-theobroxides. (El primer producto de reacción por el lado de la izda creo qye debe llevar el carbonilo en vez del Acetato)

The natural epoxy enone, bromoxone, has been prepared by Shapiro and co-workers ${ }^{80}$ using enantiodivergent routes starting from a ciscyclohexadienediol, obtained by microbial oxidation of bromobenzene with Pseudomonas putida F39/D. The common epoxide intermediate was debrominated and, after silylation-deacylation, the resulting alcohol was oxidized to an epoxy enone (Scheme 53). Subsequent desilylation and acylation under Mitsunobu conditions provided the corresponding 4-nitrobenzoyl ester, which was $\alpha$-brominated and finally saponified to give the natural (+)-bromoxone. The enantiodivergent route started by diacylation of the starting epoxide to a diol, which was transformed into (-)-bromoxone by Bandell and co-workers. ${ }^{81}$ 


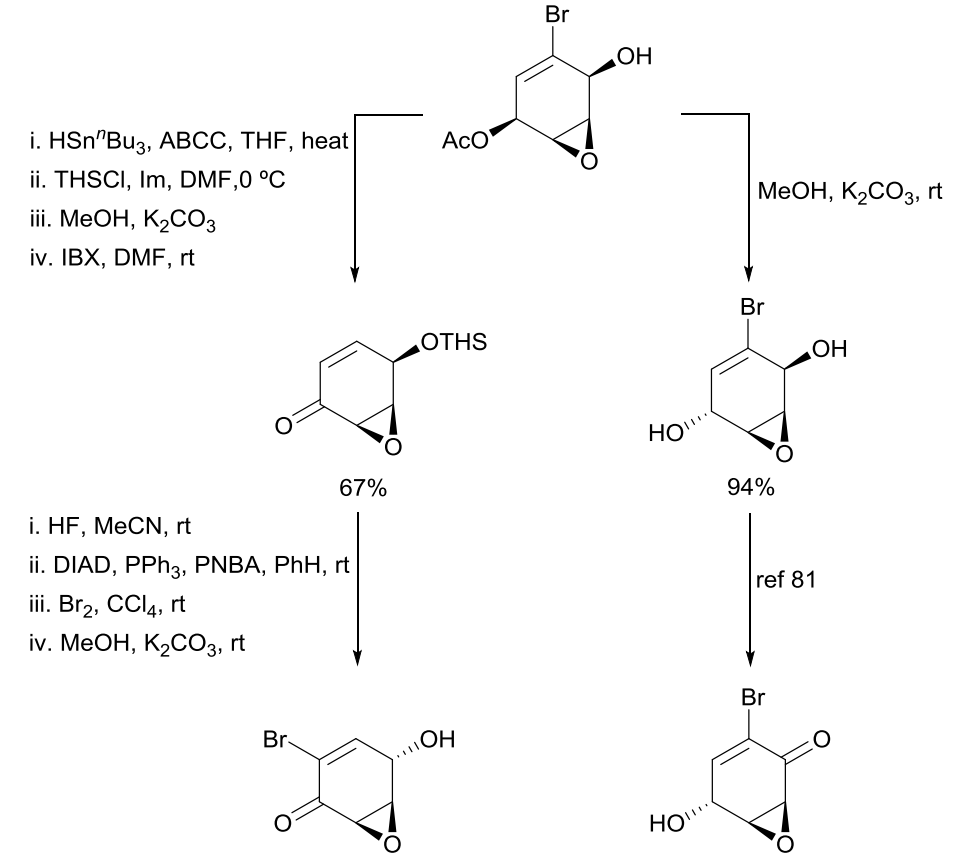

$(+), 10 \%$

$(-)$

Scheme 53 Enantiodivergent routes to (+)- and (-)-bromoxones.

Oxetane-containing compounds are important in medicinal chemistry, ${ }^{82}$ specially oxetan-3-ones are also useful in synthesis and drug discovery. Sharma and Williams ${ }^{83}$ reported diastereodivergent routes to oxetan-3-ones from allenes. Epoxidation of allenes with dimethyldioxirane (DMDO) led to a spirodiepoxide, followed by opening of this compound with lithium bromide and then intramolecular displacement of the bromide by hydroxide, gave mainly a trans2,4-substituted oxetan-3-one, illustrated by an example in Scheme 54. However, thermal rearrangement of the spiroepoxide gave the corresponding cisdiastereomer.

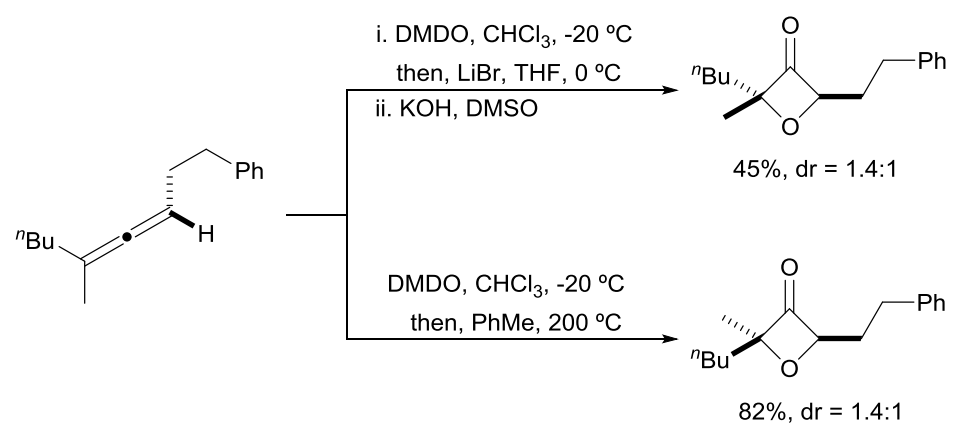

Scheme 54 Diastereodivergent routes to 2,4-substituted oxetan-3-ones.

Chiral tetrahydrofurans are important building blocks in organic synthesis, 2,5-disubstituted derivatives ${ }^{84}$ being key structural units of many natural products (see, Sections 2 and 4). In addition, 2,3-disubstituted tetrahydrofurans are used 
for the preparation of aromas, drugs and agrochemicals. ${ }^{85}$ Diastereodivergent routes to cis- and trans-2,3-disubstituted tetrahydrofurans of the roasted meat aroma, have been performed by Gatti and co-workers. ${ }^{85}$ Starting from a chiral $O$ benzylated bromohydrin, its treatment with $\mathrm{NaH}$ gave an epoxide, which was debenzylated by hydrogenolysis to give an epoxyalcohol (Scheme 55). After camphorsulfonic acid (CSA)-promoted rearrangement, an inversion of the configuration at the C-3 occurred giving $(2 S, 3 R)$-tetrahydrofuranol. Subsequent mesylation and treatment with AcSK afforded (2S,3S)-2-methyl-tetrahydrofuran3 -thiol acetate in $99.6 \%$ ee. The other trans-diastereomer was prepared from the diol, which was tosylated and cyclized to give (2S,3S)-3-bromo-2methyltetrahydrofuran. Final treatment with $\mathrm{AcSK}$ at $95^{\circ} \mathrm{C}$ gave the most odorous and pleasant trans-isomer of the roasted meat aroma.

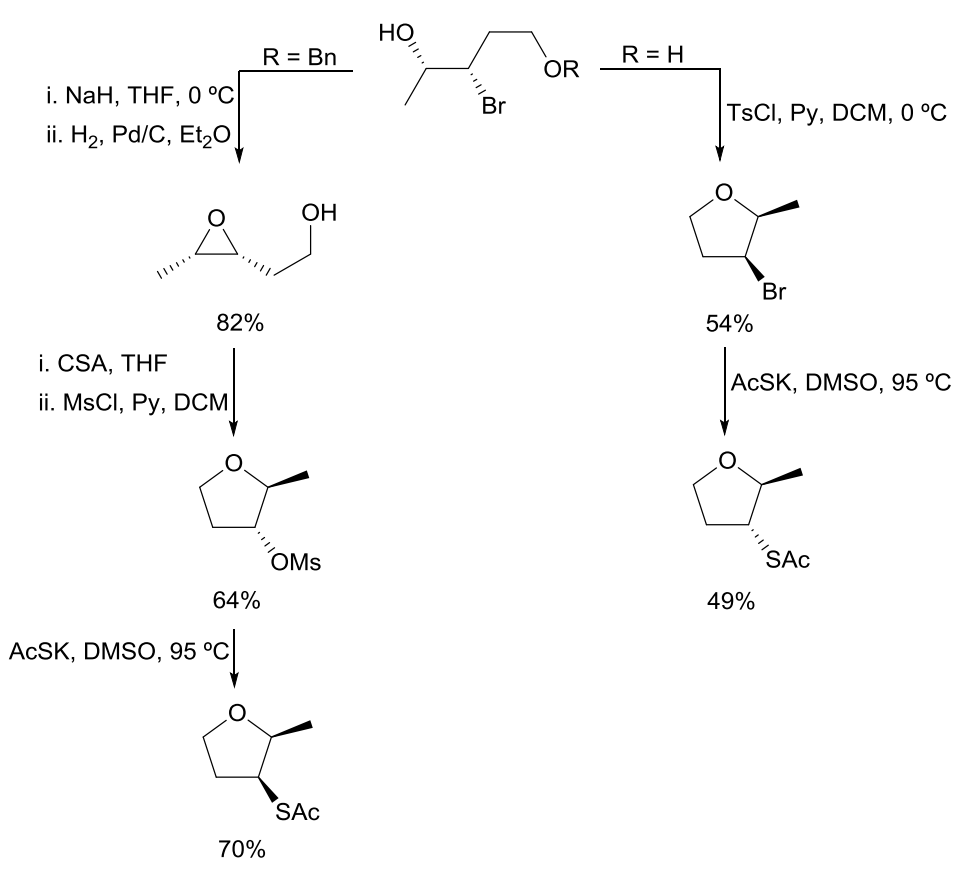

Scheme 55 Diastereodivergent routes to (2S,3S)- and (2S,3R)-2-methyl-3thioacetatetetrahydrofurans.

Evans and co-workers ${ }^{86}$ have performed diastereodivergent routes to cyclic ethers by a regioselective and enantiospecific Rh-catalyzed allylic etherification followed by ring-closing metathesis. Starting from Boc-protected $(S)$-3-buten-2-ol, etherification with copper $(I)$ alkenyl $(R)$-alkoxides using Wilkinson catalyst, the corresponding cyclic trans-disubstituted ethers, dihydrofuran, dihydropyran, tetrahydrooxepane, and tetrahydrooxocine were obtained (Scheme 56). However, working with copper(I) alkenyl (S)-alkoxides the corresponding cis-isomers were formed. This methodology was applied to the total synthesis of gaur acid, a natural product isolated from the oily secretion of the gaur ( $B$. frontalis), a wild ox in Asia. 


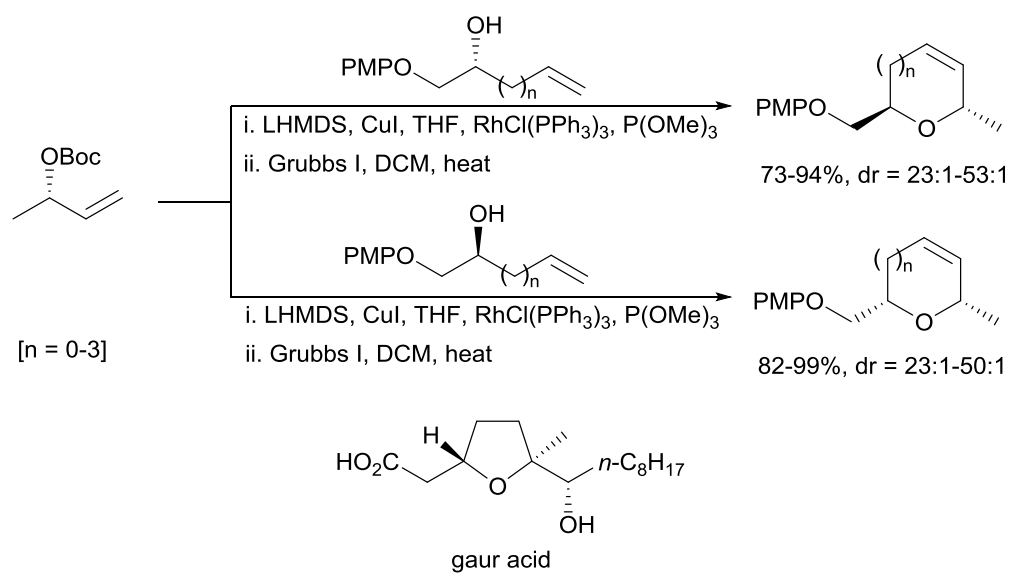

Scheme 56 Diastereodivergent routes to cyclic ethers.

Diastereodivergent routes to glycals of daunosamine and ristosamine have been reported by Carreaux and co-workers ${ }^{87}$ starting from methyl L-lactate. A dihydropyran was used as common advanced intermediate, which by reaction with trichloroacetyl isocyanate reagent (TCA-NCO), followed by basic hydrolysis, gave the carbamate precursor of L-daunosamine glycal ${ }^{88}$ (Scheme 57 ). For the ristosamine glycal precursor, the secondary alcohol of the starting dihydropyran was submitted to a Mitsunobu reaction, followed by hydrolysis and treatment with TCA-NCO.

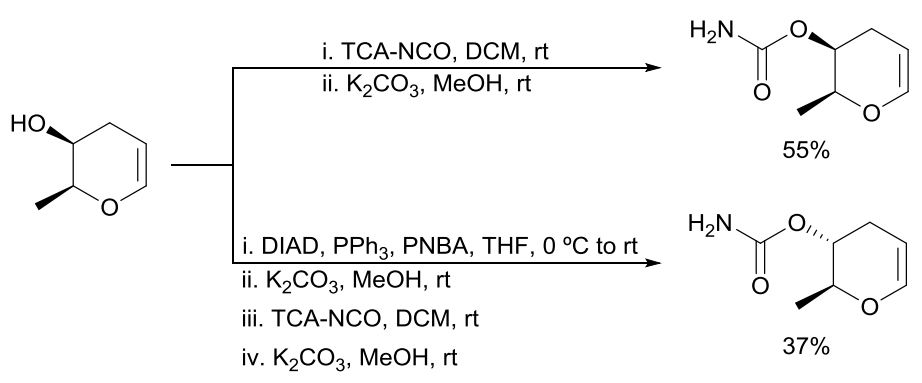

Scheme 57 Diastereodivergent routes to dihydropyran carbamates precursors of daunosamine and ristosamine glycals.

Collis and Perlmutter ${ }^{89}$ performed diastereoselective routes to cis- and trans-3,4-disubstituted 2-azetidones using a chiral aminolactone derived from Dmannitol as common starting material. These 2-azetidones play an important role in the activity of many antibiotics. ${ }^{90}$ As synthetic target it was chosen the azetidone bearing an ethyl group at C-3, a side chain found in the antibiotic (+)PS-5. ${ }^{91}$ The alkylation of the lithium enolate of the starting aminolactone with Etl was followed by hydrolysis with aqueous $\mathrm{NaOH}$ and acidification giving an amino acid. The crude amino acid was silylated and, after ester hydrolysis, the protected amino acid was submitted to a cyclization under Ohno conditions to provide the cis-3,4-azetidone in $24 \%$ overall yield from the alkylated aminolactone (Scheme 58). For the trans-isomer, the aminolactone was transformed into the 
corresponding azetidone following the same sequence developed for the alkylated aminolactone, which was obtained in $48 \%$ yield. Then, the $\mathrm{N}$-benzyl group was substituted by TBS and the resulting azetidone was alkylated by generation of the lithium enolate to furnish the trans-derivative.

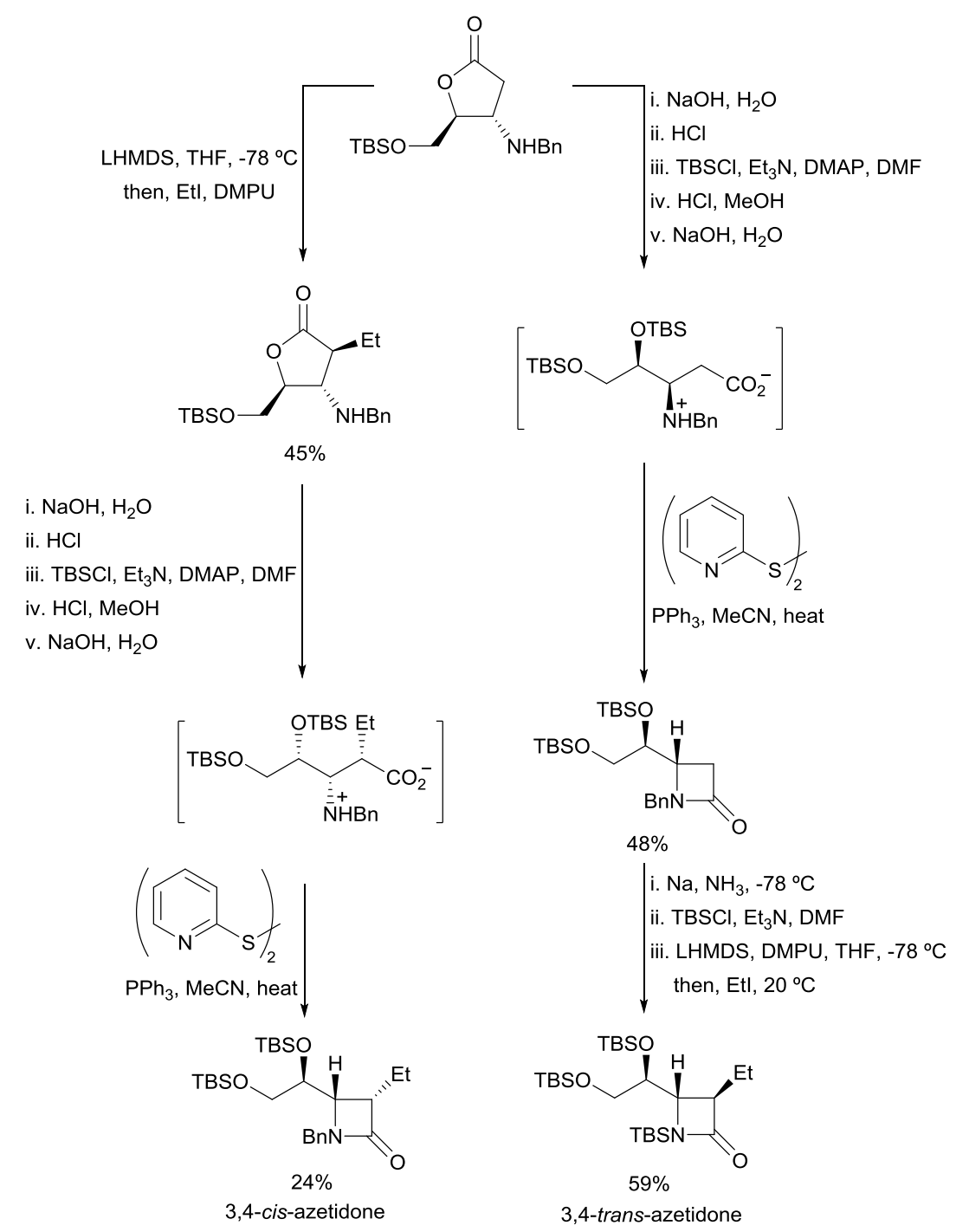

Scheme 58 Diastereodivergent routes to 3,4-cis- and trans-2-azetidones.

Diastereodivergent routes to $\beta$-hydroxy-y-lactams have been reported by Sá and co-workers ${ }^{92}$ from epoxide acetates, obtained by epoxidation of $\beta, \gamma$ unsaturated esters. In the case of the epoxide acetate depicted in Scheme 59, a direct opening with $\mathrm{NaN}_{3}$ gave the anti- $\beta$-azido alcohol, which by hydrogenolysis underwent reductive cyclization to give the trans- $\beta$-hydroxy- $\gamma$-lactam. On the other hand, opening of the epoxide with $\mathrm{LiBr}$ to anti-bromohydrin followed by a $\mathrm{S}_{\mathrm{N}} 2$ reaction with $\mathrm{NaN}_{3}$ and final hydrogenation provided the cis- $\beta$-hydroxy- $\gamma-$ lactam. The same starting epoxide has been transformed diastereodivergently into trans- and cis- $\beta$-hydroxy- $\gamma$-lactams via aziridine acetates. 


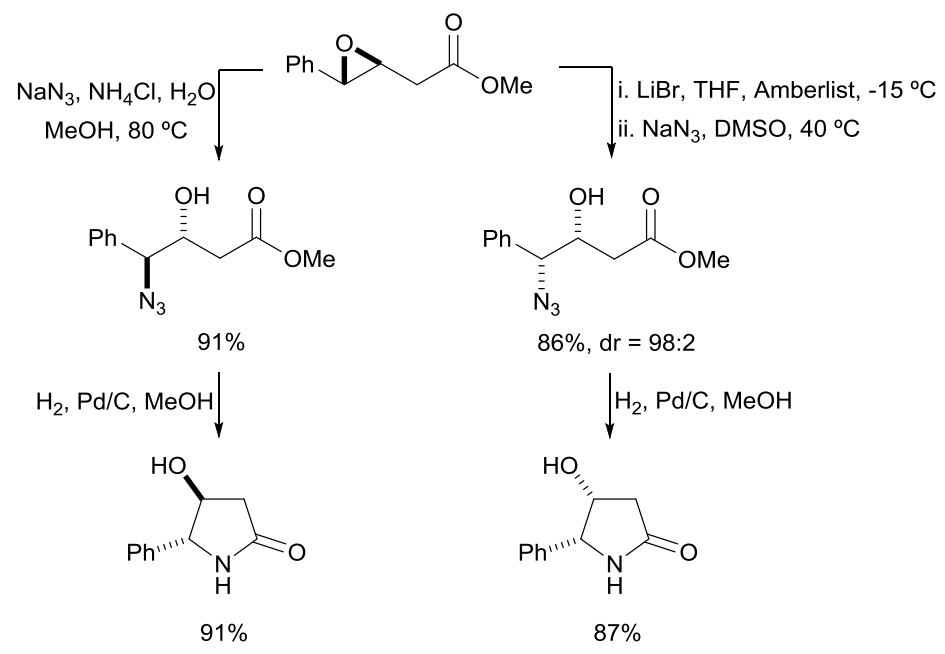

Scheme 59 Diastereodivergent routes to trans- and cis- $\beta$-hydroxy-y-lactams.

Oxazolidinones are synthetic antibacterial agents of several human pathogens ${ }^{93}$ including S. aureus, S. pneumoniae, E. faecalis and H. influenzae, and show activity against multiple-drug resistant strains of the Gram-positive organisms. Gage and co-workers ${ }^{94}$ reported diastereodivergent routes to sulfoxide-containing oxazolidinone antibiotics. As common starting material a carbamate, prepared from 3-fluoroaniline, was transformed into the corresponding cis-sulfoxide by dehydration-oxidation followed by hydrogenation of the double bond (Scheme 60). For the trans-sulfoxide, the tertiary alcohol of the carbamate was subjected to a silane reduction using poly(methylhydroxysilane) (PMHS) to provide the saturated tetrahydrothiopyran. Final oxidation under Kagan's conditions gave a mixture of sulfoxides, the transone being the major product. These cis- and trans-epoxide-carbamates were further transformed into the oxazolidinone antibiotics related to the drug linezolid. 


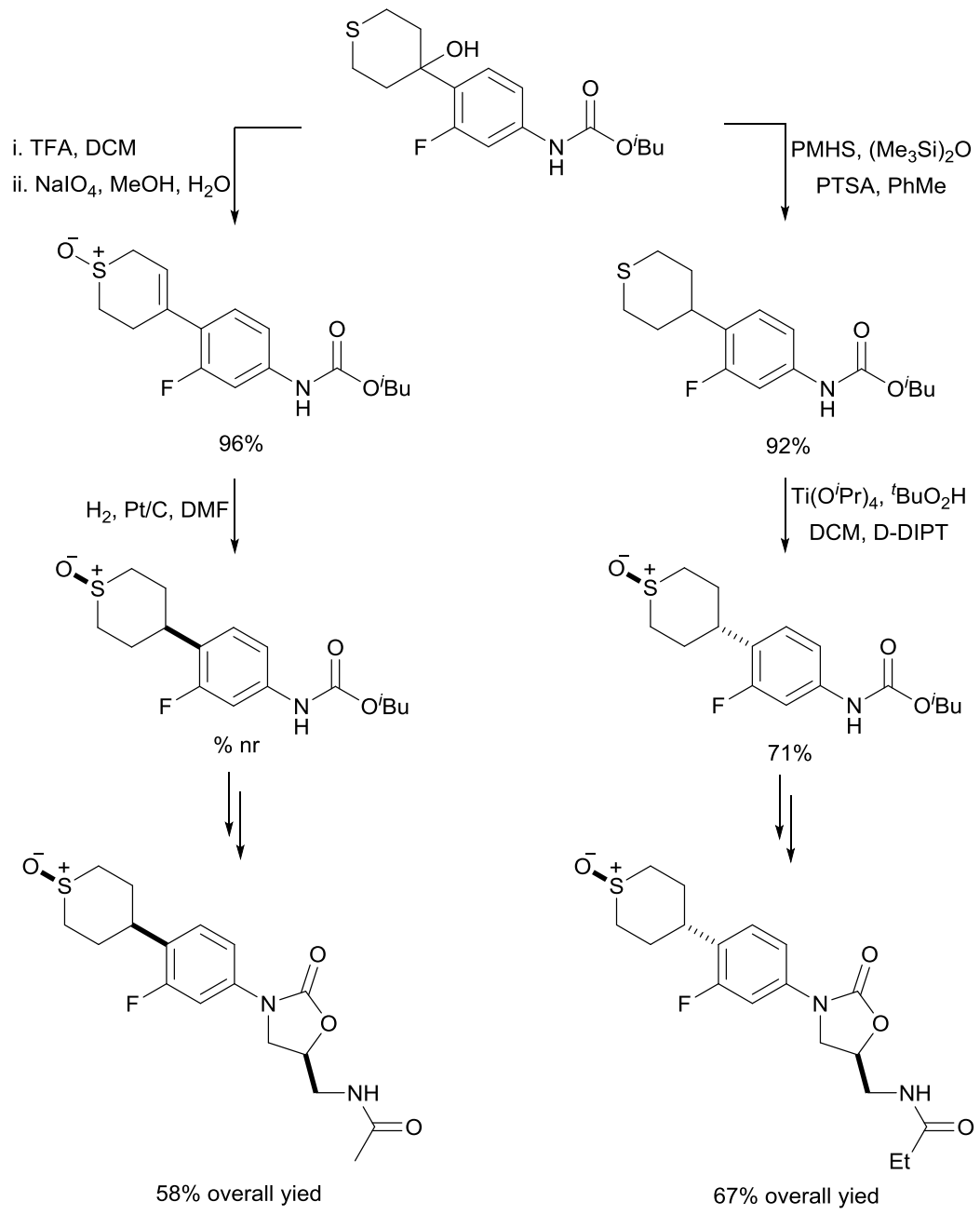

Scheme 60 Diastereodivergent routes to cis- and trans-sulfoxides precursors of oxazolidinone antibiotics.

Chiral (2,2'-bisoxazolino)alkanes are useful ligands for the preparation of catalysts for several enantioselective reactions. ${ }^{95}$ Both enantiomers are usually prepared from enantiomeric $\beta$-amino alcohols. Desimoni and co-workers ${ }^{96}$ reported diastereodivergent routes to chiral 4,5-disubstituted bis(oxazolidines) starting from diamides derived from dimethyl malonic acid. The ring-closure of these diamides with di- $n$-butyltin dichloride (Masamune protocol) afforded $(4 R, 5 S)$-dioxazoline (Scheme 61). The same diamides were transformed into their mesylates and after basic treatment the ring-closure took place with inversion of the configuration at C-5 giving the corresponding diastereomeric bis(oxazolines). The same protocol has been applied to the diastereodivergent synthesis of 4,5-disubstituted pyridine-2,6-bis(oxazoline) (pybox) ligands. ${ }^{97}$ 


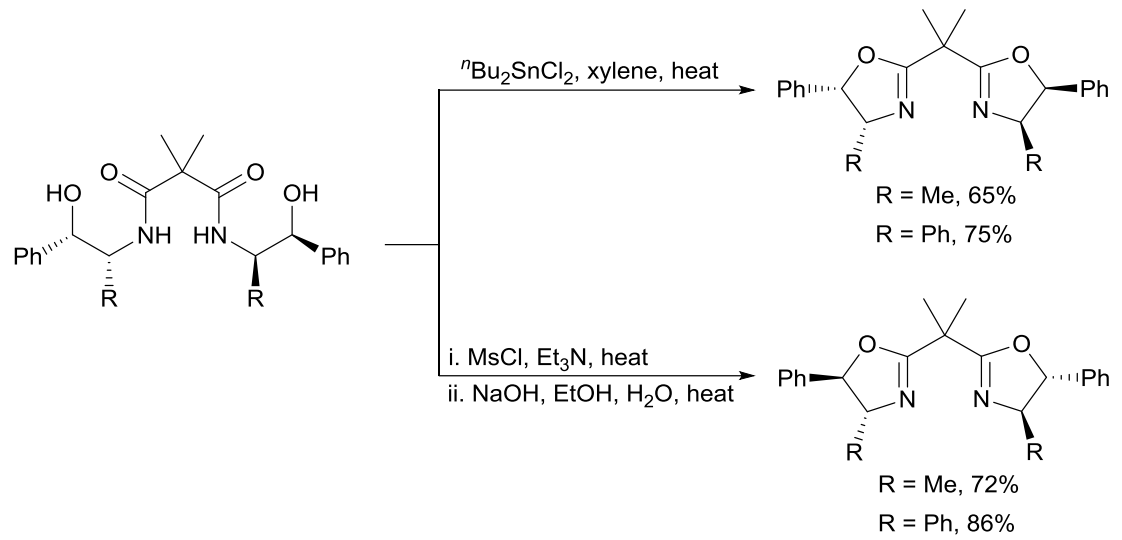

Scheme 61 Diastereodivergent routes to 4,5-disubstituted bis(oxazolines).

Diastereodivergent routes to dihydropyrido(2,1-a)isoindolone synthesis via reductive Heck reactions of a chiral 1,4-dihydropyridine have been described by Pays and Mangeney. ${ }^{98}$ In the presence of $\mathrm{Pd}(\mathrm{OAc})_{2}$ and $\mathrm{KOAc}$ in $\mathrm{DMF}$ at 90 ㄷ $\mathrm{C}$ the dihydropyridine was regioselectively converted into the corresponding dihydropyridoisoindolone through an anti-carbopalladation followed by a syn- $\beta$ elimination and isomerization of the double bond. Hydrolysis of the aminal and hydrogenation of the double bond provided the cis-derivative (Scheme 62). A tandem or domino? cyclization-hydride capture took place using $\mathrm{Pd}(\mathrm{OAc})_{2}\left(\mathrm{PPh}_{3}\right)_{2}$ and piperidinium formate gave mainly the trans-derivative.

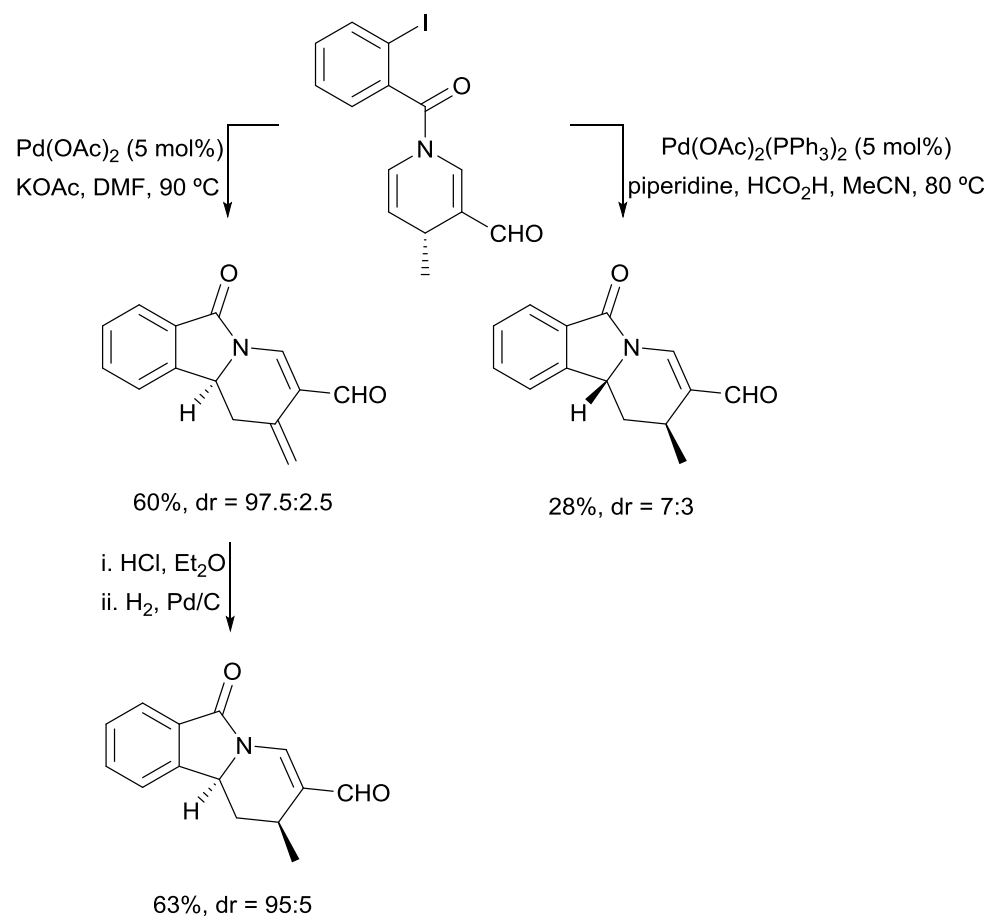

Scheme 62 Diastereodivergent routes to cis- and trans-dihydropyrido(2,1-a)isoindolones. 
The cycloadduct derived from the asymmetric Diels-Alder reaction of $\beta$ trifluoromethyl enones with 2,4-dienals under trienamine catalysis with a chiral prolinol gave diastereomeric octahydroisoquinolines during the intramolecular reductive amination. ${ }^{99}$ In the presence of benzylamine and $\mathrm{NaBH}(\mathrm{OAc})_{3}$ epimerization at the $\alpha$-carbon of the cyclohexene took place giving the cis-fused octahydroisoquinolines, probably due to the strong basicity of this hydride (Scheme 63). On the other hand, with $\mathrm{NaBH}_{3} \mathrm{CN}$ as reducing agent, the transfused octahydroisoquinolines were obtained.

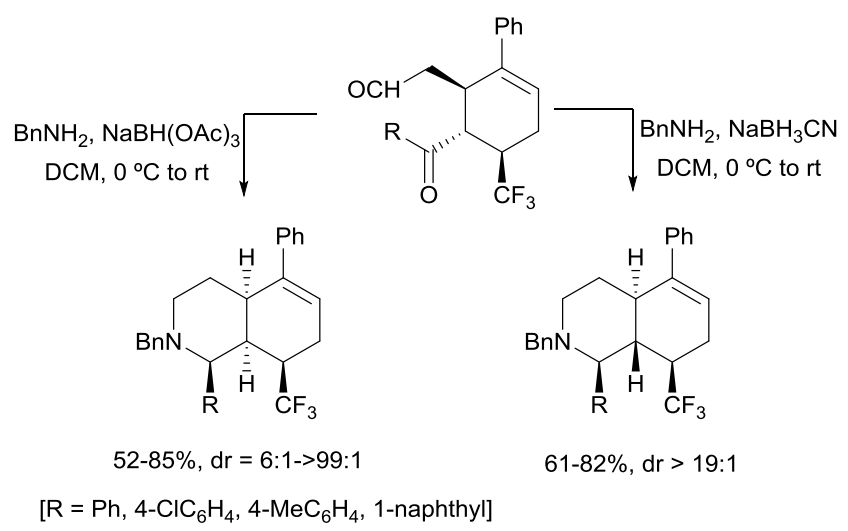

Scheme 63 Diastereodivergent routes to cis- and trans-fused octahydroisoquinolines.

\section{Unnatural compounds}

Diastereodivergent routes to (Z)- and (E)-alkenes are well-stablished methodologies based on Wittig or Horner-Wadsworth-Emmons reactions, ${ }^{100}$ Peterson ${ }^{101}$ and Julia ${ }^{102}$ olefinations as the most prominent processes. Trisubstituted alkenes are abundant structures in natural products, such as hennoxazole $A$, epothilone $D$, discodermolide and terpenes. A number of methods has been developed for the selective synthesis of either $(E)$ - or (Z)trisubstituted alkenes mainly based on Wittig, Julia and Peterson olefinations, alkyne carbometallations and olefin cross metathesis. Willis, Aggarwal and coworkers ${ }^{103}$ have reported diastereodivergent routes to these alkenes through protodeboronation of allylic boronic esters. Using TBFA, (Z)-alkenes were exclusively obtained, whereas by conversion of the boronic esters into the corresponding tetrafluoroborate salts resulted a spontaneous protodeboronation providing predominantly $(E)$-alkenes (Scheme 64$)$. In order to explain these diastereodivergent results, transition states I and II were proposed for (Z)- and $(E)$-selectivity, respectively. 


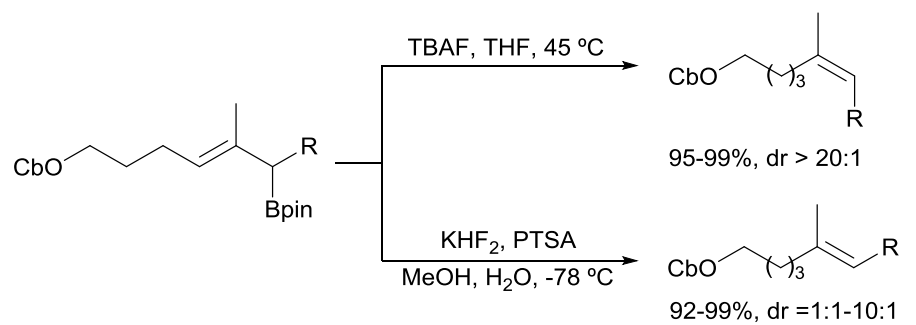

$\left[\mathrm{R}={ }^{i} \mathrm{Pr},{ }^{t} \mathrm{Bu}, \mathrm{Ph}, \mathrm{Ph}\left(\mathrm{CH}_{2}\right)_{2}, \mathrm{Ph}\left(\mathrm{CH}_{2}\right)_{2} \mathrm{CH}(\mathrm{Me})\right]$
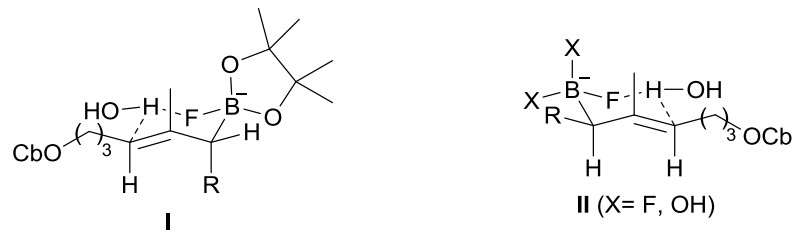

Scheme 64 Diastereodivergent routes to $(Z)$ - and $(E)$-trisubstituted alkenes.

Hydrometallation/cross coupling sequence of alkynes allowed the stereoselective synthesis of alkenes. Blanchard and co-workers ${ }^{104}$ described diastereodivergent routes to (Z)- and $(E)-\alpha-C_{3}$-vinylgermanes from $\alpha$ trifluoromethylated alkynes. Under radical conditions, (Z)-selective hydrogermylation took place, whereas under $\mathrm{Pd}$-catalyzed conditions resulted (E)-vinylgermanes (Scheme 65). These products were arylated under Pdcatalyzed arylation conditions described by Fugami and Kosugi, ${ }^{105}$ by previous transformation of the triphenylgermyl motif into trichlorogermyl, affording (Z)- and $(E)$ - a-trifluoromethylated alkenes.

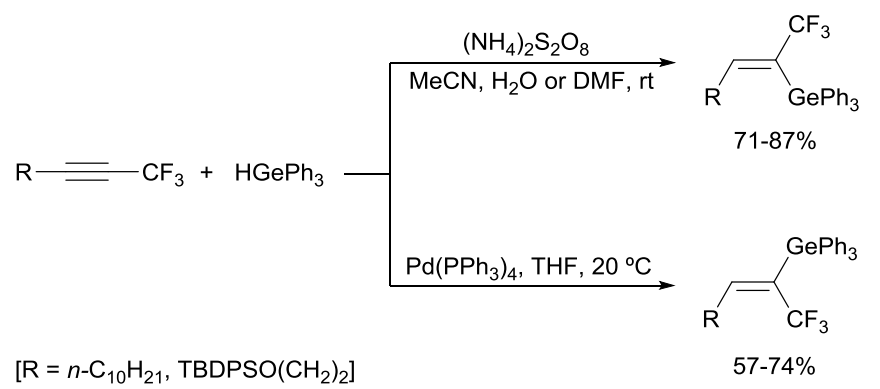

Scheme 65 Diastereodivergent routes to $(Z)$ - and $(E)-\alpha-C_{3}$-vinylgermanes.

Recently, Barbasiewicz and co-workers ${ }^{106}$ reported diastereodivergent routes to 1,2-disubstituted alkenes by a modification of the Julia-Kocienski olefination using arylated trifluoromethyl alkanesulfonates. Reduction of these acyl sulfonates with $\mathrm{LiAlH}_{4} / \mathrm{LiCl}$ gave the corresponding $\beta$-hydroxy sulfonates in a diastereoselective manner, which by treatment with ${ }^{t} \mathrm{BuOLi}$ or LHMDS underwent cyclization to the four-membered cyclic intermediates, providing by syn-fragmentation $(E)$-alkenes (Scheme 66). However, the reduction with $\mathrm{LiAlH}_{4}$ at $-78 \stackrel{\circ}{\circ} \mathrm{C}$ to room temperature gave $\beta$-hydroxysulfinic acids, which by reaction of the hydroxy group with 5-chloro-1-phenyl-1H-tetrazole experimented antifragmentation to furnish $(Z)$-alkenes. 


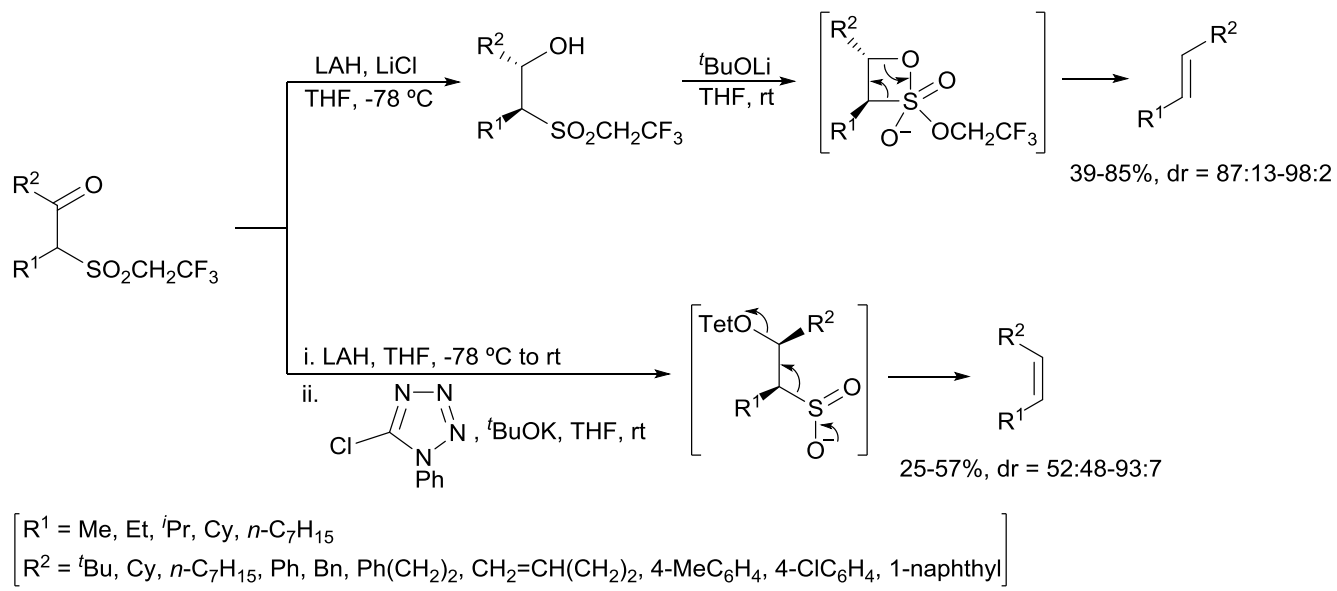

Scheme 66 Diastereodivergent routes to $(E)$ - and (Z)-alkenes.

Stereodefined $(E, E)$ - and (E,Z)-fluorodienals are synthesized using diastereodivergent routes starting from gem-difluorocyclopropylacetaldehydes. Cossy and co-workers ${ }^{107}$ reported the ring-opening of the difluorocyclopropane unit using tetramethylguanidine (TMG) to provide $(E, E)$-fluorodienals (Scheme 67). During the screening of the bases, the authors discovered an inversion of the stereochemistry in favor of the $(E, Z)$-isomer when piperidine was used. The proposed mechanism for the ring- opening occurs via an enolate or an enamine intermediate according to a concerted disrotatory C-1-C-3 bond cleavage to form the $(E, E)$-dienal. This isomer can isomerize to $(E, Z)$-diene through an addition/elimination process in the presence of piperidine.

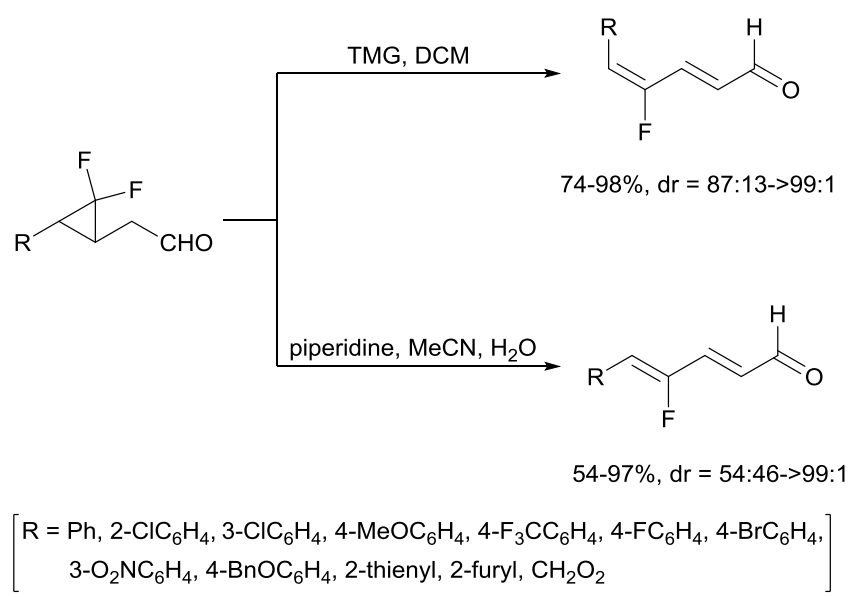

Scheme 67 Diastereodivergent routes to $(E, E)$ - and $(E, Z)$-fluorodienals.

Enantiodivergent routes to axially chiral allenes have been described by Aggarwal and co-workers ${ }^{108}$ starting from chiral $\alpha$-seleno alkenylboronic esters. When MCPBA was used as oxidant syn-elimination took place giving $(P)$-allenes 
(Scheme 68). By transforming the selenide into a selenonium salt with MeOT followed by addition of $\mathrm{NaHCO}_{3}$, anti-elimination occurred to provide $(M)$-allenes.

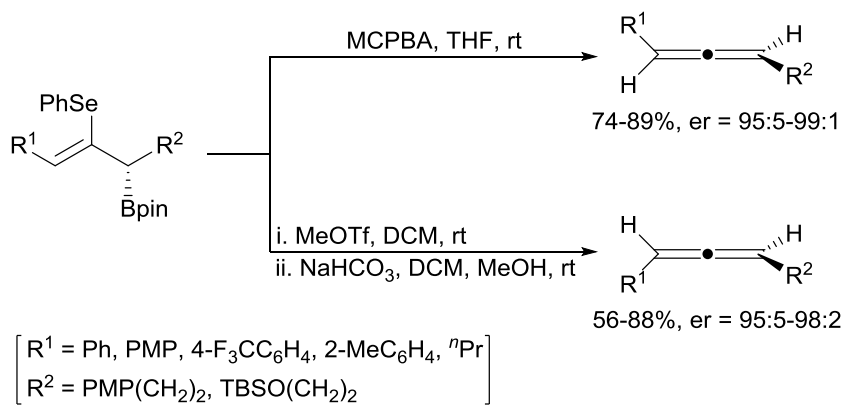

Scheme 68 Enantiodivergent routes to $(M)$ - and $(P)$-allenes.

Alkenes bearing a stereocenter at the allylic position have been synthesized from chiral benzoylated allylic alcohols using enantiodivergent routes by Breit and co-workers ${ }^{109}$ based on copper-mediated allylic substitutions. In Scheme 69 the formation of quaternary carbon centers by a directed synsubstitution using Grignard reagents is illustrated, while organozinc compounds gave a non-directed anti-substitution. A possible explanation for the approach of the organocopper reagent through intermediates I and II has been proposed.

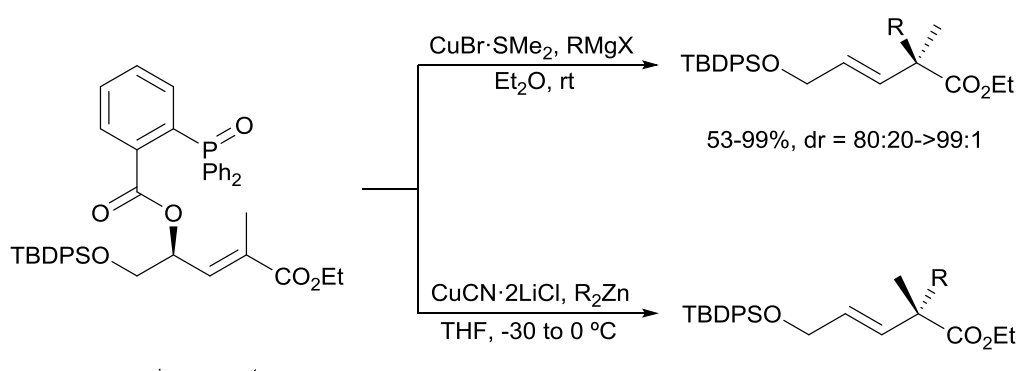

$84-94 \%, d r=95: 5->99: 1$
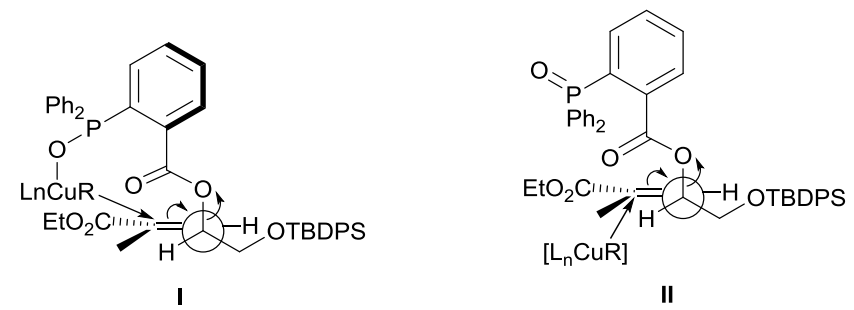

Scheme 69 Enantiodivergent routes to alkenes with a stereocenter at the allylic position.

Marek and co-workers ${ }^{110}$ have developed enantiodivergent routes for the preparation of alkenes bearing a quaternary carbon stereocenter at the allylic position starting from cyclopropenyl esters via a combined carbometalation-zinc homologation-fragmentation process. The carbometallation of chiral cyclopropenyl esters with an alkylcopper in THF gave the corresponding anti- 
cyclopropylcopper intermediates, which by reaction with the Wittig-Furukama reagent $\mathrm{Zn}\left(\mathrm{CH}_{2} \mathrm{l}\right)_{2}$, and phenanthroline as ligand, underwent zinc homologation followed by subsequent $\mathrm{C}-\mathrm{C}$ bond cleavage (Scheme 70). Diastereodivergent carbometalation occurred using toluene instead of THF to furnish the syncyclopropylcopper reagent, which by zinc-homologation-fragmentation afforded the corresponding enantiomer. The fragmentation step occurs through intermediacy of $\mathbf{I}$.
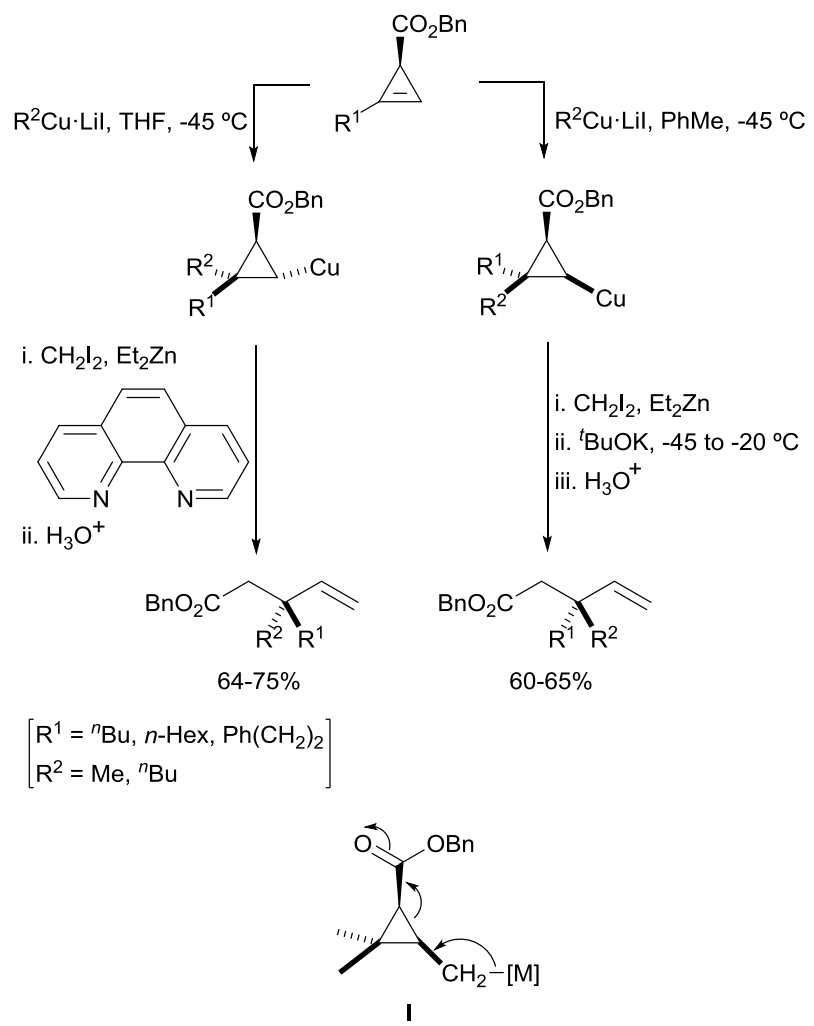

Scheme 70 Enantiodivergent routes to $\gamma, \delta$-unsaturated esters.

Cyclopropanes are found in a wide range of natural products and biologically significant molecules. ${ }^{111}$ Generally, the cyclopropane unit is generated using the Simmons-Smith reaction. Diastereoselective cyclopropanation can be performed by the binding of an allylic functional group to the zinc reagent. Davies and co-workers ${ }^{112}$ have reported diastereodivergent routes to the cyclopropanation of an allylic carbamate derived from 3aminocyclohexene. Cyclopropanation with $\mathrm{Zn}\left(\mathrm{CH}_{2}\right)_{2}$ (the Wittig-Furukawa reagent) gave the syn-derivative in $>98 \%$ de, whereas with $\mathrm{F}_{3} \mathrm{CCO}_{2} \mathrm{ZnCH}_{2} \mathrm{l}$ (Shi's carbenoid) the corresponding anti-product was formed also in $>98 \%$ de (Scheme 71). This diastereodivergent behavior has been explained by coordination of the zinc carbenoid to the carbamate (I) giving and intramolecular syncyclopropanation. However, with $\mathrm{F}_{3} \mathrm{CCO}_{2} \mathrm{ZnCH} \mathrm{H}_{2}$ a second equivalent is required (II), which is approached to the least hindered face. This protocol has been applied to the synthesis of trans-SCH-A and cis-SCH-A. ${ }^{113}$ The former 
cyclopropane trans-SCH-A has been developed as melanine-concentrating hormone receptor 1 (MCH-R1) antagonist. ${ }^{114}$

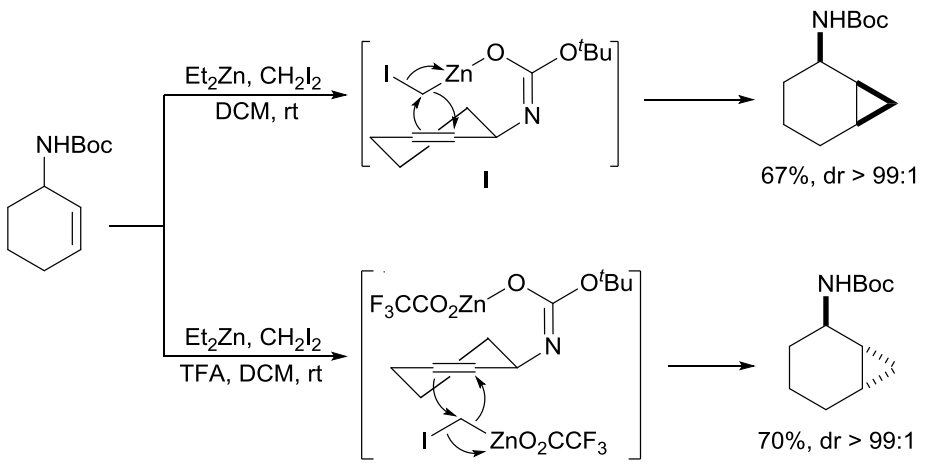

II
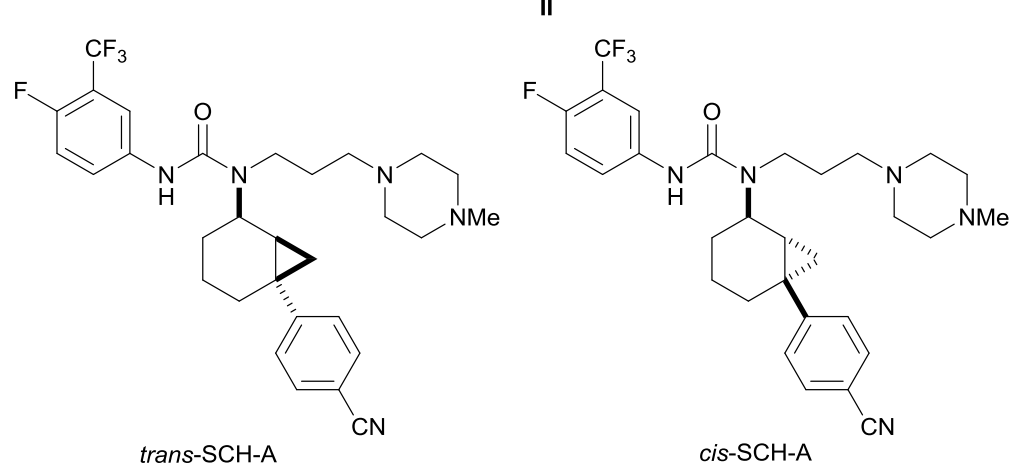

Scheme 71 Diastereodivergent routes to cis-and trans-cyclopropanation of allylic amines.

The above-mentioned diastereodivergent carbometalation of cyclopropenes ${ }^{110}$ was previously developed by Marek and co-workers ${ }^{115}$ for the synthesis of cis- and trans-cyclopropanes. The copper-catalyzed syncarbomagnesiation of cyclopropenyl esters followed by reaction with electrophiles provided functionalized syn-cyclopropanes (Scheme 72). Alternatively, anti-carbocupration with organocopper species afforded configurationally stable cyclopropylcopper species, which reacted with electrophiles to give the corresponding diastereomeric anti-cyclopropanes. For the syn-carbometalation, a chelated model I was proposed. 


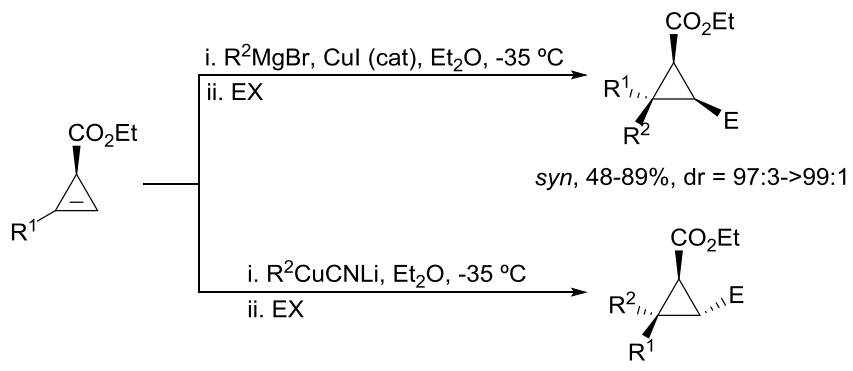

$\left[\begin{array}{l}\mathrm{R}^{1}={ }^{n} \mathrm{Bu}, n-\mathrm{Hex}, \mathrm{Bn},{ }^{n} \mathrm{BuCO}\left(\mathrm{CH}_{2}\right)_{3} \\ \mathrm{R}^{2}=\mathrm{Me},{ }^{n} \mathrm{Bu} \\ \mathrm{EX}=\mathrm{H}_{2} \mathrm{O}, \mathrm{CH}_{2}=\mathrm{CHCH}_{2} \mathrm{Br}\end{array}\right]$

anti, $63-76 \%, \mathrm{dr}=88: 12-97: 3$

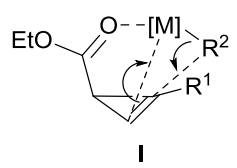

Scheme 72 Diastereodivergent routes to functionalized syn- and anti-cyclopropanes.

Diastereodivergent enantioselective organocatalytic routes to bicyclo[3.1.0]hexanes from enals and 4-alkenyl sulfamidate imines have been reported by Carrillo, Vicario and co-workers. ${ }^{116}$ Using TMS-protected (S)diphenylprolinol, when the reaction was carried out at $-30{ }^{\circ} \mathrm{C}$, the cyclohexane derivatives were isolated by means of a Michael/Michael cascade reaction. These compounds were treated with benzydrylamine to provide the bicyclic adducts up to 87:13 dr (Scheme 73). When this stepwise protocol was performed under refluxing DCE, in the presence of DABCO, a cascade Michel/Michael/transannular alkylation/hydrolysis process occurred to lead the formation of the diastereomeric fused cyclopropane-cyclopentanone.

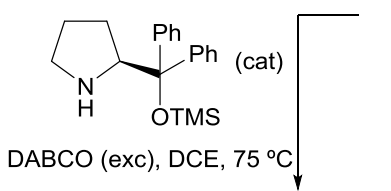<smiles>[R]C=CC=O</smiles><smiles>[R]C1[C@H](C)C(=O)[C@@H]2[C@H]([R])[C@]12C=O</smiles>

\footnotetext{
$\mathrm{R}^{1}=\mathrm{Me}, \mathrm{Ph}$

$\mathrm{R}^{2}=\mathrm{Ph}, 4-\mathrm{MeC}_{6} \mathrm{H}_{4}, 4-\mathrm{ClC}_{6} \mathrm{H}_{4}, 4-\mathrm{BrC}_{6} \mathrm{H}_{4}, 4-\mathrm{O}_{2} \mathrm{NC}_{6} \mathrm{H}_{4}$, 4- $\mathrm{NCC}_{6} \mathrm{H}_{4}, 4-\mathrm{F}_{3} \mathrm{CC}_{6} \mathrm{H}_{4}, 4-\mathrm{AcO}-3-\mathrm{MeOC}_{6} \mathrm{H}_{3}$
}

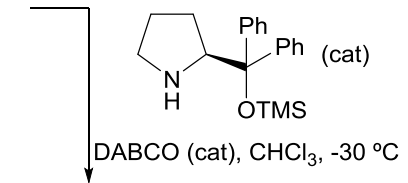<smiles>[R]C1C(C)C2=NS(=O)(=O)OC2C([R])C1C=O</smiles>

i. $\mathrm{Ph}_{2} \mathrm{CHNH}_{2}$, DCE, $75^{\circ} \mathrm{C}$ ii. $\mathrm{HCl}, \mathrm{H}_{2} \mathrm{O}$

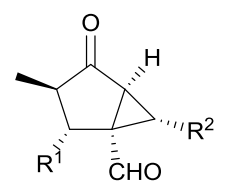

$51-80 \%$ (overall) $\mathrm{dr}=75: 25-87: 13$ 
Scheme 73 Diastereodivergent routes to bicyclo[3.1.0]hexanes.

Enantiodivergent routes to 2,5-dimethoxyphenyl methyl carbinols have been reported by Carreño, Urbano and co-workers ${ }^{117}$ starting from $[(S) s]-3,6$ dimethhoxy-2-( $p$-tolylsulfonyl)benzaldehyde. The addition of $\mathrm{MeMgBr}$ gave the $(S)$-alcohol in $98 \%$ de, while $\mathrm{Me}_{3} \mathrm{Al}$ afforded the $(R)$-alcohol also in $98 \%$ de (Scheme 74). Cleavage of the sulfoxide group was achieved with $n$-BuLi at -78 ${ }^{\circ} \mathrm{C}$ to give the corresponding lithium intermediates, which were trapped with water to give the expected alcohols. The opposite diastereoselection has been explained from the evolution of intermediates I and II, respectively.

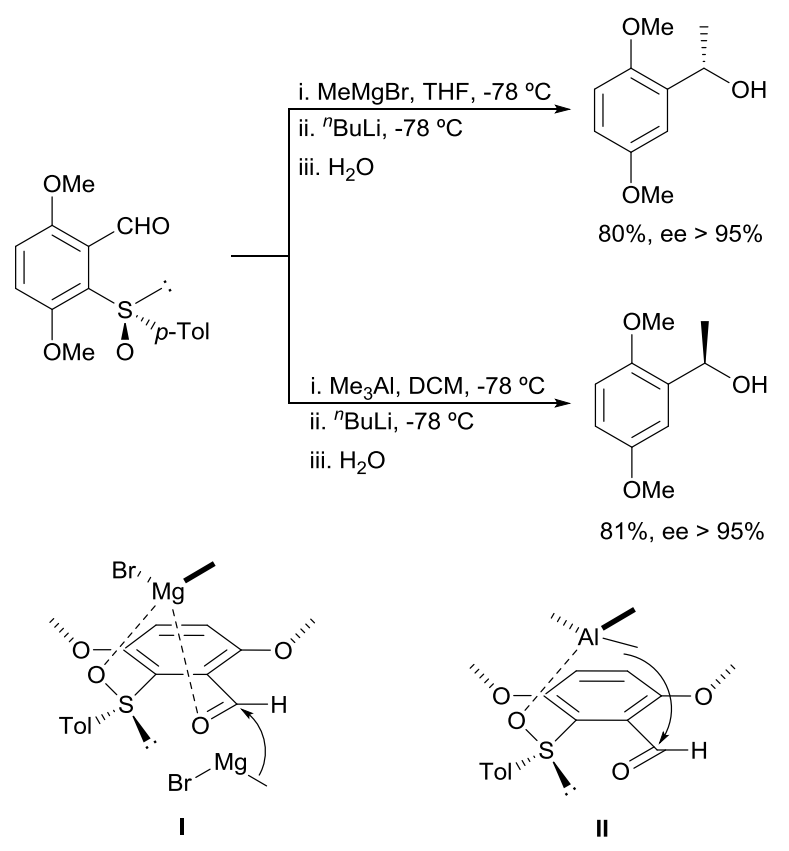

Scheme 74 Enantiodivergent routes to 2,5-dimethoxyphenyl methyl carbinols.

Vrancken, Gérard and co-workers ${ }^{118}$ reported diastereodivergent routes to homopropargylic alcohols by addition of allenylcuprates to aldehydes. The addition of allenyl(cyano)cuprates, prepared by initial lithiation of acetylenes, gave the anti-homopropargylic alcohols through a proposed nine-membered transition state $\mathbf{I}$. On the other hand, allenyl(alkyl)cuprates provided the corresponding syn-alcohols. Experimental and theoretical support shows that the lithium cation acts as a Lewis acid activator forming transition state II. Scheme 75 depicts the results using 1-phenylbut-4-yne and isobutyraldehyde. 

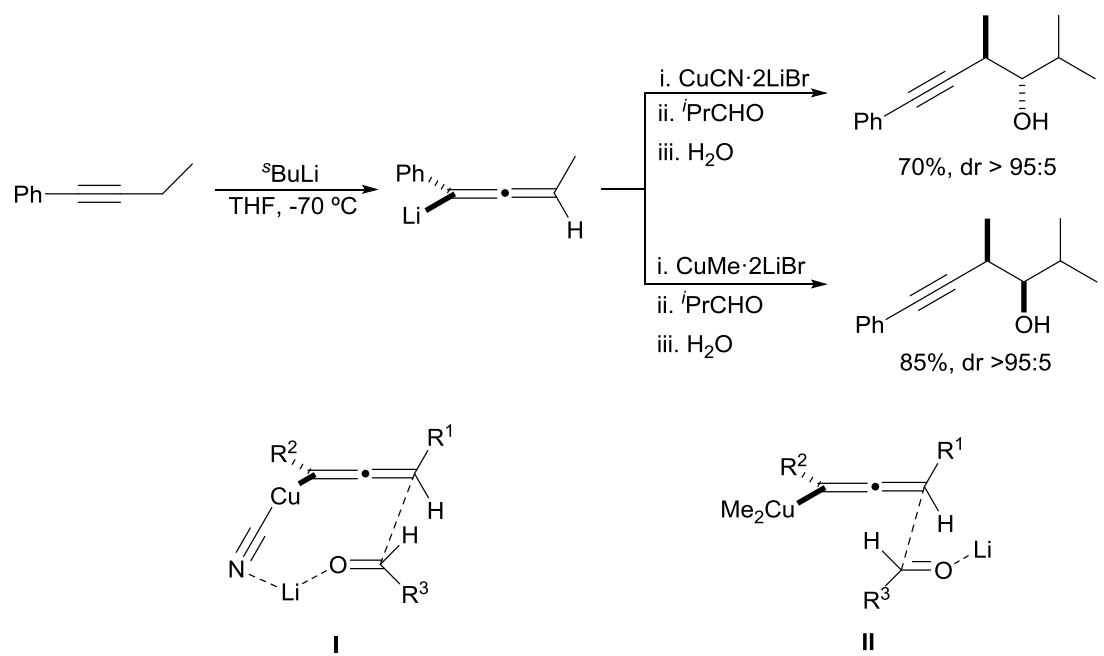

Scheme 75 Diastereodivergent routes to anti- and syn-homopropargylic alcohols.

Diastereodivergent routes to $(E)$ - and (Z)-allylic alcohols by hydroborationoxidation of allenes were described by Sato, Chida and co-workers. ${ }^{119}$ Hydroboration with 9-BBN provided, after oxidation, thermodynamically stable $(E)$-allylic alcohols, whereas with $\mathrm{HB}(\mathrm{Sia})_{2}$ the kinetic $(Z)$-alcohols were obtained (Scheme 76).

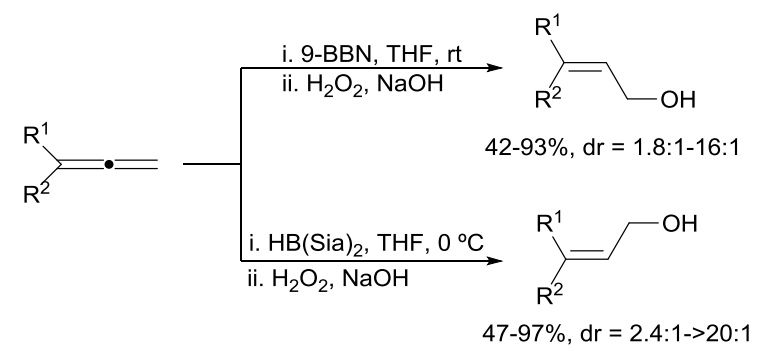

$\left[\begin{array}{l}\mathrm{R}^{1}=\mathrm{Cy}, \mathrm{TBDPSCH} \\ \mathrm{R}^{2}, \mathrm{H}, \mathrm{Me}\end{array}\right.$

Scheme 76 Diastereodivergent routes to $(E)$ - and (Z)-allylic alcohols.

Propargylic alcohols can be converted into $(E)$ - or (Z)-allylic alcohols using diastereodivergent routes as it has been reported by Tanaka and co-workers. ${ }^{120}$ Reduction of syn-diols [obtained by Carreira's asymmetric alkynation of $O$ protected a-oxy aldehydes using $(1 S, 2 R)-(+)-N$-methylephedrin as chiral ligand] ${ }^{121}$ with $\mathrm{LiAlH}_{4}$ followed by acylation gave trifluoroacetylated $(E)$-allylic alcohols (Scheme 77). On the other hand, semihydrogenation of the carboncarbon triple bond using the Lindlar catalyst provided, after acylation, (Z)trifluoroacetylated alcohols. 


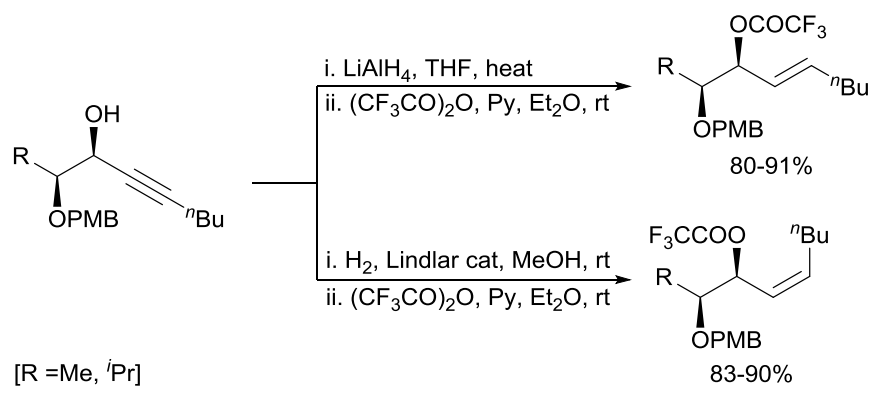

Scheme 77 Diastereodivergent routes to $(E)$ - and (Z)-allylic alcohol derivatives.

Polypropionates contain alternatively methyl- and hydroxy-substituents in alkyl chains are found in several natural products. ${ }^{122}$ Vogel and co-workers ${ }^{123}$ have reported diastereodivergent routes to long-chain polyketides. Thus, starting from $\quad(1 Z, 2 S, 3 R, 4 S)$-1-ethylidene-2.4-dimethyl-3-[(1S)-1-phenylethoxy-5oxohept-1-yl] isobutyrate, an anti,syn-stereotriad ?NO ENTIENDO, REVISAR FRASE?, by an aldol reaction with acetaldehyde using Peterson's method gave, after borate oxidation, mainly the corresponding anti-aldol (Scheme 78). By application of Evans's methodology for the Mukaiyama cross aldol reaction with acetaldehyde, the corresponding syn-aldol was mainly formed. After subsequent reductions diastereomeric stereohexads were obtained.

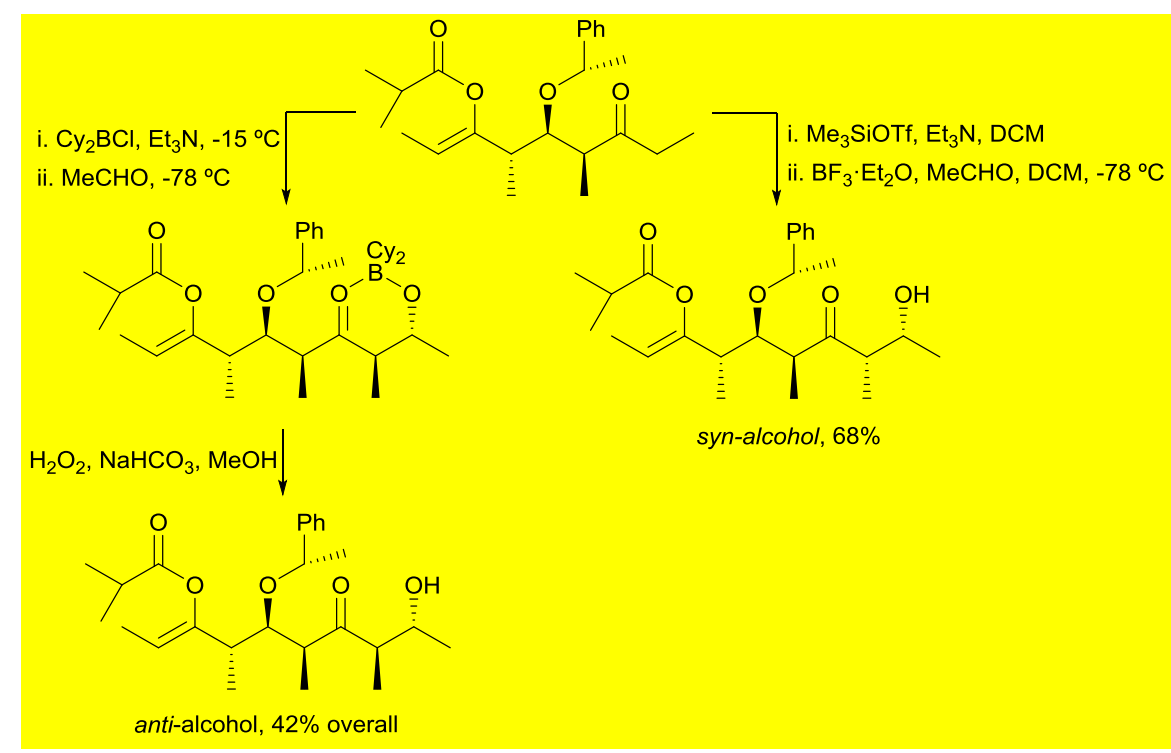

Scheme 78 Diastereodivergent routes to anti- and syn-aldols.

Diastereodivergent routes to trifluoromethylated $\mathrm{N}$-sulfinamides have been described by Shibata and co-workers ${ }^{124}$ by addition of fluorform to (Ss)-Nsulfinylimines. When the trifluoromethylation was performed using KHMDS as base, the corresponding $(S s, S)$-trifluoromethylated $N$-sulfinamides were mainly obtained (Scheme 79). On the other hand, using the Schwesinger base $\mathrm{P}_{4-t}-\mathrm{Bu}$ the diastereomeric $(S \mathrm{~s}, R)$-sulfinamides were mainly isolated. This reversal of 
diastereoselectivity was explained by a chelated and an open transition state I and II, respectively. The hydrolysis of the $\mathrm{CF}_{3}$-sulfinamides with $4 \mathrm{M} \mathrm{HCl}$ in methanol gave the corresponding enantiopure a-trifluoromethyl amines. This methodology has been applied to the synthesis of trifluoromethylated drug analogues NPS R-568 and cinacalcet.

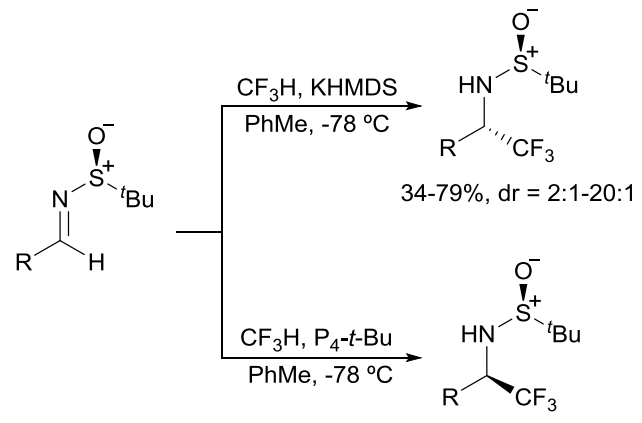

$\left[\mathrm{R}={ }^{t} \mathrm{Bu}, \mathrm{Ar}, \mathrm{PhCH}=\mathrm{CH}\right]$

$61-96 \%, d r=6: 1-48: 1$

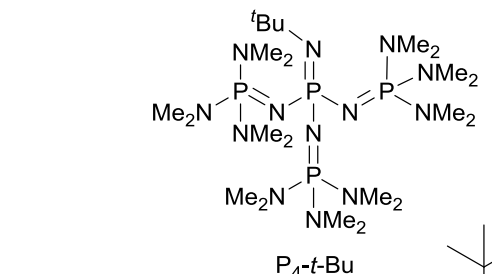

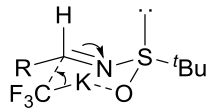

I

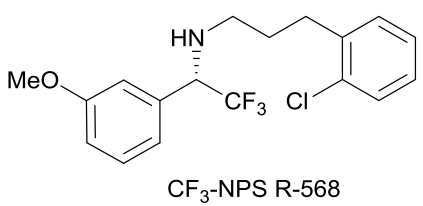

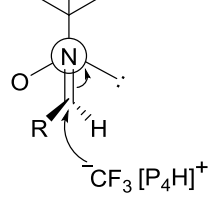

II

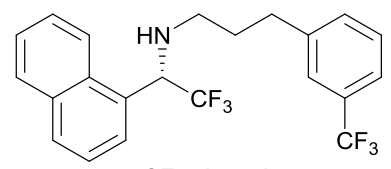

$\mathrm{CF}_{3}$-cinacalcet

Scheme 79 Diastereodivergent routes to trifluoromethylated $\mathrm{N}$-sulfinamides.

Bäckvall and co-workers ${ }^{125}$ reported diastereodivergent routes to enantiomerically pure cis- and trans-4-aminocyclohex-2-enols starting from cis$(1 R, 4 S)-4$-acetoxycyclohex-2-enol as common intermediate. The free hydroxy group of this acetate was protected as tetrahydropyranyl (THP) and the acetate group was hydrolyzed under basic conditions. The resulting alcohol was transformed into its 2,4-dichlorobenzoate ester, which was submitted to a Pdcatalyzed amination. Final removal of the THP group afforded cis-(1R,4S)-4aminocyclohex-2-enols (Scheme 80). For the synthesis of the trans-isomer the starting acetate was silylated, the acetate hydrolyzed, and the resulting hydroxy group was transformed into a chloride by mesylation and a $S_{\mathrm{N}} 2$ reaction with $\mathrm{LiCl}$. Deprotection of the silyl group and acetylation gave the trans-4-acetoxy-1- 
chlorocyclohexene, which was submitted to a Pd-catalyzed amination to afford after saponification trans- $(1 R, 4 R)$-4-aminocyclohex-2-enols.

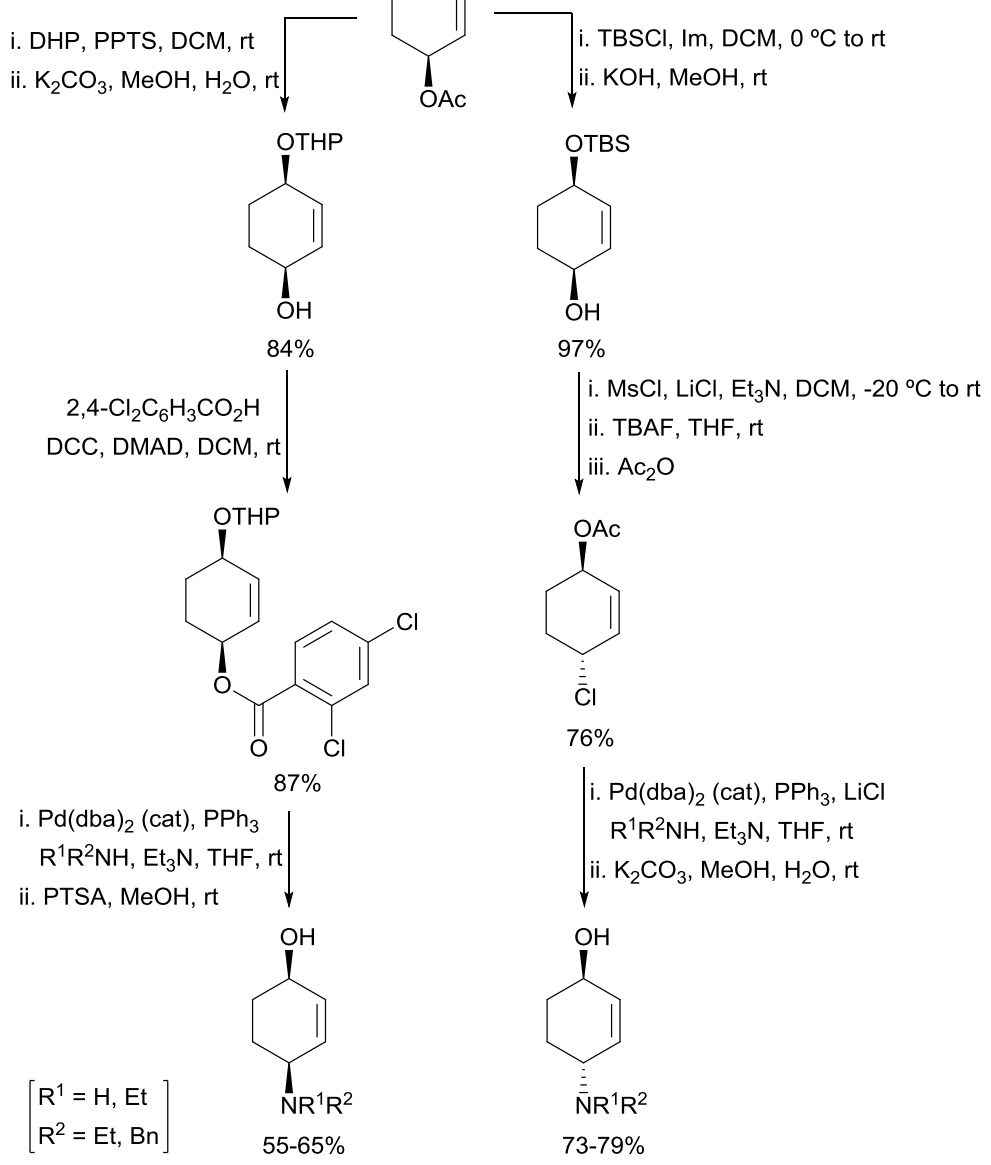

Scheme 80 Diastereodivergent routes to cis- $(1 R, 4 S)$ - and trans-(1R,4R)-4-aminocyclohex-2enols.

Diastereodivergent results were obtained by addition of ethylmagnesium bromide or diethylzinc to protected (S)-serinal by Andrés and Pedrosa. ${ }^{126}$ Thus, addition of diethylzinc gave the syn-amino alcohol, whereas ethylmagnesium bromide addition afforded the corresponding anti-isomer (Scheme 81). These products were further transformed into diastereomeric $\alpha$-amino- $\beta$ hydroxypentanol?? derivatives. 


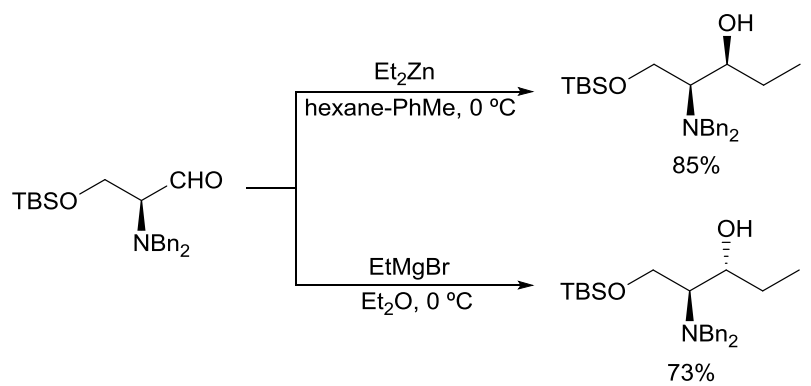

Scheme 81 Diastereodivergent routes to syn- and anti- $\beta$-amino alcohols.

1,2-Amino alcohols have been prepared using regioselective ring-opening of vinyl epoxides or vinyl aziridines employing diastereodivergent routes, by Somfai and co-workers. ${ }^{127}$ Aminolysis of vinyl epoxides under microwave (MW) irradiation afforded anti-amino alcohols, whereas Pd-catalyzed ring-opening in the presence of tosyl isocyanate gave oxazolidinones, which were detosylated and hydrolyzed to syn-amino alcohols (Scheme 82). In the case of vinyl aziridines, hydrolysis under acidic conditions gave anti-amino alcohols, while acylation of the $\mathrm{NH}$ group, followed by treatment of these aziridines with $\mathrm{BF}_{3}$ and final hydrolysis furnished syn-amino alcohols.
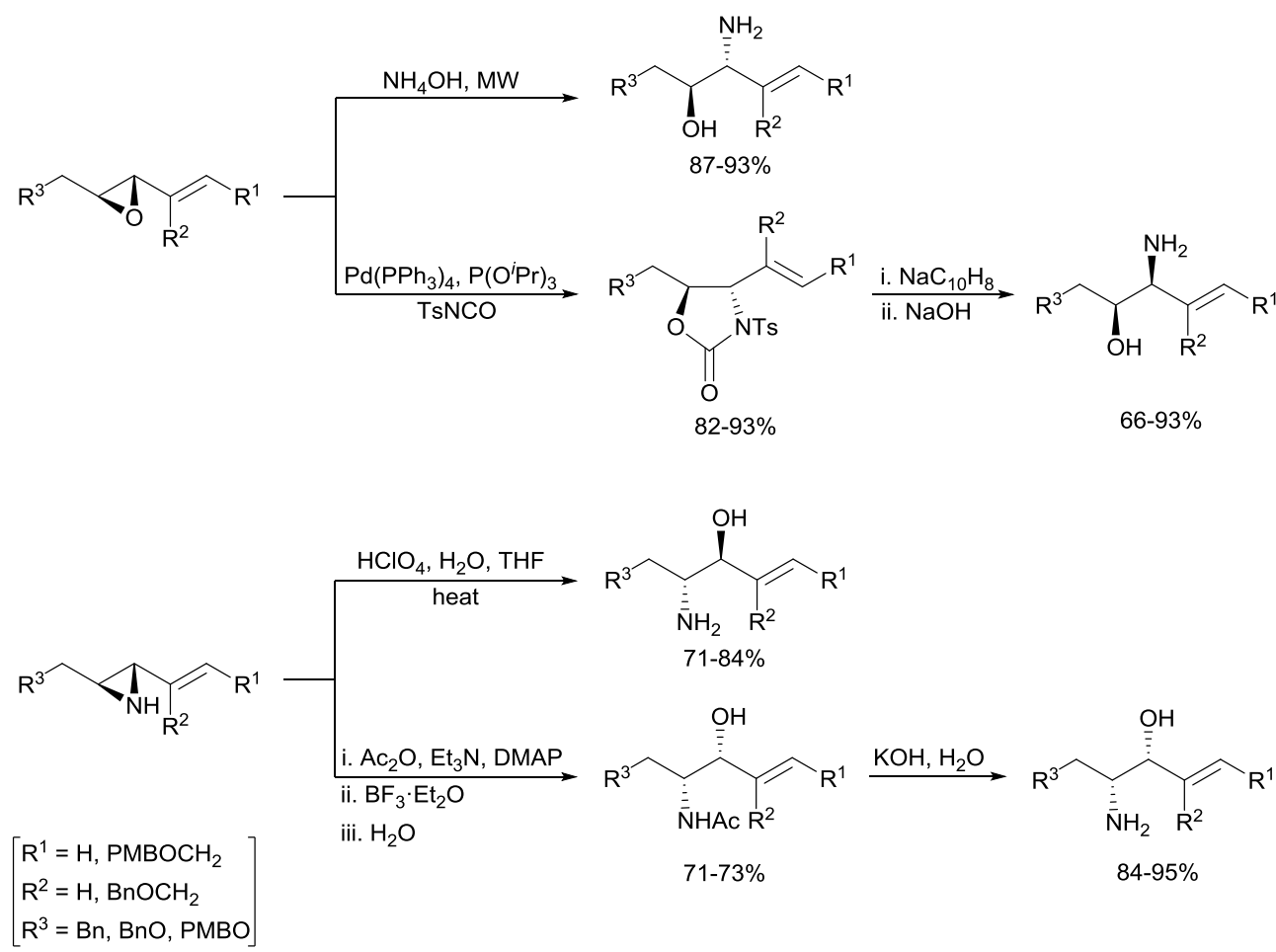

Scheme 82 Diastereodivergent routes to syn- and anti-2-amino alcohols.

Starting from (-)-menthone as chiral auxiliary, chiral alkene derivatives have been used for the enantiodivergent synthesis of $\beta$-amino alcohols by Spino and co-workers. ${ }^{128}$ In Scheme 83, enantiodivergent routes to protected 2-(1- 
naphthyl)-2-aminoethanol are illustrated. Desilylation of the allylic alcohol followed by Jones's oxidation and Curtius rearrangement provided an allylic carbonate, which after ozonolysis and reduction, gave the $(R)$-amino alcohol. For the synthesis of the $(S)$-enantiomer, the starting silylated allylic alcohol was submitted to ozonolysis and reduction to provide the monosilylated diol. Subsequent Curtius rearrangement and final desilylation furnished the carbamate derived from $(S)$-amino alcohol. These carbamates were further transformed into a-amino acids and oxazolidinones.

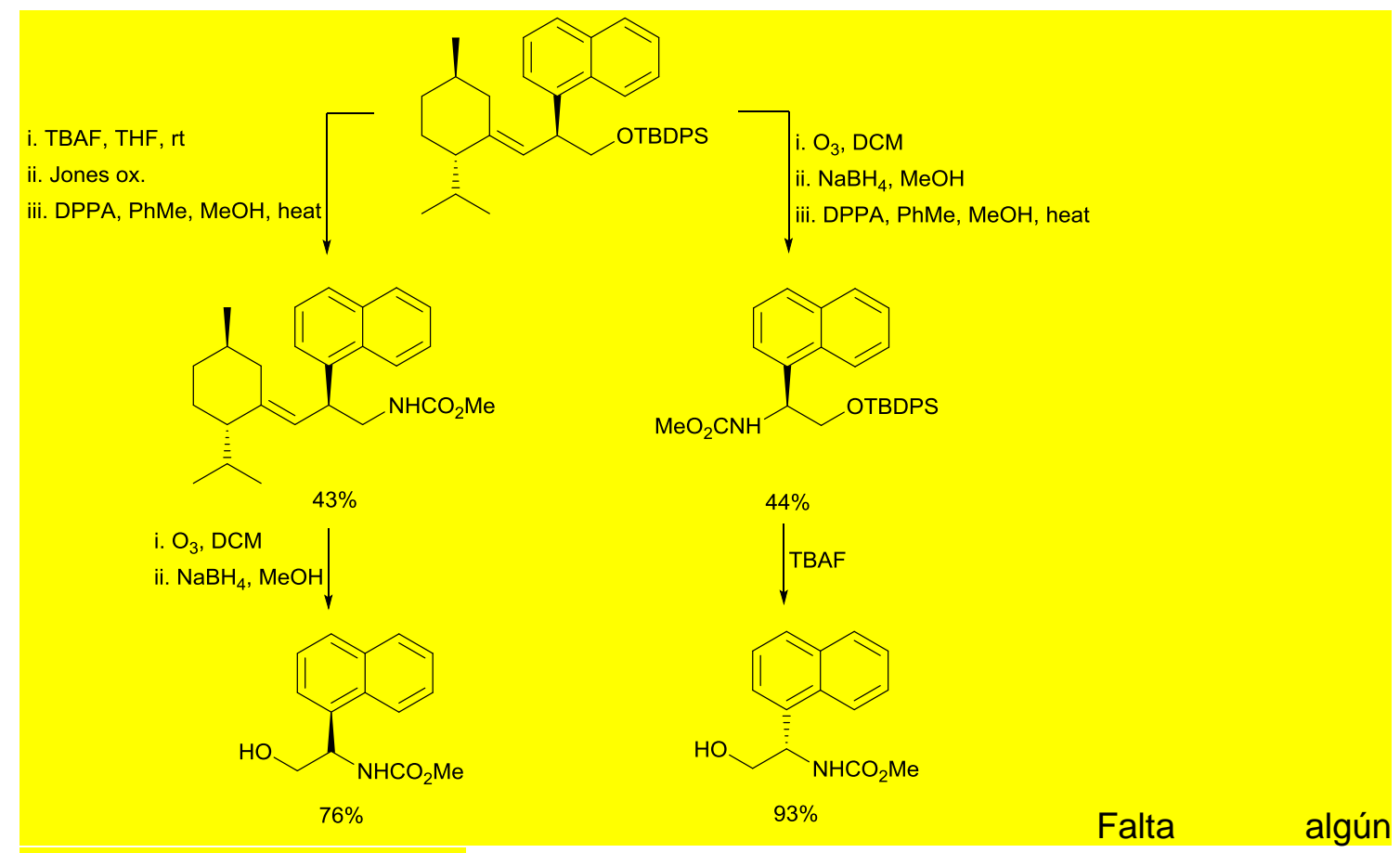

reactive $[\mathrm{O}]$ en la derecha??

Scheme 83 Enantiodivergent routes to carbamates derived from 2-(1-naphthyl)-2-aminoethanol.

Enantiodivergent routes to protected cyclobutene $\beta$-amino acids have been reported by Ortuño and co-workers ${ }^{129}$ starting from 1,2-cyclobutanecarboxylic half-ester. The $(1 R, 2 S)-\beta$-amino acid was prepared by Curtius rearrangement (Scheme 84). For the preparation of the corresponding enantiomer, a longer route was performed. Esterification of the carboxylic group followed by saponification of the methyl ester provided a tert-butyl half-ester, which was submitted to a Curtius rearrangement to afford a $\beta$-amino tert-butyl ester. Deprotection of the tert-butyl ester and esterification with diazomethane followed by Cbzdeprotection in the presence of (Boc) ${ }_{2} \mathrm{O}$ afforded methyl $(1 S, 2 R)$ - $\beta$-amino methylcyclobutanecarboxylate. 


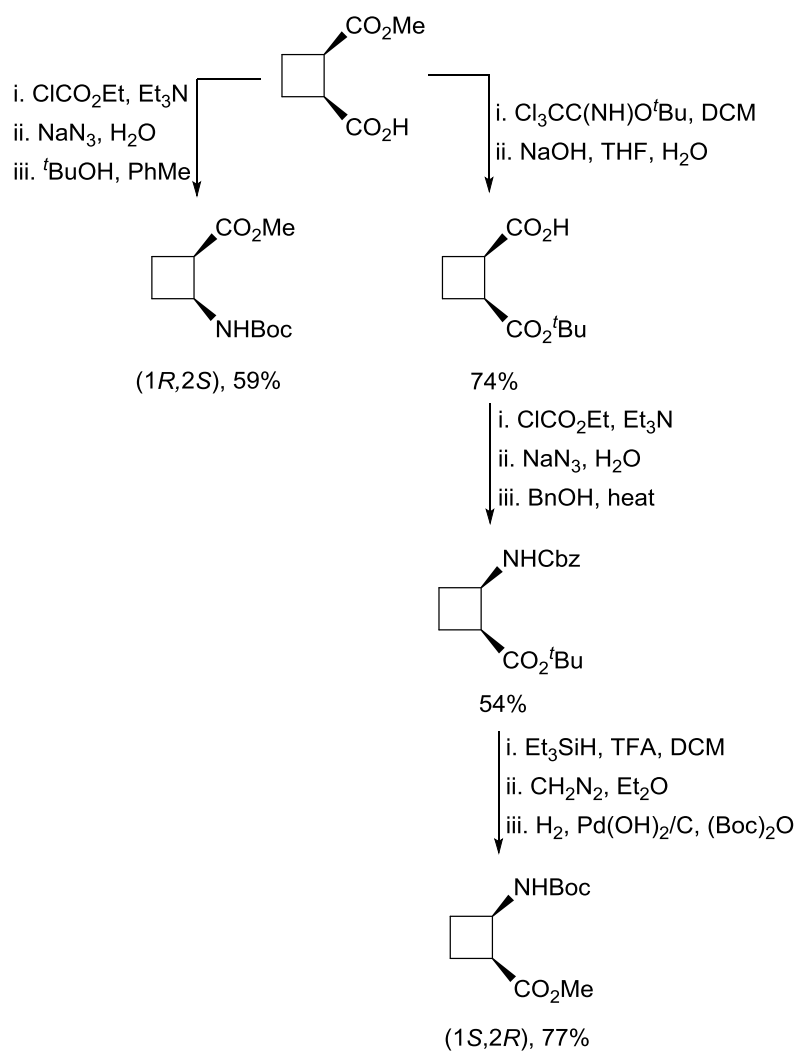

Scheme 84 Enantiodivergent routes to methyl $\mathrm{N}$-Boc-2-aminocyclobutanecarboxylates.

$\mathrm{\gamma}, \bar{\delta}$-Unsaturated carboxylic acids bearing a tertiary alcohol at the $\alpha$-position have been prepared by diastereodivergent Irelan-Claisen rearrangement studied by Zakarian and co-workers. ${ }^{130}$ Starting from $\alpha$-alkoxy-hydrocynnamic or lactic esters, and using KHMDS in toluene, the (Z)-enolate I was formed, which gave the syn- $\alpha, \beta$-disubstituted hex-4-enoic acids (Scheme 85). On the other hand, using LDA the $(E)$-enolate II is formed, the chelation-controlled enolate generation being overcome, so providing anti-diastereomers.

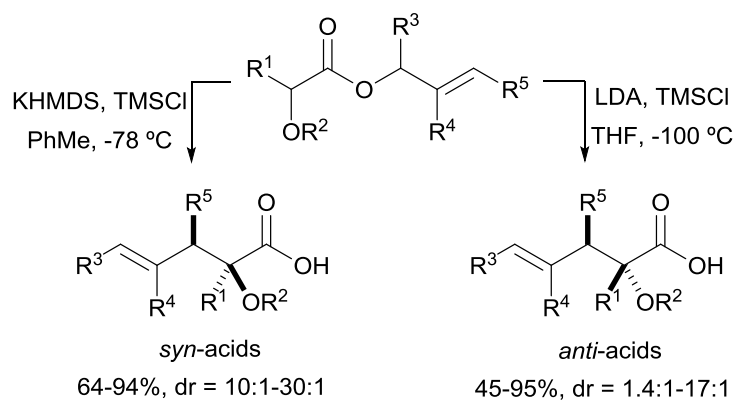

$$
\left[\begin{array}{l}
R^{1}=\mathrm{Me}, \mathrm{Bn} \\
\mathrm{R}^{2}=\mathrm{Me}, \mathrm{Bn} \\
\mathrm{R}^{3}=\mathrm{H}, \mathrm{Me},{ }^{n} \mathrm{Bu} \\
\mathrm{R}^{4}=\mathrm{H}, \mathrm{Me}
\end{array}\right.
$$$$
{ }_{\mathrm{R}^{1}}
$$$$
\text { II } R_{\mathrm{OR}^{2}}^{\mathrm{OLi}}
$$$$
\text { chelation control }
$$$$
\text { (Z)-enolate }
$$$$
\text { non-chelation control }
$$$$
\text { (E)-enolate }
$$ 
Scheme 85 Diastereodivergent routes to $\alpha$-alkoxy- $ү, \delta$-unsaturated carboxylic acids.

The Geissman-Waiss lactone is a useful intermediate in the synthesis of pyrrolizidine alkaloids. Thaning and Wistrand ${ }^{131}$ described enantiodivergent routes to this lactone from $O$-silylated 2-methoxy-3-hydroxy-1(methoxycarbonyl)pyrrolidine. The reaction with allyltrimethylsilane and $\mathrm{BF}_{3} \cdot \mathrm{Et}_{2} \mathrm{O}$ as Lewis acid gave, at room temperature, mainly the cis-isomer (Scheme 86). Ozonolysis of the allyl group at the 2-position of deprotected alcohol gave a hemiacetal, which was oxidized by $\mathrm{Ag}_{2} \mathrm{CO}_{3}$ on celite to the (-)-lactone, direct precursor of the Geissman-Waiss lactone by $\mathrm{N}$-deprotection under acidic conditions. The trans-2-allyl-3-hydroxypyrrolidine, mainly obtained at $-78^{\circ} \mathrm{C}$, was oxidized to the trans-aldehyde, which was oxidized to an acid with $\mathrm{PtO}_{2} / \mathrm{O}_{2}$ and under Mitsunobu conditions gave the (+)-lactone.

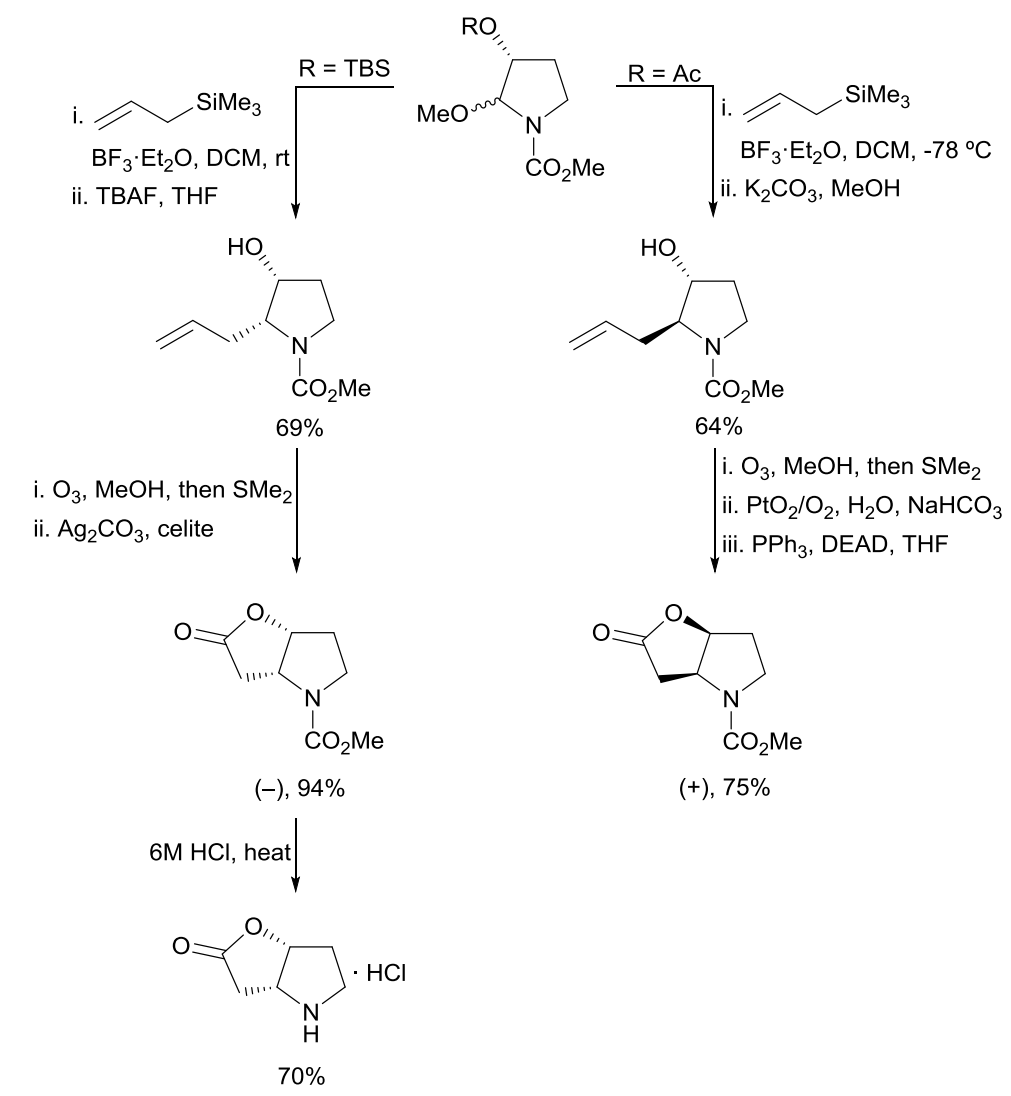

Scheme 86 Enantiodivergent routes to precursors of both Geissman-Waiss lactones.

Enantiodivergent routes to cis-2-methyl-5-hexanolide from $(E)-(2 S, 5 R)-5$ acetoxy-3-hexen-2-ol have been reported by Schink and Bäckvall. ${ }^{132}$ This lactone is the major component of the Carpenter bee Xylocopa hirutissima. The acetate group was displaced under Pd-catalysis by the anion of (phenylsulfonyl)nitromethane giving mainly the $(2 S, 5 R)$-isomer. Diimide reduction [potassium azodicarboxylate (PADA) and $\mathrm{AcOH}$ in DMSO] of the 
carbon-carbon double bond followed by ozonolysis in $\mathrm{MeOH}$ and final acidic treatment provided the (-)-lactone (Scheme 87). The preparation of the other enantiomer started by formation of the corresponding carbonate followed by Pdcatalyzed reaction with (phenylsulfonyl)nitromethane. After subsequent hydrolysis of the acetate group and cyclization, (+)-lactone was obtained as described above.

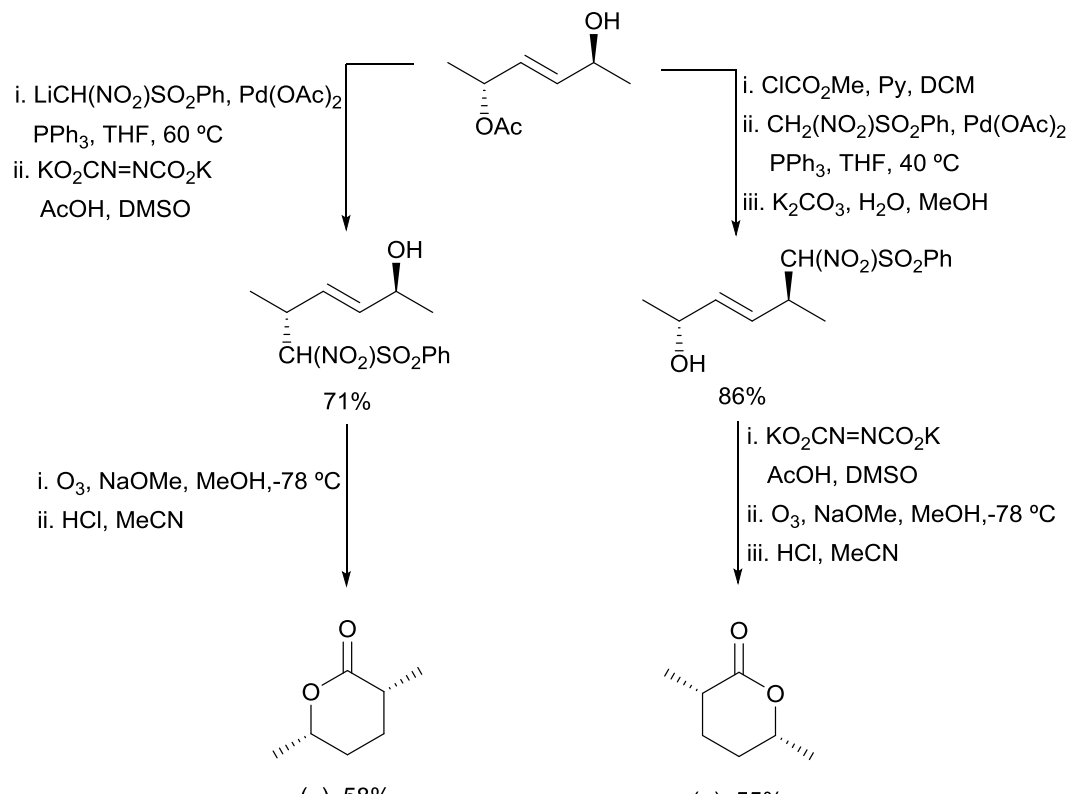

$(-), 58 \%$

$(+), 55 \%$

Scheme 87 Enantiodivergent routes to (-)- and (+)-cis-2-methyl-5-hexanolides.

Palladium-catalyzed lactonization reactions have been used for the diastereodivergent synthesis of lactones from cycloheptadienylacetyl acids by Bäckvall's group. ${ }^{133}$ For instance, (S)-cycloheptadienylacetic acid underwent trans-acetoxylactonization using $\mathrm{Pd}(\mathrm{OAc})_{2}$, $p$-benzoquinone and $\mathrm{AcOH}$, whereas in the presence of $\mathrm{LiCl}$ resulted cis-acetoxylactonization (Scheme 88). Similar results were obtained starting from $(R)$-cycloheptadienylacetic acid.

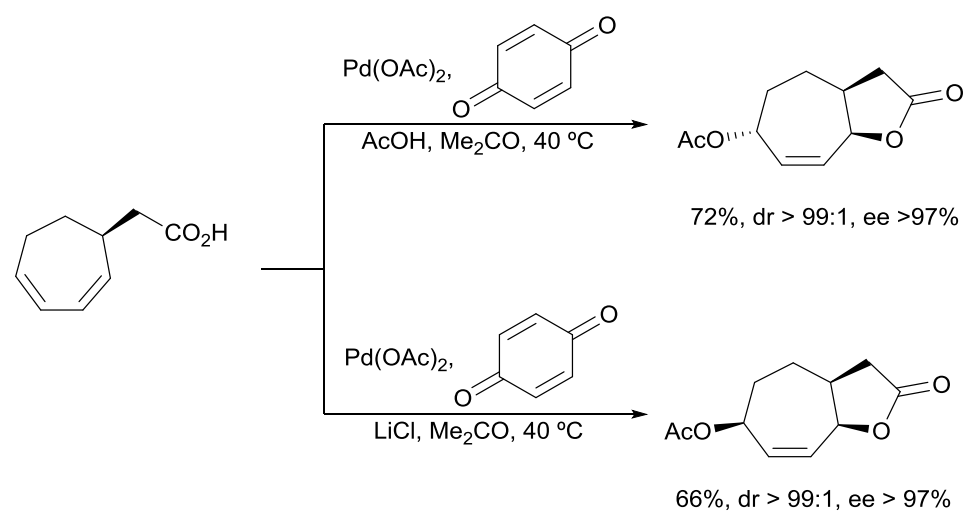

Scheme 88 Diastereodivergent routes to acetoxylactones. 
Optically active cis- and trans-6-benzyloxymethyl-4-hydroxytetrahydro-2pyrones have been prepared from a common (E)-allylic alcohol using diastereodivergent routes by Takano and co-workers. ${ }^{134}$ Asymmetric KatsukiSharpless epoxidation of the allylic alcohol gave the $(2 S, 3 S)$-epoxide as a single product. Chemoselective substitution of the primary alcohol to the corresponding phenyl sulfide was carried out with diphenyl disulfide and tri- $n$-butylphosphine. Treatment of this sulfide with an excess of $n$-BuLi induced the cleavage of the epoxide giving a 3:2 mixture of (E/Z)-3,5-dihydroxyalkenyl phenyl sulfides. Cyclization to an acetal took place with $\mathrm{Hg}(\mathrm{OAc})_{2} / \mathrm{HgO}$ in $\mathrm{MeOH}$ and after demercuration, and a sequential addition of $\mathrm{AcOH}$ and then NIS, the translactone was obtained (Scheme 89). To construct to cis-isomer the KatsukiSharpless epoxidation in the presence of diisopropyl D-tartrate provided the $(2 R, 3 R)$-epoxide. After the same treatment as before with $(\mathrm{PhS})_{2} / \mathrm{PPh}_{3}$, then $n$ BuLi and cyclization with $\mathrm{Hg}(\mathrm{OAc})_{2} / \mathrm{HgO}$, the diastereomeric cyclic acetal was formed. Finally, sequential hydrolysis and oxidation gave the cis-diastereomer.

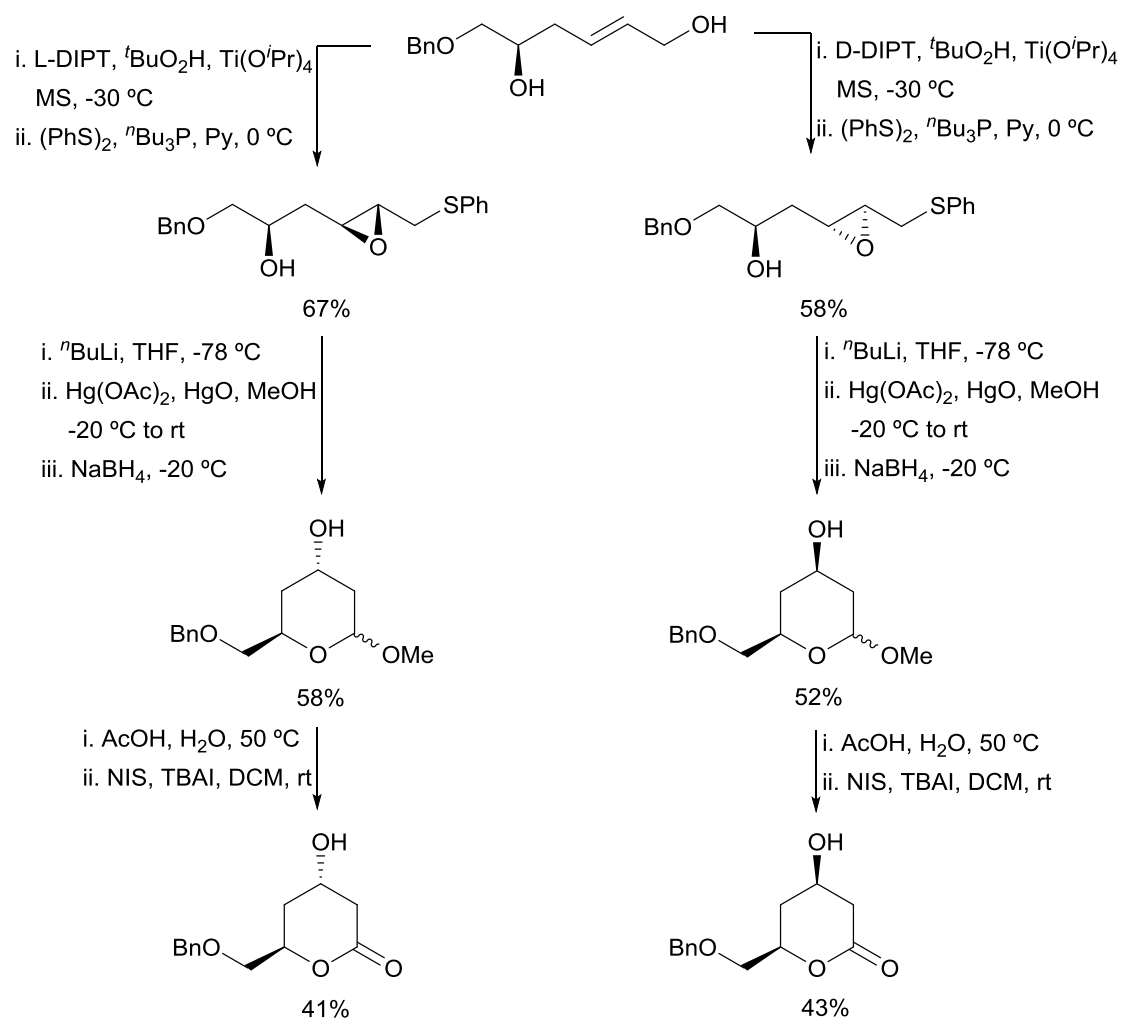

Scheme 89 Diastereodivergent routes to trans- and cis-6-benzyloxymethyl-4-hydroxytetrahydro2-pyrones.

Enantiodivergent routes to $\beta$-phenyl- $\gamma$-butyrolactones have been reported by Braun and co-workers ${ }^{135}$ from a bromo-substituted allyl alcohol. For the synthesis of the $(R)$-butyrolactone the bromo-allyl alcohol was dibrominated with $t$-BuLi and quenched with $\mathrm{MeOH}$, followed by transformation of the secondary 
alcohol into the corresponding carbonate (Scheme 90). Pd-catalyzed nucleophilic substitution with sodium diethyl malonate occurred with inversion of the configuration and Z/E-isomerization forming the syn-syn-m-allylpalladium intermediate I. Decarboxylation by means of $\mathrm{NaCN} / \mathrm{Lil}$ and hydrolysis with $\mathrm{LiOH}$ provided an acid, which after ozonolysis and $\mathrm{NaBH}_{4}$ reduction furnished the $(R)$ lactone. On the other hand, the enantiomeric butyrolactone was prepared by debromination of the starting alcohol with ${ }^{n} \mathrm{Bu} 3 \mathrm{SnH}$ under radical conditions, which led to the formation of the thermodynamically favored $(E)$-alcohol. Subsequent transformations as described above gave the (S)-lactone. The first route was carried out also with a 3-cyclopentyloxy-4-methoxyphenyl substituent (instead of the phenyl group) to give the $(R)$-lactone, which is the precursor of the antidepressant Rolipram ${ }^{\circledR}$.
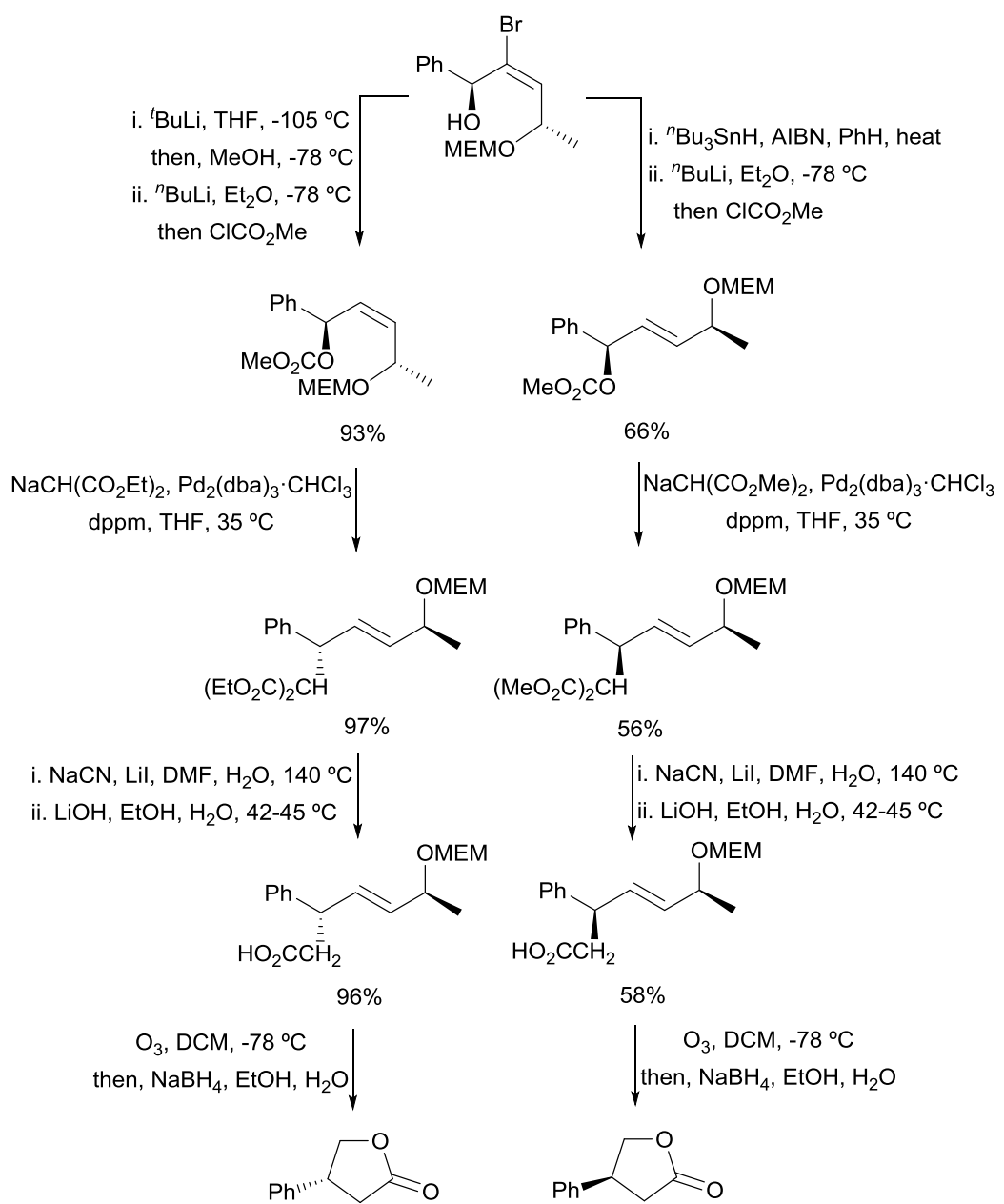

(R), $69 \%$

(S), $88 \%$

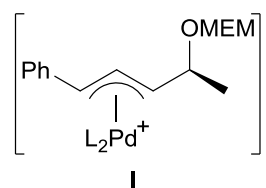

Scheme 90 Enantioselective routes to $(R)$ - and (S)- $\beta$-phenyl- - -butyrolactones. 
Starting from vinyl epoxides, prepared by a catalyzed diastereoselective epoxidation of aldehydes with sulfonium ylides, diastereodivergent routes to trans- and cis- $\beta$-hydroxy- $\alpha$-methylene $\gamma$-butyrolactones have been described by Metzner, Brière and co-workers. ${ }^{136}$ Lactonization of these epoxides under acidic conditions provides trans-lactones by epimerization of the carbocation and formation of a diol (Scheme 91). However, under Pd-catalyzed $\mathrm{CO}_{2}$ insertion an isomerization occurred giving cyclic trans-carbonates which, after hydrolysis to the syn-diol, were cyclized to cis-lactones under acidic conditions. This isomerization was explained by participation of $\pi$-allyl intermediates I and II.

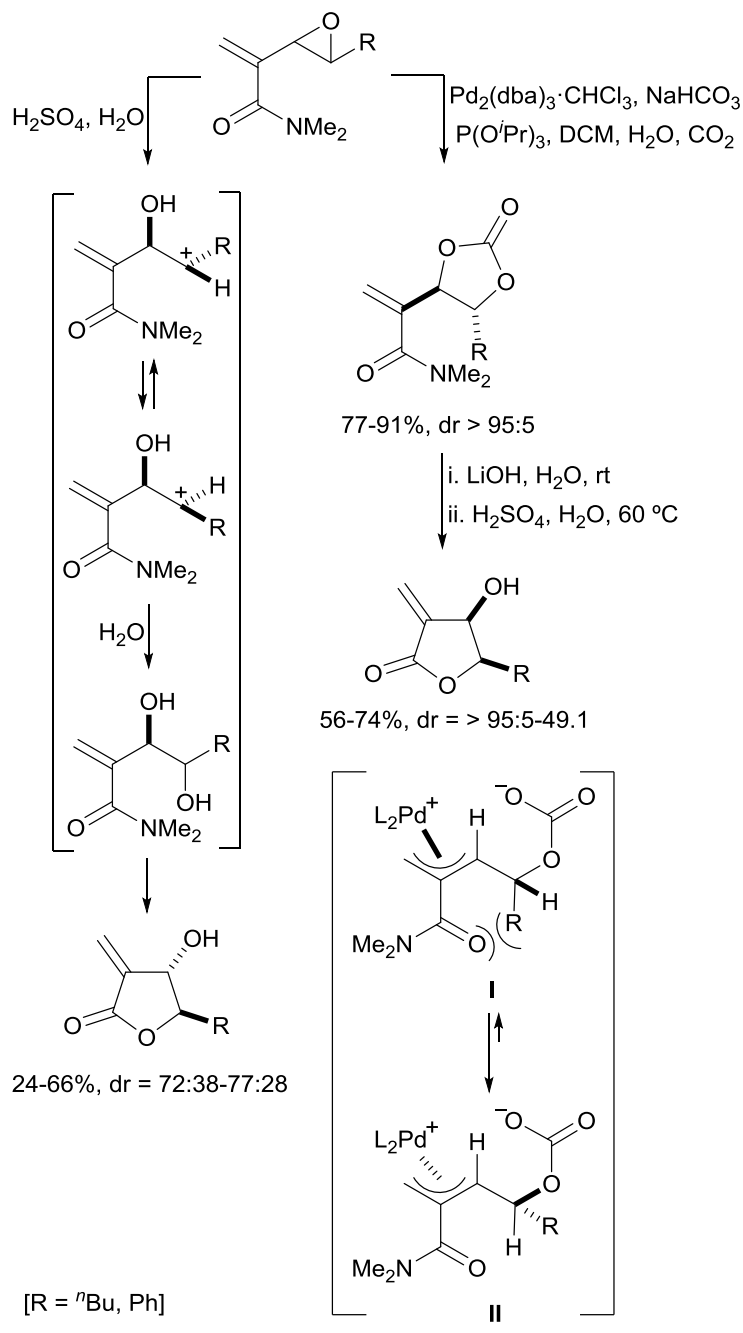

Scheme 91 Diastereodivergent routes to trans- and cis- $\beta$-hydroxy- $\alpha$-methylene- $\gamma$-butyrolactones.

Diastereodivergent routes to bromoiminolactones using electrochemical and chemical bromoiminolactonization of $\alpha$-allylmalonamides have been performed by Onamura and co-workers. ${ }^{137}$ Electrochemical lactonizations were carried out in the presence of $\mathrm{Zn}(\mathrm{OTf})_{2}$ and 2,2'-bipyridine using $\mathrm{Et}_{4} \mathrm{NBr}$ (TEAB) in DCM at room temperature (Scheme 92). For the chemical lactonization, NBS in toluene at room temperature was used. These iminolactones can be easily 
transformed into $y$-butyrolactones by treatment with oxalic acid in aqueous THF at room temperature.

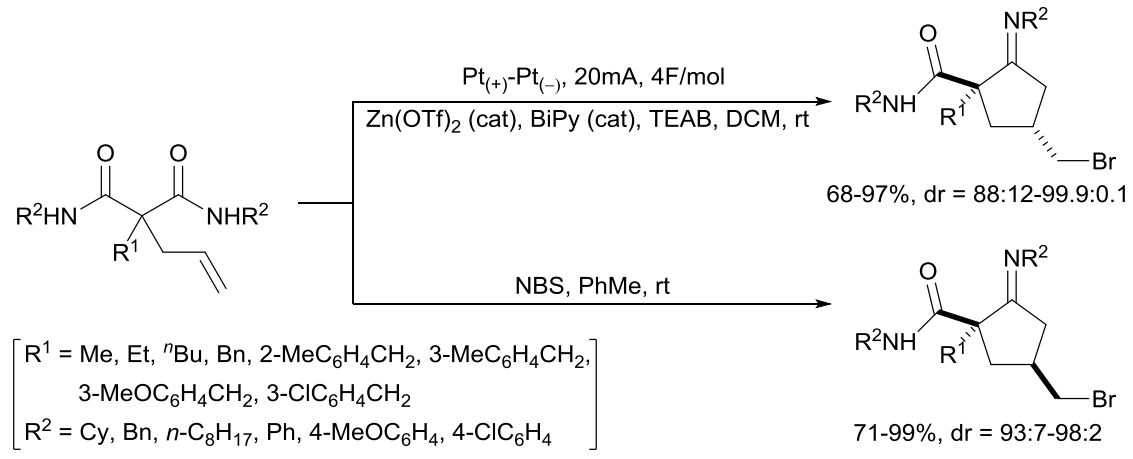

Scheme 92 Diastereodivergent routes to trans- and cis-bromoiminolactones.

2-Alkyl-2-p-tolylsulfinylacetonitriles were diastereodivergently alkylated using different reaction conditions by García Ruano, Martín-Castro and coworkers. ${ }^{138}$ Using NHMDS as base, the alkylation of the resulting carbanion gave mainly one diastereomer, whereas with KHDMS and 18-crown-6 ether opposite alkylation occurred (Scheme 93). This reversal diastereoselectivity in the quaternization process was explained by formation of carbanions I and II, a chelated pyramidal structure for the sodium of the benzylic carbanion and an almost planar naked carbanionic structure for the potassium benzylic carbanion in the presence of 18 -crown- 6 ether, respectively.

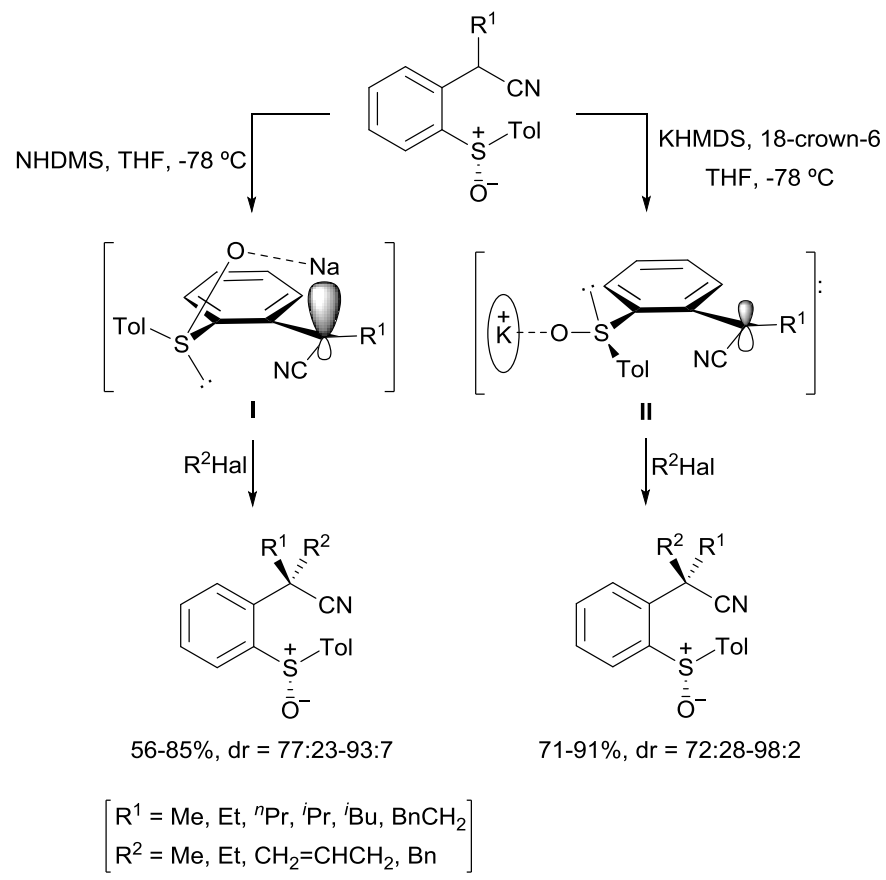

Scheme 93 Diastereodivergent routes to $\alpha, \alpha$-disubstituted $\alpha$-[2-(4-tolylsulfinyl)]acetonitriles. 
Enantiodivergent deprotonation/acylation of chiral $\alpha$-amino nitriles has been reported by Otani, Takeda and co-workers. ${ }^{139}$ Using NHMDS as base, the configuration of the $\alpha$-amino carbanion is kept after acylation with aroyl chlorides, while deprotonation with LDA promoted reversal of the configuration (Scheme 94). This base-dependent enantiodivergence has been explained by precomplexation of the electrophile to the countercation of the base to provide intermediates I and II, according to experimental and DFT calculations.

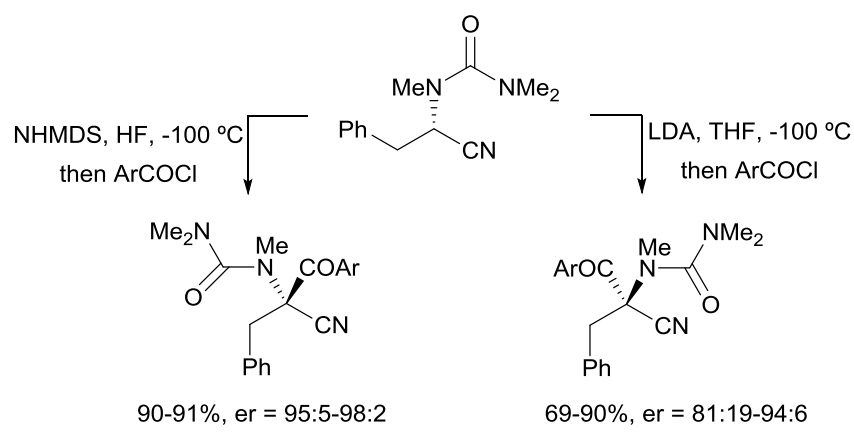

$\left[\mathrm{Ar}=4-\mathrm{MeOC}_{6} \mathrm{H}_{4}, 2-\mathrm{FC}_{6} \mathrm{H}_{4}, 2-\mathrm{ClC}_{6} \mathrm{H}_{4}\right]$
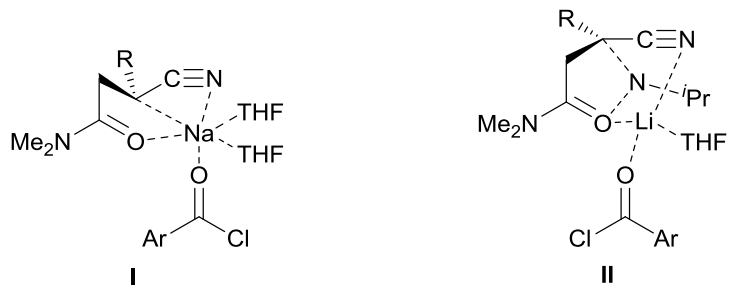

Scheme 94 Enantiodivergent routes to $N$-carbamoyl $\alpha$-aroyl-a-alkylamino nitriles.

\section{Conclusions}

In this review article, stereodivergent routes to marine natural products, lactones and other natural products are covered as well as heterocyclic and unnatural compounds. Among different methodologies to stereodivergent routes, it can be pointed out that hydroxy groups in a secondary stereocenters are epimerized mainly by (a) Mitsunobu reaction, (b) sulfonylation followed by $S_{N} 2$ reactions, and (c) oxidation to a ketone und further reduction with achiral hydrides or with chiral oxazoborolidines. In the case of allylic diols, Pd-catalyzed nucleophilic substitution can be modulated using different protecting groups. Starting from aldehydes, nucleophilic addition of organometallic reagents to give the corresponding secondary alcohols can be diastereodivergently carried out using Grignard or organozinc reagents. Stereodivergent preparation of epoxides is based mainly in the Katsuki-Sharpless epoxidation of the carbon-carbon double bond and starting from 1,2-diols by regioselective sulfonylation or Mitsunobu reactions and subsequent intramolecular nucleophilic substitution (DECIR AQUÍ ALGO SOBRE OXIDAC DEL CARBONILO REDUCCIÓN CON AYUDA DE GRUPO VECINO?. The ring opening of epoxides to provide alcohols is carried 
out with LAH or under dissolving metals. For the diastereodivergent preparation of $\beta$-functionalized alcohols, the nucleophile-promoted ring opening of epoxides is performed in the presence or absence of a Lewis acid or under Pd-catalysis. Stereodivergent lactonization routes are usually performed using Yamaguchi or Shiina methods and using inversion methodologies, such as the Mitsunobu reaction or using $S_{N} 2$ reactions by previous sulfonylation of the hydroxy group. Apart from well-known stereodivergent olefinations, such as Wittig, JuliaKocienski and Peterson reactions. New methodologies based on protodeborylation of allylboronates or potassium trifluoroborates and $\mathrm{S}_{\mathrm{N}}$ ' with organomagnesium or organozinc reagents of allylic benzoates have been recently described. $\beta$-Elimination of $\alpha$-phenylselenyl allylboronates promoted by MCPBA oxidation or methylation to forma selenonium intermediate followed by base-promoted elimination afforded the corresponding enantiomeric allenes. Allylic alcohols can be submitted to a hydroboration-oxidation process using 9$\mathrm{BBN}$ or $\mathrm{HB}(\mathrm{Sia}) 2$ to give either $(E)$ - or (Z)-allylic alcohols, respectively. In the case of propargylic alcohols, treatment with LAH gave the $(E)$-allylic alcohols whereas semihydrogenation the (Z)-isomers are mainly formed. Allylic esters derived from a-alkoxycarboxylic acids underwent enantiodivergent Irelan-Claisen rearrangement depending on the use of LDA or KHMDS. For the synthesis of polyketides, Peterson's conditions gave anti-aldols, whereas the Mukaiyama reaction using Evans conditions provided syn-diastereomers. Alkylation of chiral a-amino nitriles can be carried out enantiodivergently using LDA or NHDMS as base.

\section{Abbreviations}

AAA: asymmetric allylic alkylation

ABCC: 1,1'-azobis(cyclohexanecarbonitrile)

Ac: acetyl

AD: asymmetric dihydroxylation

AIBN: azobisisobutyronitrile

9-BBN: 9-borabicyclo[3.3.1]nonane

$\mathrm{BC}$ : breast cancer

BiPy: 2,2'-bipyridine

Bn: benzyl

Boc: tert-butoxycarbonyl

BOM: benzyloxymethyl

Bz: benzoyl

18-C-6: 18-crown-6 
CAN: cerium ammonium nitrate

cat: catalyst, catalytic amount

Cb: N,N'-diisopropylcarbamoyl

CBS: Corey-Bakshi-Shibata

Cbz: benzyloxycarbonyl

COX: cyclooxygenase

CSA: camphorsulfonic acid

Cy: cyclohexyl

dba: dibenzylideneacetone

DBU: 1,8-diazabicyclo[5.4.0]undec-7-ene

DCC: dicyclohexylcarbodiimide

DCE: 1,2-dichloroethane

DCl: carbonyldiimidazole

DCM: dichloromethane

DDQ: dichloro dicyano quinone

de: diastereomeric excess

DEAD: diethyl azodicarboxylate

DFT: density functional theory

DHP: dihydropyran

DIAD: diisopropylazodicarboxylate

DIBALH: diisopropylaluminum hydride

DIPA: diisopropylamine

DIPT: diisopropyl tartrate

DMAP: 4-dimethylaminopyridine

DMDO: dimethyldioxirane

DMF: dimethylformamide

DMP: Dess-Martin periodinane

DMPU: $N, N^{\prime}$-dimethylpropyleneurea

DMSO: dimethylsulfoxide

DPPA: diphenylphosphoryl azide 
dppm: bis(diphenylphosphino)methane

$\mathrm{dr}$ : diastereomeric ratio

ee: enantiomeric excess

er: enantiomeric ratio

exc: excess

Fr: 2-furoate

HC: hairy cells

Hex: hexyl

H-G: Hoveyda-Grubbs

HMPA: hexamethyl phosphoramide

HWE: Horner-Wadsworth-Emmons

IBX: 2-iodoxybenzoic acid

$\lg \mathrm{E}$ : immunoglobulin $\mathrm{E}$

Im: imidazole

KB: epidermoid carcinoma

KHMDS: potassium hexamethyldisilazide

L: ligand

LAH: lithium aluminum hydride

LHMDS: lithium hexamethyldisilazide

MCPBA: meta-chloroperbenzoic acid

MEM: 2-methoxyethoxymethyl

MMPA: bis(monoperoxy phthalate)

MNBA: 2-methyl-6-nitrobenzoic anhydride

MOM: methoxymethyl

Ms: mesyl, methanesulfonyl

MS: molecular sieves

MW: microwaves

NBS: N-bromosuccinimide

NHMDS: sodium bis(trimethylsilyl)amide

NIS: $N$-iodosuccinimide

NMO: morpholine $\mathrm{N}$-oxide 
nr: no reported

ox: oxidation

PADA: potassium azodicarboxylate

PDC: pyridinium dichromate

Pent: pentyl

PHMS: poly(methylhydroxysilane)

pin: pinacolate

Piv: pivaloyl

PLE: pancreatic liver estearase

PMB: para-methoxybenzyl

PMP: para-methoxyphenyl

PNBA: para-nitrobenzoic acid

PPTS: pyridinium para-toluenesulfonate

PTSA: para-toluenesulfonic acid

Py: pyridine

Pybox: pyridine-2,6-bis(oxazoline)

Ra-Ni: Raney nickel

$\mathrm{RCM}$ : ring closing metathesis

ref: reference

rt: room temperature

SEM: [2-(trimethylsilyl)ethoxy]methyl

Sia: siamyl

sp.: species pluralis

TBAF: tetra- $n$-butylammonium fluoride

TBAI: tetra- $n$-butylammonium iodide

TBDPS: tert-butyldiphenylsilyl

TBHP: tert-butyl hydroperoxide

TBS: tert-butyldimethylsilyl

TCA: trichloroacetyl

TEAB: tetraethylammonium bromide

TEMPO: (2,2,6,6-tetramethylpiperidin-1-yl)oxyl 
TES: triethylsilyl

Tet: 1-phenyl-1 $H$-tetrazol-5-yl

Tf: triflic, trifluoromethylsulfonyl

TFA: trifluoroacetic acid

TFAA: trifluoroacetic anhydride

THF: tetrahydrofuran

THP: tetrahydropyranyl

THS: dimethylhexylsilyl

TMG: tetramethylguanidine

TMS: trimethylsilyl

Tol: 4-methylphenyl

TPAP: tetrapropylammonium perruthenate

Tris: 2,4,6-triisopropylbenzenesulfonyl

Ts: tosyl, 4-methylphenylsulfonyl

Conflict of interest

There are no conflicts to declare.

\section{Acknowledgements}

We thank to the the Spanish Ministerio de Economía, Industria y Competitividad, Agencia Estatal de Investigación (AEI) and Fondo Europeo de Desarrollo Regional (FEDER, EU) (projects CTQ2016-76782-P, CTQ2016-81797-REDC, and CTQ2017-85093-P), the Generalitat Valenciana (PROMETEOII/ 2014/017) and the University of Alicante for financial support.

\section{References}

1. C. Nájera, F. Foubelo, J. M. Sansano and M. Yus, Org. Biomol. Chem., submitted.

2. J. T. Jimenez, M. Šturdikovd and E. Šturdík, Acta Chim. Slovaca, 2009, 2, 63.

3. M. Kanto and M. Sasaki, Org. Lett., 2016, 18, 112. 
4. M. Kanto, S. Sato, M. Tsuda and M. Sasaki, J. Org. Chem., 2016, 81, 9105.

5. G. Pazos, M. Pérez, Z. Gándara, G. Gómez and Y. Fall, Tetrahedron, 2012, 68, 8994.

6. M. C. Carreño, R. Des Mazery, A. Urbano, F. Colobert and G. Solladié, Org. Lett., 2005, 7, 2039.

7. N. C. Eichenauer, R. Tscheirsich and J. Pietruszka, J. Nat. Prod., 2015, 78, 2782.

8. R. Towada, Y. Kurashina and S. Kuwahara, Tetrahedron Lett., 2013, 54, 6878.

9. S. Z. Y. Ting, L. J. Baird, E. Dunn, P. Hanna, D. Leahy, A. Chan, J. H. Miller, P. H. Teesdale-Spittle and J. E. Harvey, Tetrahedron, 2013, 69, 10581.

10. H. Takamura, H. Wada, M. Ogino, T. Kikuchi, I. Kadota and D. Uemura, J. Org. Chem., 2015, 80, 3111.

11. S. E. Denmark, J. H.-C. Liu and J. M. Muhuhi, J. Org. Chem., 2011, 76, 201.

12. N. K. Garg, D. D. Caspi and B. M. Stoltz, J. Am. Chem. Soc., 2005, 127, 5970.

13. T. Honda and T. Ogino, Tetrahedron: Asymmetry, 1998, 9, 2663.

14. T. Bando and K. Shishido, J. Chem. Soc., Chem. Commun., 1996, 1357.

15. B. M. Trost and G. Dong, Chem.-Eur. J., 2009, 15, 6910.

16. S. S. C. Koch and A. R. Chamberlin in Enantiomerically Pure $\mathrm{Y}^{-}$ Butyrolactones in Natural Products Synthesis, Atta-ur-Rahman, Ed., Elsevier Science: Amsterdam, 1995, p 687.

17. K. Suzuki, M. Shoji, E. Kobayashi and K. Inomata, Tetrahedron, 2001, 12, 2789.

18. S. Takano, A. Kurotaki and K. Ogasawara, Synthesis, 1987, 1075.

19. (a) V. Popsavin, I. Kristić and M. Popsavin, Tetrahedron Lett., 2003, 44, 8897; (b) V. Popsavin, I. Kristić, M. Popsavin, B. Srećo, G. Benedeković, V. Kofić and G. Bogdanović, Tetrahedron, 2006, 62, 11044.

20. (a) M. Popsavin, V. Popsavin, N. Vukojević and D. Miljković, Collect. Czech Chem. Commun., 1994, 59, 1884; (b) W. Szeja, Pol. J. Chem., 1980, 54, 1323.

21. M. Saniere, I. Charvet, Y. Le Merrer and J.-C. Depezay, Tetrahedron, 1995, 51, 1653. 
22. (a) V. Popsavin, G. Benedeković, B. Srećo, M. Popsavin, J. Francuz, V. Kojić and G. Bogdanović, Org. Lett., 2007, 9, 4235; (b) V. Popsavin, G. Benedeković, B. Srećo, J. Francuz, M. Popsavin, V. Kojić, G. Bogdanović and V. Divjaković, Tetrahedron, 2009, 65, 10596.

23. R. Bandichhor, B. Nasse and O. Reiser, Top. Curr. Chem., 2005, 243, 43.

24. M. Gosh, S. Bose. S. Maity and S. Ghosh, Tetrahedron Lett., 2009, 50, 7102.

25. (a) K. Matcha and S. Ghosh, Tetrahedron Lett., 2008, 49, 3433; (b) S. Banerjee, S. Ghosh, S. Sinha and S. Ghosh, J. Org. Chem., 2005, 70, 4199.

26. C. D. Donner, Synthesis, 2010, 415.

27. (a) G. A. Kraus, J. Li, M. S. Gordon and J. H. Jensen, J. Am. Chem. Soc., 1993, 115, 5859; (b) G. A. Kraus, J. Li, M. S. Gordon and J. H. Jensen, J. Org. Chem., 1995, 60, 1154.

28. J.-P. Gesson, J.-C. Jacquesy and M. Mondon, Tetrahedron, 1989, 45, 2627.

29. D. Hurem and T. Dudding, RSC Adv., 2014, 4, 15552.

30. A. Parenty, X. Moreau and J.-M. Campagne, Chem. Rev., 2006, 106, 911.

31. F. Bracher and B. Schulte, J. Chem. Soc., Perkin Trans. 1, 1996, 2619.

32. H. Gerlach and A. Thalmann, Helv. Chim. Acta, 1977, 60, 2866.

33. F. Bracher and B. Schulte, Liebigs Ann./Recueil, 1997, 1979.

34. F. Bracher and J. Krauß, Eur. J. Org. Chem., 2001, 4701.

35. K. R. Prasad, V. R. Gandi, J. E. Nidhiry and K. S. Bhat, Synthesis, 2010, 2521.

36. C. V. Ramana, M. A. Mondal, V. G. Purani and M. K. Gurjar, Tetrahedron Lett., 2007, 48, 7524.

37. J. Popsil, C. Müller and A. Fürstner, Chem.-Eur. J., 2009, 15, 5956.

38. K. R. Prasad and K. Ponchalaiah, Tetrahedron, 2011, 67, 4268.

39. A. H. Al-Hakim, A. H. Haines and C. Morley, Synthesis, 1985, 207.

40. K. R. Prasad and K. Ponchalaiah, Tetrahedron: Asymmetry, 2010, 21, 2853.

41. P. Davoli, F. Fava, S. Morandi, A. Spaggiari and F. Prati, Tetrahedron, 2005, 61, 4427. 
42. N. Kanoh, A. Kawamata, T. Itagaki, Y. Mizayaki, K. Yahata, E. Kwon and Y. Iwabuchi, Org. Lett., 2014, 16, 5216.

43. (a) M. T. Crimmins and F. Caussanel, J. Am. Chem. Soc., 2006, 128, 3128; (b) J. S. Yadav, S. K. Das and G. Sabitha, J. Org. Chem., 2012, 77, 11109.

44. H. Nakano, A. Sugawara, T. Hirose, H. Gouda, S. Hirono, S. Ömura and T. Sunazuka, Tetrahedron, 2015, 71, 6569.

45. S.-M. Paek, Molecules, 2014, 19, 15982.

46. C. Häcker and B. Plietker, J. Org. Chem., 2015, 80, 8055.

47. L. Shiina, M. Kubota and R. Ibuka, Tetrahedron Lett., 2002, 43, 7535.

48. J. Li, J. Xing, D. Lücke, D. Lübken, L. Millbrodt, R. R. Plentz and M. Kalesse, Synthesis, 2018, 50, 529.

49. A. Machara, J. Křivánek, K. Dolejšová, J. Havličková, L. Bednárová, R. Hanus, P. Majer and P. Kyjaková, J. Nat. Prod., 2018, 81, 2266.

50. K. Simizu and K. Ogasawara, Chem. Lett., 1995, 543.

51. N. Maezaki, N. Kojima, M. Asai, H. Tominaga and T. Tanaka, Org. Lett., 2002, 4, 2977.

52. N. Maezaki, N. Kojima, H. Tominaga, M. Yanai and T. Tanaka, Org. Lett., 2003, 5, 1411.

53. B. Schmidt and F. Hölter, Chem.-Eur. J., 2009, 15, 11948.

54. K. Kubota and J. L. Leighton, Angew. Chem., Int. Ed., 2003, 42, 946.

55. S. Takano, M. Yanase, M. Takahashi and K. Ogasawara, Chem. Lett., 1987, 2017.

56. J. W. Huffman, H. H. Joyner, M. D. Lee, R. D. Jordan and W. T. Pennington, J. Org. Chem., 1991, 56, 2081.

57. F.-P. Montforts, I. Gesing-Zibulak and W. Grammenos, Helv. Chim. Acta, 1989, 72, 1852.

58. S. Akai, T. Tsujino, N. Fukuda, K. Lio, Y. Takeda, K. Kawaguchi, T. Naka, K. Higuchi and Y. Kita, Org. Lett., 2001, 3, 4015.

59. A. L. E. Larsson, R. G. P. Gatti and J. E. Bäckvall, J. Chem. Soc., Perkin Trans. 1, 1997, 2873.

60. (a) J. E. Bäckvall, J. E. Nyström and S. E. Nordberg, J. Am. Chem. Soc., 1985, 107, 3676; (b) J. Vågberg and J. E. Bäckvall, Org. Synth., 1990, $69,38$.

61. J. M. Andrés and R. Pedrosa, Tetrahedron: Asymmetry, 1998, 9, 2493. 
62. (a) J. M. Andrés and R. Pedrosa, Tetrahedron, 1998, 54, 5607; (b) T. Laïb, J. Chastanet and J. Zhu, J. Org. Chem., 1998, 63, 1709.

63. N. Khiar, K. Singh, M. García and M. Martín-Lomas, Tetrahedron Lett., 1999, 40, 5779.

64. B. Olofsson and P. Somfai, J. Org. Chem., 2003, 68, 2514.

65. U. Jahn, J. M. Galano and T. Durand, Angew. Chem., Int. Ed., 2008, 47, 5894.

66. T. O. Schrader and M. L. Snapper, J. Am. Chem. Soc., 2002, 124, 10998.

67. D. F. Taber, P. Gu and R. Li, J. Org. Chem., 2009, 74, 5516.

68. (a) H. Beiderbeck, K. Taraz, H. Budzikiewicz and A. E. Walsby, Z. Naturforsch., 2000, 55c, 681; (b) Y. Itou, S. Okada and M. Murakami, Tetrahedron, 2001, 57, 9093.

69. K. Gademann and Y. Bethuel, Org. Lett., 2004, 6, 4707.

70. K. Prasad and P. Anbarasan, Tetrahedron, 2006, 62, 8303.

71. W. Francke, F. Schroder, P. Philipp, H. Meyer, V. Sinnwell and G. Gries, Bioorg. Med. Chem., 1996, 4, 363.

72. F. Fullas, D. M. Brown, M. C. Wani, M. E. Wall, T. E. Chagwedera, N. R. Farnsworth, J. M. Pezzuto and A. D. Kinghorn, J. Nat. Prod., 1995, 58, 1625.

73. H. Takamura, H. Wada, N. Lu, O. Ohno, K. Suenaga and I. Kadota, J. Org. Chem., 2013, 78, 2443.

74. B. Ananthan, W.-C. Chang, J.-S. Lin, P.-H. Li and T.-H. Yan, J. Org. Chem., 2014, 79, 2898.

75. B. A. Bierl, M. Beroza and C. W. Collier, Science, 1970, 170, 87.

76. K. R. Prasad and P. Anbarasan, J. Org. Chem., 2007, 72, 3155.

77. Y. Garg, A. K. Tiwari and S. K. Pandey, Tetrahedron Lett., 2017, 58, 3344.

78. P. Castejón, M. Pastó, A. Moyano, M. A. Pericás and A. Riera, Tetrahedron Lett., 1995, 36, 3019.

79. T. Kamikubo and K. Ogasawara, Tetrahedron Lett., 1995, 36, 1685.

80. M. Labora, E. M. Pandolfi and V. Shapiro, Tetrahedron: Asymmetry, 2010, 21, 153.

81. D. M. Pinkerton, M. G. Banwell and A. C. Willis, Org. Lett., 2009, 11, 4290. 
82. (a) G. Wuitschik, M. Roger-Evans, K. Müller, H. Fischer, B. Wagner, F. Schuler, L. Polonchuk and E. M. Carreira, Angew. Chem., Int. Ed. Engl., 2006, 45, 7736; (b) G. Wuitschik, E. M. Carreira, B. Wagner, H. Fischer, I. Parrilla, F. Schuler, M. Rogers-Evans and K. Müller, J. Med. Chem., 2010, 53, 3227.

83. R. Sharma and L. J. Williams, Org. Lett., 2013, 15, 2202.

84. J. P. Wolfe and M. B. Hay, Tetrahedron, 2007, 63, 261.

85. E. Brenna, M. Crotti, F. G. Gatti, L. Marinoni, D. Monti and S. Quaiato, J. Org. Chem., 2017, 82, 2114.

86. P. A. Evans, D. K. Leahy, W. J. Andrews and D. Uraguchi, Angew. Chem., Int. Ed., 2004, 43, 4788.

87. P.-A. Nocquet, A. Macé, F. Legros, J. Lebreton, G. Dujardin, S. Collet, A. Martel, B. Carboni and F. Carreaux, Beilstein J. Org. Chem., 2018, 14, 2949.

88. K. A. Parker and W. Chang, Org. Lett., 2005, 7, 1785.

89. M. P. Collis and P. Perlmutter, Tetrahedron: Asymmetry, 1996, 7, 2177.

90. The Organic Chemistry of $\beta$-Lactams, G. I. Georg, Ed.; VCH: Weinheim, 1993.

91. C. Palomo in Recent. Prog. Chem. Synth. Antibiot., G. Lukacs and M. Ohno, Eds.; Springer: Berlin, 1990, p 565.

92. T. B. Bisol, A. J. Bortoluzzi and M. M. Sá, J. Org. Chem., 2011, 76, 948.

93. S. J. Brickner, D. K. Hutchinson, M. R. Barbachyn, P. R. Manninen, D. A. Ulanowicz, S. A. Garmon, K. C. Grega, S. K. Hendges, D. S. Toops, C. W. Ford and G. E. Zurenko, J. Med. Chem., 1996, 39, 673.

94. J. R. Gage, W. R. Perrault, T.-J. Poel and R. C. Thomas, Tetrahedron Lett., 2000, 41, 4301.

95. A. K. Ghosh, P. Mathivanan and J. Cappiello, Tetrahedron: Asymmetry, 1998, 9, 1.

96. G. Desimoni, G. Faita and M. Mella, Tetrahedron, 1996, 52, 13649.

97. G. Desimoni, G. Faita, M. Guala and C. Pratelli, Tetrahedron: Asymmetry, 2002, 13, 1651.

98. C. Pays and P. Manganey, Tetrahedron Lett., 2001, 42, 589.

99. X. Yuan, S.-J. Zhang, W. Du and Y.-C. Chen, Chem.-Eur. J., 2016, 22, 11048.

100. (a) B. E. Maryanoff and A. B. Reitz, Chem. Rev., 1989, 89, 863; (b) K. C. Nicolau, M. W. Härter, J. L. Gunzner and A. Nadin, Liebigs Ann./Recueil, 1997, 1283. 
101. L. F. van Standen, D. Gravestock and D. J. Ager, Chem. Soc. Rev., 2002, 31, 195.

102. (a) P. R. Blackemore, J. Chem. Soc., Perkin Trans. 1, 2002, 2563; (b) C. Aïssa, Eur. J. Org. Chem., 2009, 1831.

103. M. J. Hesse, C. P. Butts, C. L. Willis and V. K. Aggarwal, Angew. Chem., Int. Ed., 2012, 51, 12444.

104. S. Schweizer, C. Tresse, P. Bisseret, J. Lalevée, G. Evano and N. Blanchard, Org. Lett., 2015, 17, 1794.

105. T. Enokido, K. Fugami, M. Endo, M. Kameyama and M. Kosugi, Adv. Synth. Catal., 2004, 346, 1685.

106. B. Górski, D. Bassiak, L. Grzesinski and M. Barbasiewicz, Org. Biomol. Chem., 2019, 17, 7660.

107. S. Specklin, J. Fenneteau, P. Subramanian and J. Cossy, Chem.- Eur. J., 2018, 24, 332.

108. R. J. Armstrong, M. Nandakumar, R. M. P. Dias, A. Noble, E. L. Myers and V. K: Aggarwal, Angew. Chem., Int. Ed., 2018, 57, 8203.

109. B. Breit, P. Demel, D. Grauer and C. Studte, Chem.-Asian J., 2006, 1, 586.

110. S. R. Roy, D. Didier, A. Kleiner and I. Marek, Chem. Sci., 2016, 7, 5989.

111. (a) S. Patai and Z. Rappoport, The Chemistry of the Cyclopropyl Group, Wiley \& Sons: New York, 1987; (b) W. A. Donaldson, Tetrahedron, 2001, 57, 8589; (c) R. Faust, Angew. Chem., Int. Ed., 2001, 40, 2251.

112. S. G. Davies, K. B. Ling, P. M. Roberts, A. J. Russell and J. E. Thomson, Chem. Commun., 2007, 4029.

113. K. Csatayová, S. G. Davies, J. A. Lee, K. B. Ling, P. M. Roberts, A. J. Russell and J. E. Thomson, Org. Lett., 2010, 12, 3152.

114. M. D. McBriar, H. Guzik, R. Xu, J. Paruchova, S. Li, A. Palani, J. W. Clader, W. J. Greenlee, B. E. Hawes, T. J. Kowalski, K. O'Neill, B. Spar and B. Weig, J. Med. Chem., 2005, 48, 2274.

115. D. Didier, P.-O. Delaye, M. Simaan, B. Island, G. Eppe, H. Eijsberg, A. Kleiner, P. Knochel and I. Marek, Chem.-Eur. J., 2014, 20, 1038.

116. I. Riaño, U. Uria, E. Reyes, L. Carrillo and J. L. Vicario, J. Org. Chem., 2018, 83, 4180.

117. A. Almorín, M. C. Carreño, A. Somoza and A. Urbano, Tetrahedron Lett., 2003, 44, 5597.

118. E. Vrancken, H. Gérard, D. Linder, S. Ouizem, N. Alouane, E. Roubineau, K. Bentayeb, J. Marrot and P. Mangeney, J. Am. Chem. Soc., 2011, 133, 10790. 
119. Y. Nagashima, K. Sasaki, T, Suto, T. Sato and N. Chida, Chem.-Asian. J., 2018, 13, 1024.

120. N. Maezaki, M. Yano, Y. Hirose, Y. Itoh and T. Tanaka, Tetrahedron, 2006, 62, 10361.

121. D. E. Frants, R. Fässler and E. M. Carreira, J. Am. Chem. Soc., 2000, 122, 1806.

122. M. M. Faul and B. E. Huff, Chem. Rev., 2000, 100, 2407.

123. M. Turks, K. A. Fairweather, R. Scopelliti and P. Vogel, Eur. J. Org. Chem., 2011, 3317.

124. N. Punna, T. Saito, M. Kosobokov, E. Tokunaga, Y. Sumii and N. Shibata, Chem. Commun., 2018, 54, 4294.

125. R. G. P. Gatti, A. L. E. Larsson and J.-E. Bäckvall, J. Chem. Soc., Perkin Trans. 1, 1997, 577.

126. J. M. Andrés and R. Pedrosa, Tetrahedron, 1998, 54, 5607.

127. (a) B. Olofsson, U. Khamrai and P. Somfai, Org. Lett., 2000, 2, 4087; (b)

B. Olofsson and P. Somfai, J. Org. Chem., 2002, 67, 8574.

128. C. Spino, M.-C. Tremblay and C. Gobdout, Org. Lett., 2004, 6, 2801.

129. M. Sans, O. Illa and R. M. Ortuño, Org. Lett., 2012, 14, 2431.

130. M. Podunavac, J. J. Lacharity, K. E. Jones and A. Zakarian, Org. Lett., 2018, 20, 4867.

131. M. Thaning and L. G. Wistrand, J. Org. Chem., 1990, 55, 1406.

132. H. E. Schink and J.-E. Bäckvall, J. Org. Chem., 1992, 57, 1588.

133. J.-E. Bäckvall, R. Gatti and H. E. Schink, Synthesis, 1993, 343

134. S. Takano, Y. Sugihara and K. Ogasawara, Tetrahedron: Asymmetry, 1993, 4, 1795.

135. M. Braun, C. Unger and K. Opdenbusch, Eur. J. Org. Chem., 1998, 2389.

136 M. Davoust, F. Cantagrel, P. Metzner and J. F. Brière, Org. Biomol. Chem., 2008, 6, 1981.

137. K. Yamamoto, K. Ishimaru, S. Mizuta, D. Minato, M. Kuriyama and O. Onomura, Synlett, 2019, 30, 1204.

138. J. L. García Ruano, A. M. Martín-Castro, F. Tato, E. Torrente and A. M. Poveda, Chem.-Eur. J., 2010, 16, 6317.

139. M. Sasaki, T. Takegawa, K. Sakamoto Y. Kotomori, Y. Otani, T. Ohwada, M. Kawahata, K. Yamaguchi and K. Takeda, Angew. Chem., Int. Ed., 2013, 52, 12956. 
GRAPHICAL ABSTRACT

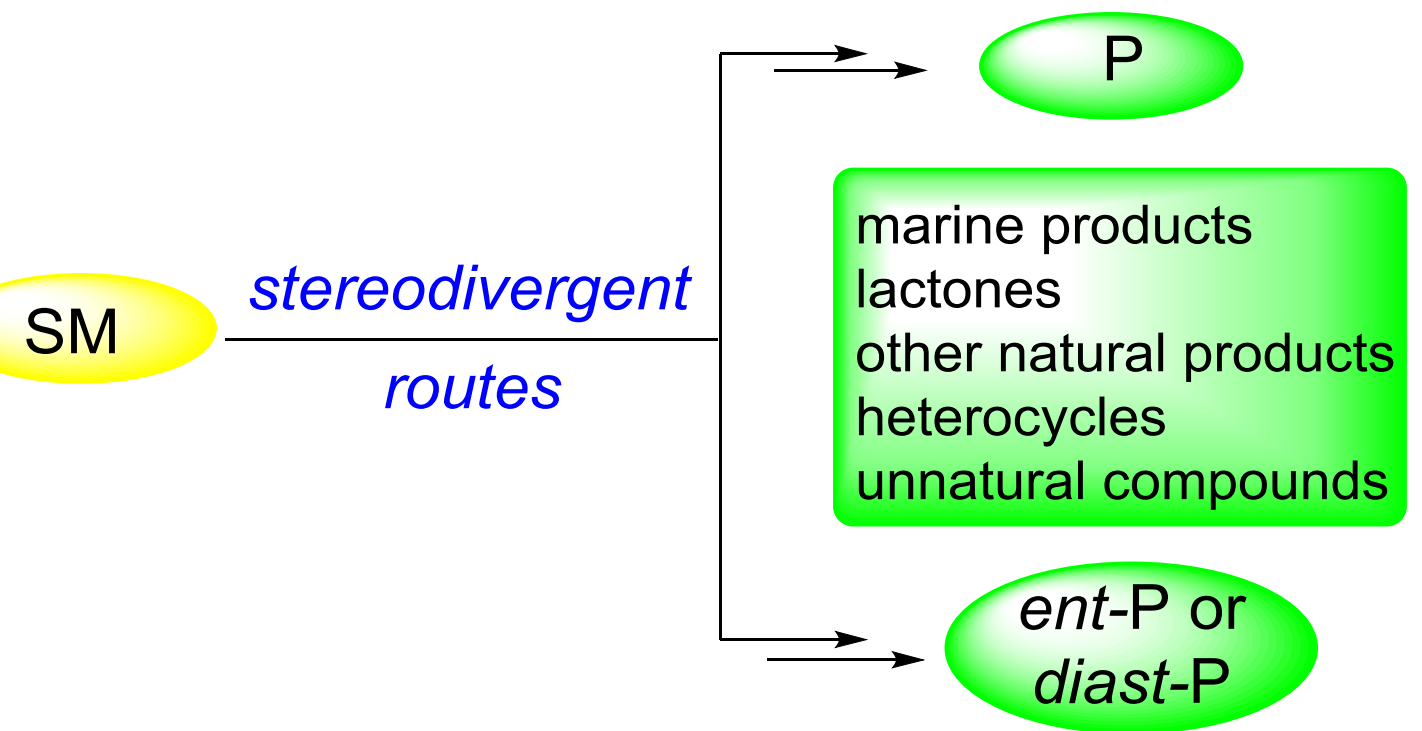

